\title{
Sensor for Viscosity and Shear Strength Measurement
}

\author{
Topical Report \\ January 1998
}

\author{
By: \\ M. A. Ebadian; J. Dillion \\ J. Moore; K. Jones
}

Work Performed Under Contract No.: DE-FG21-95EW55094

For

U.S. Department of Energy

Office of Fossil Energy

Federal Energy Technology Center

P.O. Box 880

Morgantown, West Virginia 26507-0880

By

Florida International University

Hemispheric Center for Environmental Technology (HCET)

Center for Engineering \& Applied Sciences

10555 West Flagler Street

EAS-2100

RECEIVED

OCT 201998

QSTI

Miami, Florida 33174 


\section{Disclaimer}

This report was prepared as an account of work sponsored by an agency of the United States Government. Neither the United States Government nor any agency thereof, nor any of their employees, makes any warranty, express or implied, or assumes any legal liability or responsibility for the accuracy, completeness, or usefulness of any information, apparatus, product, or process disclosed, or represents that its use would not infringe privately owed rights. Reference herein to any specific commercial product, process, or service by trade name, trademark, manufacturer, or otherwise does not necessarily constitute or imply its endorsement, recommendation, or favoring by the United States Government or any agency thereof. The views and opinions of authors expressed herein do not necessarily state or reflect those of the United States Government or any agency thereof. 


\section{DISCLAIMER}

Portions of this document may be illegible in electronic image products. Images are produced from the best available original document. 
TABLE OF FIGURES

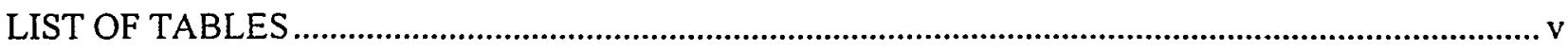

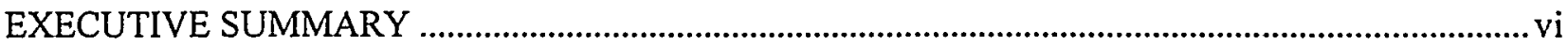

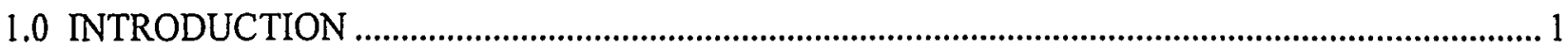

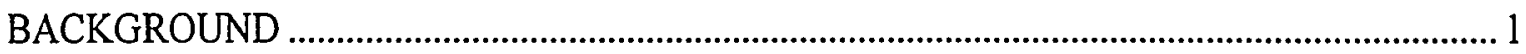

PROJECT TEAMS AND TASKS............................................................................................ 2

SUMMARY OF FY96 RESULTS FOR THE OSCILLATING CYLINDER

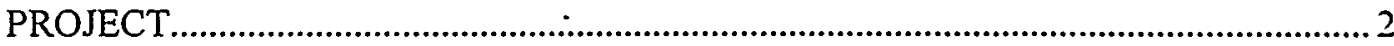

REVIEW OF FY96 RESULTS FOR THE ACOUSTIC PROJECT ……........................................ 3

2.0 FY97 ACCOMPLISHMENTS AND PROJECT STATUS.......................................................... 9

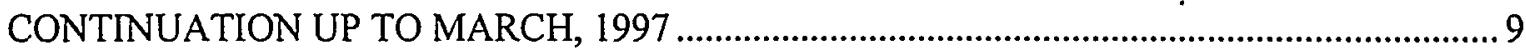

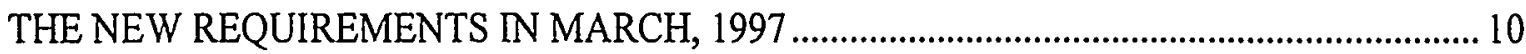

DECISIONS MADE IN MARCH .......................................................................................... 10

THE BASE CAPABILITY VISCOSITY INSTRUMENTATION SYSTEM ............................... 10

AN AUTOMATED VISCOSITY INSTRUMENTATION SYSTEM .......................................... 13

PROJECT STATUS......................................................................................................... 14

3.0 PROOF OF CONCEPT FOR THE OSCILLATING CYLINDER METHOD ……........................... 15

EXPERIMENTAL LIQUIDS .................................................................................... 15

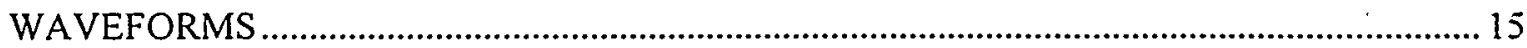

EXPERIMENTAL RESULTS............................................................................................ 19

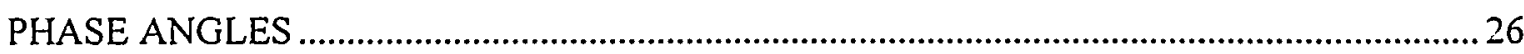

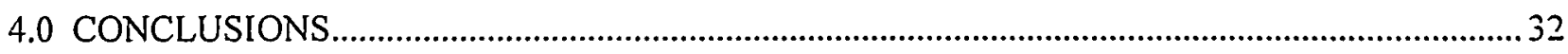

OSCILLATING CYLINDER DESIGN …….......................................................................

5.0 PROOF OF CONCEPT FOR THE ACOUSTIC VISCOMETER ……...........................................33

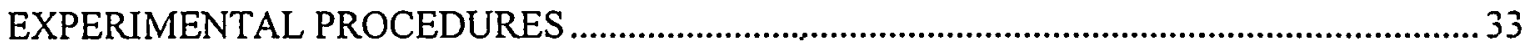

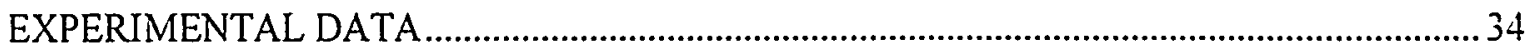

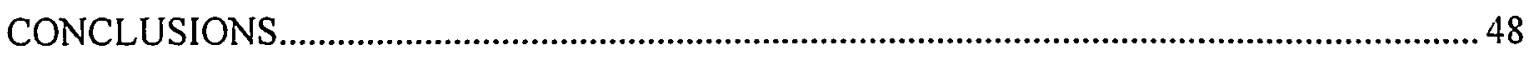

6.0 FLORIDA INTERNATIONAL UNIVERSITY'S AUTOMATED VISCOSITY

INSTRUMENTATION SYSTEM.......................................................................................... 49

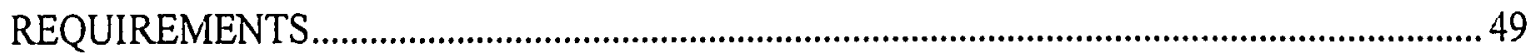

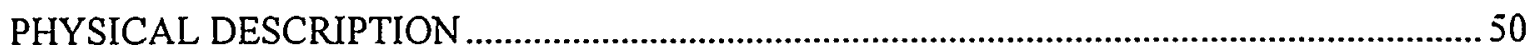

FUNCTIONAL DESCRIPTION .......................................................................................... 52

ACOUSTIC DATA ACQUISITION, REDUCTION, ANALYSIS, LOGGING,

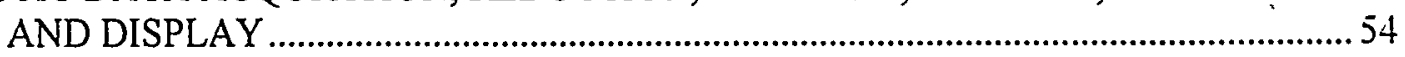

TOP LEVELS OF THE LABVIEW SOFTWARE FOR THE VIRTUAL

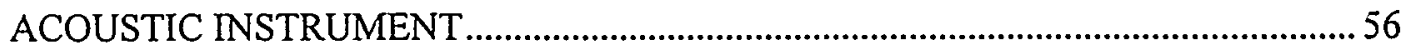




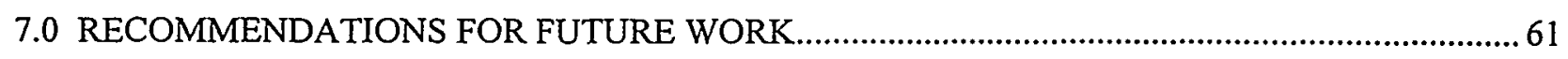

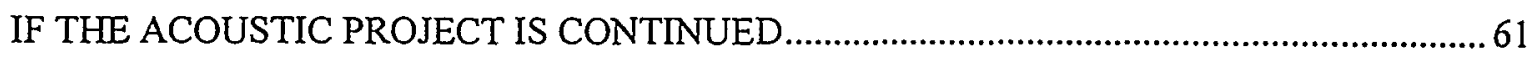

IF THE OSCILLATING CYLINDER PROJECT IS CONTINUED ........................................62

IF EITHER PROJECT IS CONTINUED, ADDITIONAL WORK IS

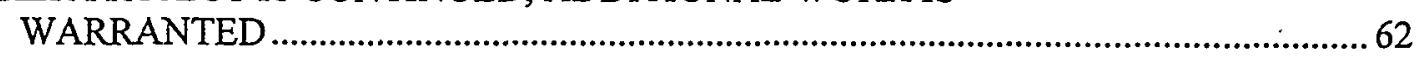

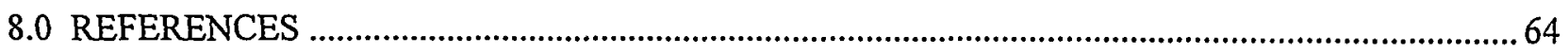

APPENDIX A. Viscosity Principles

APPENDIX B. Fubctional Description of the Current Automated Instrumentation System

APPENDIX C. Alogorithms for Instrumentation System Software 
Figure 1. One-transducer configuration used in reflected mode measurements............................. 4

Figure 2. Experimental setup for reflective mode measurements................................................. 4

Figure 3. A typical waveform for an aluminum waveguide

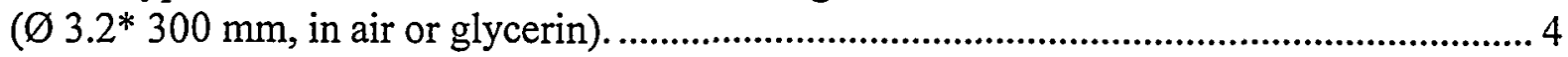

Figure 4. Configurations in transducers, rods, and waveguides. ................................................ 7

Figure 5. A promising acoustic probe assembly ....................................................................

Figure 6. The complete automated viscosity instrumentation system......................................... 11

Figure 7. Illustration of the prototype oscillating cylinder viscometer........................................ 12

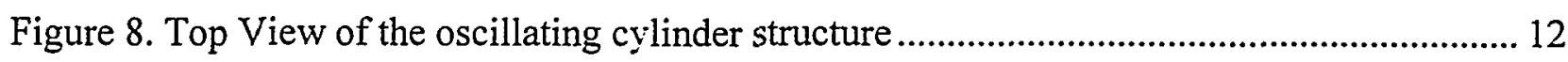

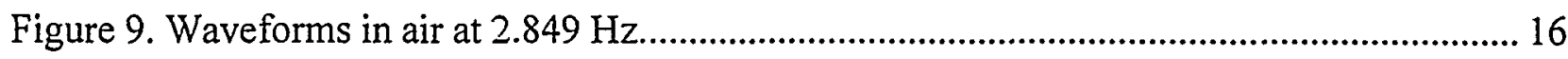

Figure 10. Detail of the waveforms for a frequency of $2.849 \mathrm{~Hz}$............................................. 17

Figure 11. The same waveforms as shown in Figure 12, but using ensemble averaging.............. 17

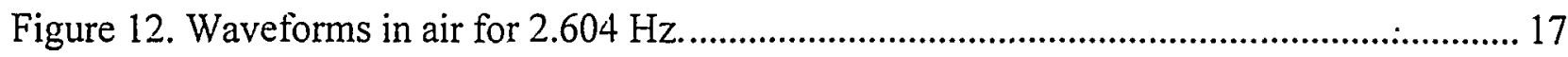

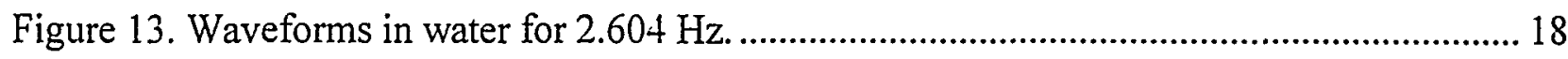

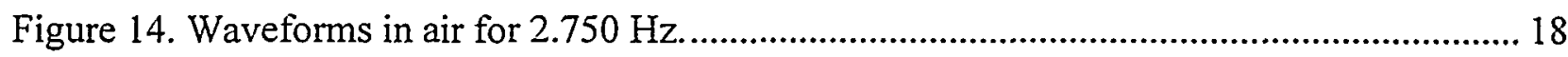

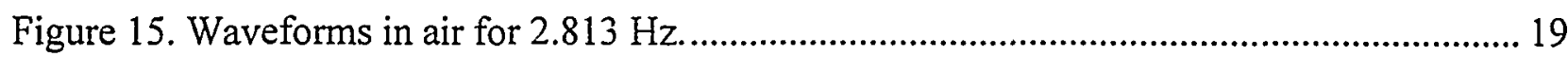

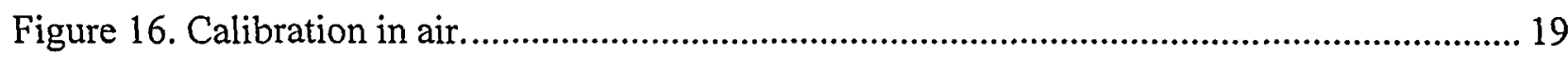

Figure 17. Predicted force versus measured force for water. …………….............................. 21

Figure 18. Predicted force versus experimental force for $25 \%$

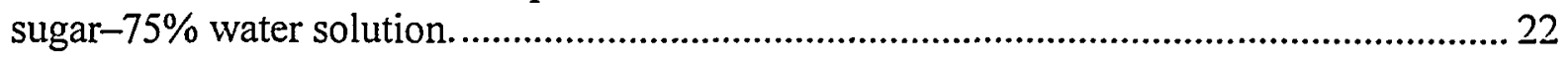

Figure 19. Predicted force versus measured force for $40 \%$

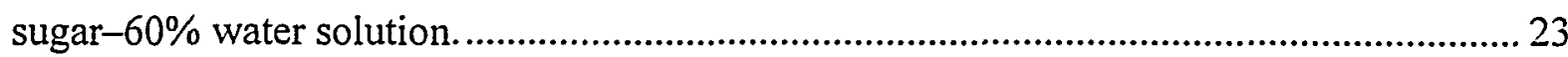

Figure 20. Predicted force versus measured force for a $50 \%$ sugar-50\% water solution........................................................................................... 24

Figure 21. Predicted force versus measured force for $60 \%$

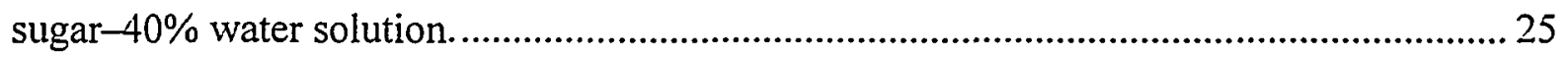

Figure 22. Predicted force versus experimental measured force

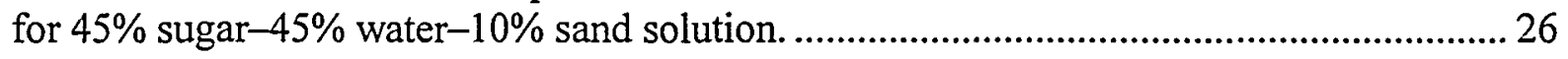

Figure 23. Predicted phase angle versus measured phase angle for water. .................................. 27

Figure 24. Predicted phase angle versus experimental phase angle

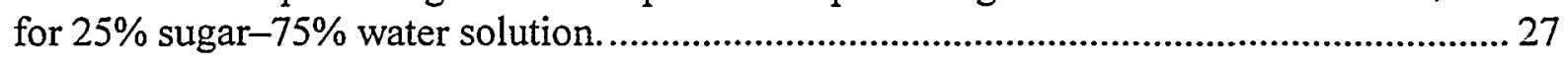

Figure 25. Predicted phase angle versus measured angle

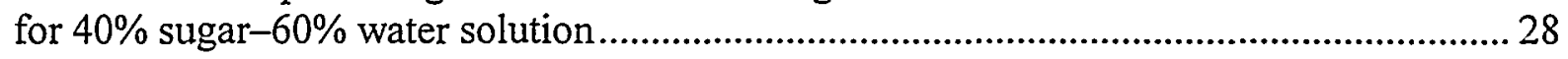


Figure 26. Predicted phase angle versus measured phase angle for $50 \%$ sugar- $50 \%$ water solution.

Figure 27. Predicted phase angle versus measured phase angle

for $60 \%$ sugar- $40 \%$ water solution.

Figure 28. Predicted phase angle versus measured phase angle

for $45 \%$ sugar $-45 \%$ water- $10 \%$ sand solution. 30

Figure 29. Waveforms in the four-transducer transmission mode............................................... 34

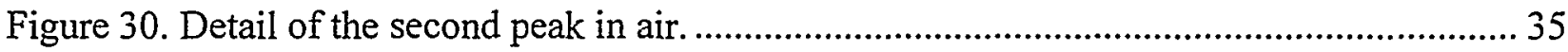

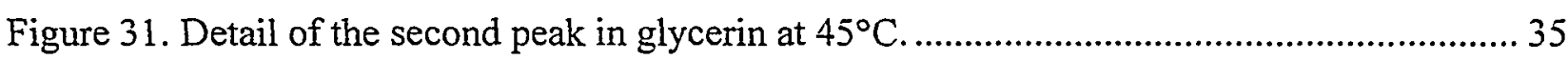

Figure 32. Kinematic viscosity for Solutions 1, 2, and 3 for

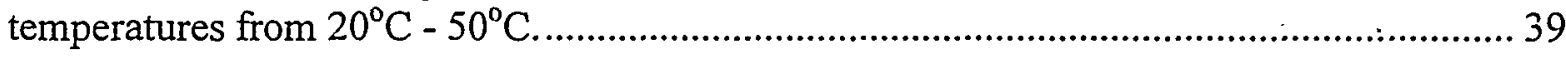

Figure 33. The effect of \% sucrose on the viscosity of Solutions 1, 2, and 3..............................39

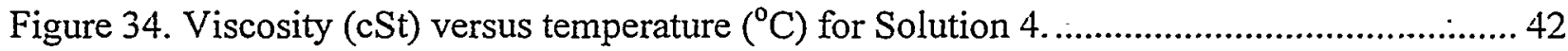

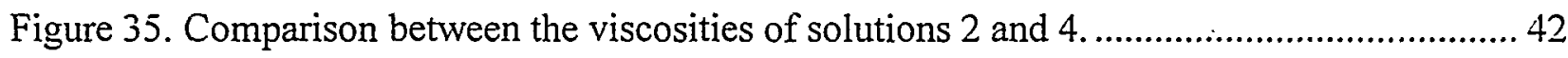

Figure 36. Waveforms when both waveguides are in air........................................................... 43

Figure 37. Waveforms when waveguide 1 is in air and waveguide

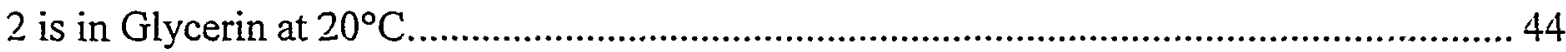

Figure 38. Viscosity $(\mathrm{cSt})$ versus temperature $\left({ }^{\circ} \mathrm{C}\right)$ for Glycerin............................................... 46

Figure 39. Viscosity $(\mathrm{cSt})$ versus temperature $\left({ }^{\circ} \mathrm{C}\right)$ for different glycerol solutions. .................... 47

Figure 40. The FIU/HCET automated viscosity instrumentation system.................................... 51

Figure 41. Signal flow for the automated instrument. ...................................................... 53

Figure 42. Selecting process options from the top-level panel of the virtual instrument. ............55 57

Figure 43. Part of the signal flow diagram for the top-level instrument.....................................57

Figure 44. Front panel for the Full Instrument sub-sub vi.......................................................5.8

Figure 45. The Adjust sub-instrument panel..................................................................... 58 :

Figure 46. The Step sub-instrument panel. ........................................................................ 59

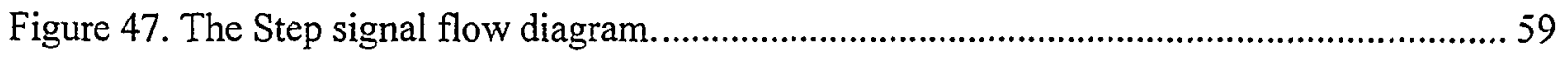

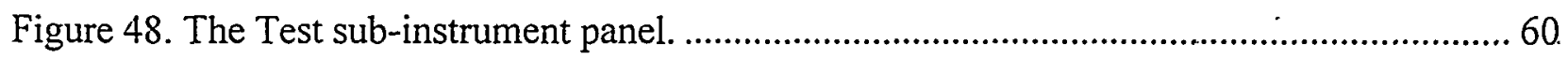




\section{LIST OF TABLES}

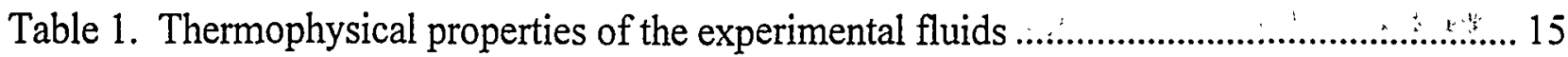

Table 2. Experimental data for calibrating the oscillating cylinder sensor in air .........................20

Table 3. Force peak amplitude and the corresponding frequencies

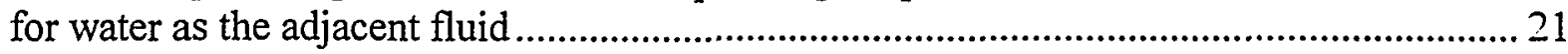

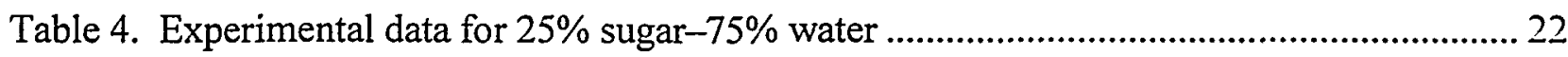

Table 5. Experimental data for $60 \%$ sugar $-40 \%$ water ................................................................ 24

Table 6. Experimental data for $45 \%$ sugar-45\% water-10\% sand.............................................. 26

Table 7. Predicted and calculated phase angles for $45 \%$ sugar $-45 \%$

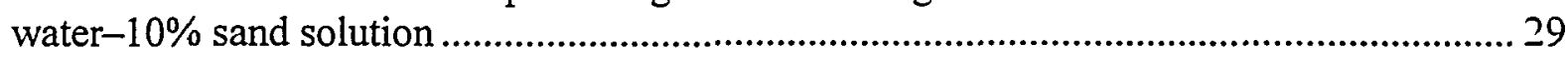

Table 8. Comparative measured-predicted force results for the fluids measured......................... 30

Table 9. Comparative measured-predicted phase lag results for the fluids measured.................. 31

Table 10. Some experimental fluids .......................................................................................... 33

Table 11. Initial results for water and sucrose-water solutions ................................................36

Table 12. How the solubility of sucrose increases with temperature ...........................................37

Table 13. Raw data (shift in peak position) as a function

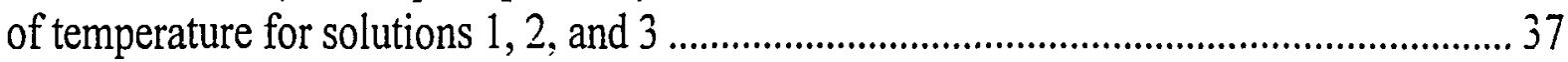

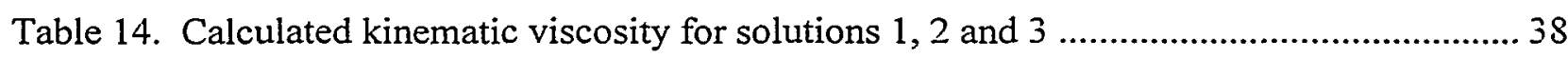

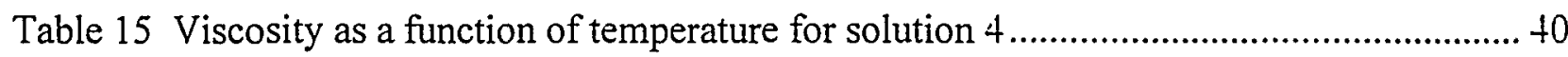

Table 16. Raw data as a function of temperature for $68 \%$ glycerin $-32 \%$ water solution ........................................................................................

Table 17. Calculated viscosity versus the temperature for

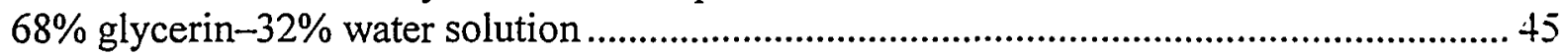

Table 18. Raw data of glycerol solutions versus temperatures..................................................... 46

Table 19. Calculated viscosity as a function of temperature for glycerol. ................................... 47

Table 20. Summary of experimental data for the tested solutions, compared to published data ............................................................................... 48

Table 21. How to select the time quantity to be measured ......................................................... 54

Table 22. The four processes of the acoustic virtual instrument ………………........................55 


\section{EXECUTIVE SUMMARY}

Measurement of the physical properties (viscosity and density) of waste slurries is critical in evaluating transport parameters to ensure turbulent flow through transport pipes. The environment for measurement and sensor exposure is extremely harsh; therefore, reliability and ruggedness are critical in the sensor design.

Two different viscometer techniques are being investigated in this study, based on:

- Magnetostrictive pulse generated acoustic waves

- An oscillating cylinder

Prototype sensors have been built and tested which are based on both techniques. A base capability instrumentation system has been designed, constructed, and tested which incorporates both of these sensors. It requires manual data acquisition and off-line calculation. A broad range of viscous media has been tested using this system. Extensive test results appear in this report. The concept for each technique has been validated by these test results.

This base capability system will need to be refined further before it is appropriate for field tests. The mass of the oscillating system structure will need to be reduced. A robust acoustic probe assembly will need to be developed.

In addition, in March 1997 it was made known for the first time that the requirement was for a deliverable automated viscosity instrumentation system. Since then such a system has been designed, and the hardware has been constructed so that the automated concept can be proved. The rest of the hardware, which interfaced to a computer, has also been constructed and tested as far as possible. However, for both techniques the computer software for automated data acquisition, calculation, and logging had not been completed before funding and time ran out. 


\subsection{INTRODUCTION}

\section{BACKGROUND}

The introduction consists of topics needed to introduce this year's work, but which are not strictly parts of this year's work. In the Appendix appear definitions of nomenclature, some principles of viscosity, and the details on last and this year's instruments and waveforms. While some of this work in the Appendix began in the prior year, the theoretical background, summary, and analysis of it spilled over into the present year. It is placed in the Appendix to make clear that the main body includes only this year's results.

The main body of this report covers this year's original research in Sections 2.0-5.0. It is presented top-down:

Section 2.0 summarizes the history of the research this year. It describes the base capability. instrumentation system that was used to obtain the measurements that demonstrated proof of concept. Section 2.0 presents the sub-systems in greater detail. The first two subsystems consist of the instrumentation probes/apparatus and the principles on which they work. Then follows a summary of the electronics used to process the signals in a base capability sufficient to validate the concept.

The Proof of Concept results are given in Section 3.0 (Oscillating Cylinder) and Section 4.0 (Acoustics).

Section 5.0 discusses the electronics in greater detail. The electronics used to prove the concept is a subset of a larger automated instrumentation system that has been designed and most of which has been implemented.

Two papers on which this research was based are "Instruments for simultaneous measurement of density and viscosity" by Jin O. Kim and Haim H. Bau [1989] and "Method for the calculation of velocity, rate of flow and viscous drag in arteries when the pressure gradient is known," by J.R. Womersely.

These two articles about viscosity sensor principles and designs became the theoretical basis for further research and development at Florida International University:

The contents of the two articles will be briefly summarized in the next two sub-sections. Details follow on these two approaches.

In the first mentioned article, an on-line, real-time instrument for the simultaneous measurement of fluid density and viscosity is discussed by Kim and Bau. The discussion focuses on Newtonian fluids. It was anticipated that a similar methodology could be used for nonNewtonian fluids.

Consider a torsional stress wave traveling in a waveguide with a uniform cross-section and a density of $\rho_{s}$ submerged in a liquid with a fluid density $\rho_{\mathrm{f}}$. The solid-liquid interface will be accelerated and decelerated as the wave travels through the waveguide. Consequently. the inertia which needs to be overcome by the torsional pulse is a combination of the solid waveguide's 
inertia $\mathrm{I}_{\mathrm{s}}$ and the adjacent liquid's apparent inertia $\mathrm{I}_{\mathrm{f}}$. The torsional wave speed, which is in direct correlation with the viscosity of the fluid, can be calculated as follows:

$$
c=K\left(G / \rho_{s}\right)^{1 / 2} \cdot\left(1+\rho_{f} I_{f} / \rho_{s} I_{s}\right)^{1 / 2}
$$

where $\mathrm{c}$ is the torsional wave speed, $\mathrm{G}$ is the shear modulus of the solid, $K=\sqrt{\frac{D}{I S}}$, and $\mathrm{D}$ is the torsional rigidity.

If the flight time in air is $t_{0}$ and $t$ is the flight time in liquid at the same temperature, $\Delta t=t-t_{0}$ describes the difference in the delay in the transmission times of a torsional wave in a waveguide submerged in liquid and one in air. It has been demonstrated that for a waveguide with a circular cross-section of radius a,

$$
I_{f} / I_{s}=\left(8 v / \omega a^{2}\right)^{1 / 2},
$$

where $\omega$ is the wave's frequency and $v$ is the kinematic viscosity. It has been shown that the inner radius of a hollow circular wareguide does not influence the measurements, so the same theory was applied in the design of the waveguide sensor.

FIU Professor James Moore extended a concept discussed in Womersely's article. Moore has defined the second approach for a mechanical sensor rather than acoustic. Based on Womersely's article, Moore developed a new theory for finding the viscosity of Newtonian and nonNewtonian fluids. The system consists of an outer stationary housing that approximates a static case moving against an oscillating inner cylinder. Measurements of the displacement and shear force allow the viscosity to be calculated. This tye of device is designed with no open bearings and is shielded by the connecting pipes and local shielding from some harsh environments like the tank slurries.

\section{PROJECT TEAMS AND TASKS}

Last year the acoustic and mechanical methods of measurement of viscosity were investigated in independent projects. Dr. W. Kinzy Jones was the principal investigator on both. Dr. Jerry Dillion and Liana Pernes, a Mechanical Engineering Masters student, worked with Dr. Jones on the acoustic project. Dr. James Moore and Alan Santamarina, a Mechanical Engineering Masters student, worked on the mechanical project.

The acoustic project consisted of parallel derelopments on an acoustic probe and in the associated electronics. Ms. Pernes and Dr. Jones worked on the acoustic probe, and Dr. Dillion worked on the electronics

\section{SUMMARY OF FY96 RESULTS FOR THE OSCILLATING CYLINDER PROJECT}

The oscillating cylinder project achieved the following: a) theoretical derivations resulting in usable Bessel function equations to calculate viscosity from amplitude, force, and phase shift; $b$ ) the development of Mathcad software to perform the calculations; and c) an investigation of a 
drive mechanism for an oscillating cylinder. A linear drive was investigated, based on the same principle as the voice coil in a loudspeaker, with a restraining spring. The driving force was to be inferred indirectly from a measurement of coil current.

\section{REVIEW OF FY96 RESULTS FOR THE ACOUSTIC PROJECT}

In the acoustic project, a literature search was conducted and equipment was assembled. The experimental setup developed by $\mathrm{Kim}$ and Bau was duplicated using a magnetostrictive pulser/receiver. Torsional waves were generated using a circumferentially magnetized piezomagnetic Remendur wire. However, the use of high modular (stainless steel) waveguides, in addition to problems with the generation of the torsional waves, did not allow the duplication of results for water or glycerin in water.

\section{Generation of acoustic waves}

A Panametrics Model 5055PR generates the acoustic waves. This Pulser-Receiver generates up to a 350 volt negative pulse that shock excites the transmit transducer located at the beginning of the delay-line. It does so with adjustable amplitude, pulse repetition rate, and damping. When the Panametric KT-55 magnetostrictive transducer is pulsed, it rings at its characteristic frequency $(100 \mathrm{kHz})$. The 5055PR can also process the received reflections. Each wave train has several cycles; that is, each is under-damped or can be considered amplitude modulated. In the frequency domain, this modulation has a wide bandwidth of around 40 percent of the carrier frequency $(100 \mathrm{KHz})$. The Remendur magnetostrictive rod moves due to the transmit transducer in which it is inserted. This rod has to be long enough so that it can introduce propagation delays that separate each wave train. Hence, this rod length cannot be reduced by more than a factor of two or so when used with $100 \mathrm{kHz}$ transducers.

Unfortunately, the flexures during vibration of a solid rod are much less than with a hollow cylinder; hence, the rod does not interact efficiently with an acoustic medium and the delay times are very small. To obtain greater flexure, a hollow waveguide is mechanically attached to the far end of the rod so that the rod's acoustic energy is coupled to it (Figures 1 and 2). This waveguide is inserted in the viscous medium.

\section{Propagation of acoustic waves}

The propagation of the acoustic wave is in the torsional mode. Particles of the rod rotate primarily around the center axis although the acoustic wave train still travels down the rod, but at a different propagation velocity. The same transducer can generate either mode of propagation (it will alternately be a transducer and a receiver) by means of the selection of different rods and the optional use of a transducer magnet.

As either type of wave propagates down the rod, the juncture between the rod and waveguide represents an acoustic impedance mismatch. Some energy is reflected back to the sending end, while the rest travels to the end of the waveguide before reflecting back. This second energy can differ from the first, so the two wave shapes can have different amplitudes. 


\section{Reception of acoustic waves}

If the configuration is of one transducer and one delay line (i.e., the reflective mode), as shown in Figure 1 and 2, typical received waveforms are shown by Figure 3.

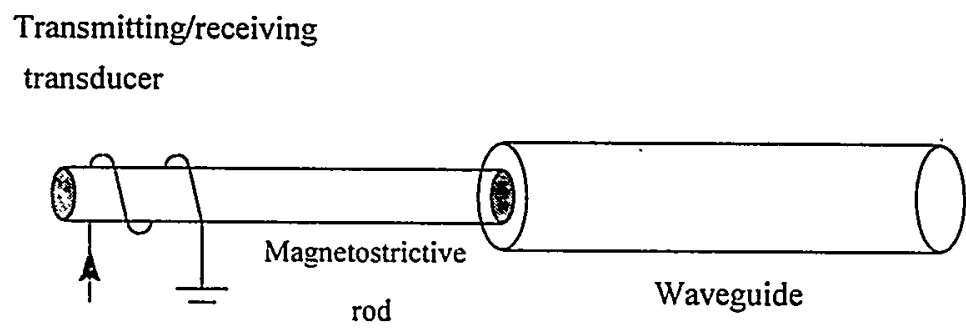

Figure 1. One-transducer configuration used in reflected mode measurements.

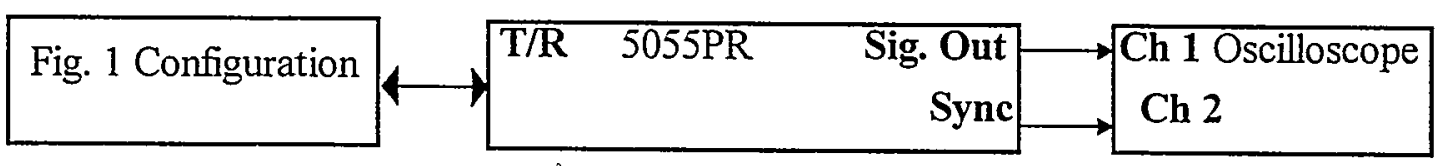

Figure 2. Experimental setup for reflective mode measurements.

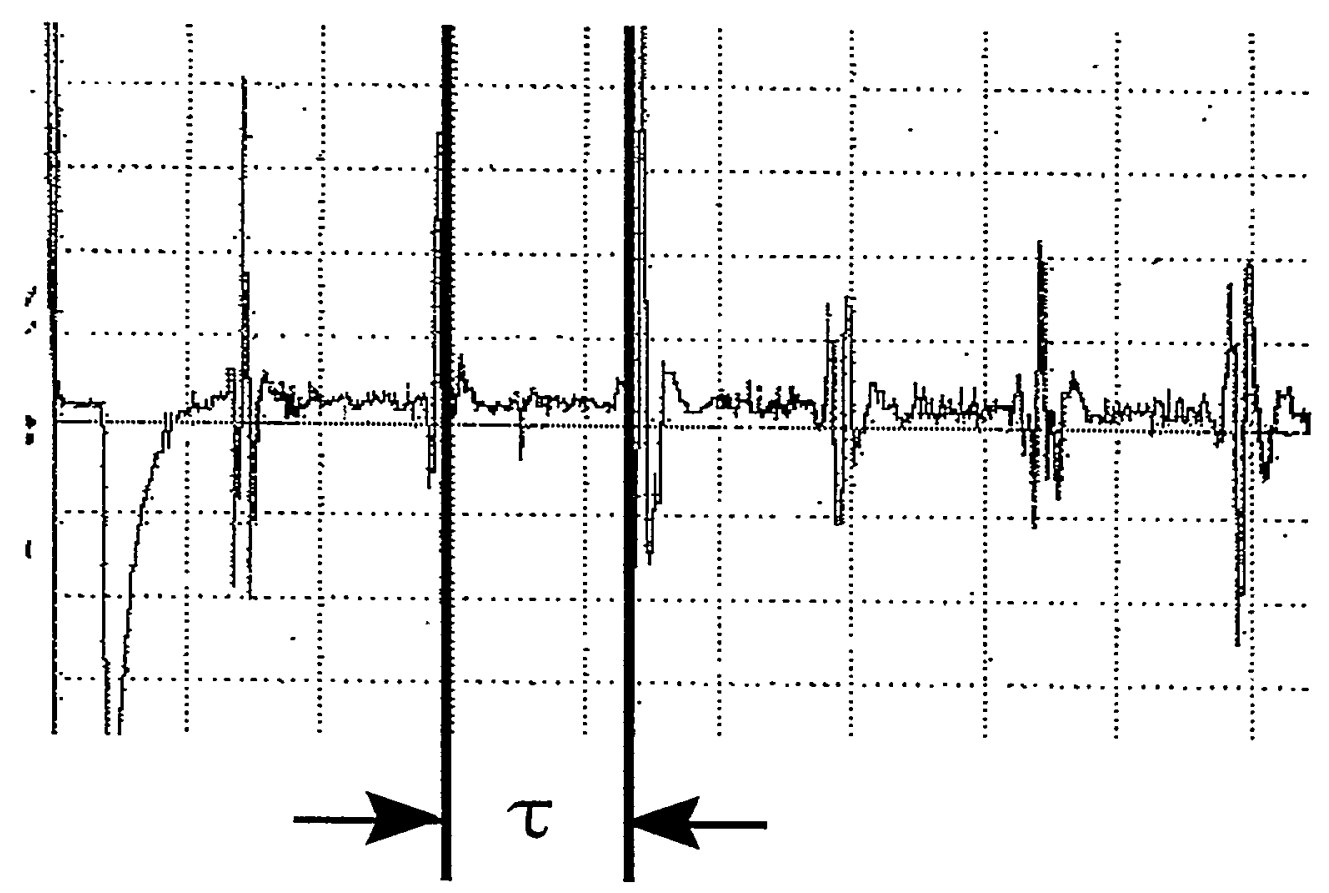

Figure 3. A typical waveform for an aluminum waveguide $\left(\varnothing 3.2^{*} 300 \mathrm{~mm}\right.$, in air or glycerin). 
The peaks are received at the transducer in the following order:

- The first (negative and positive) peak corresponds to the residue of the transmit pulse, although clipped and attenuated.

- The second (positive) peak is due to the acoustic impedance mismatch at the interface between the delay line and waveguide.

- The third peak is from the end of the waveguide.

The second and third pulse trains are the ones of interest in measurement. We measure time between these two pulse trains as the round-trip flight time, defined as $\tau$, between the ends of the waveguide. A typical value for torsional waves is 230 microseconds. Reflections continue to bounce back and forth from both ends of the rod and waveguide, generating a mishmash of following signals. Hence, the signals before and after the interval from the second and through the third pulse trains are visually ignored or need to be eliminated. Unfortunately, the reflected wave shapes are altered significantly by the value of damping resistance placed across the transducer.

In the reflective mode of measurement, the same transducer was used for both generation and reception. However, due to the attenuation of reflected energies, the received wave trains at the transducer are in the range of millivolts. The 5055PR is complex, with clippers, attenuators, and amplifiers. It clips the $350 \mathrm{~V}$ transmit pulse at the $\mathrm{T} / \mathrm{R}$ terminal and generates a usable receiver output at a separate terminal (see Figure 2). The sync output is also provided, which annunciates the beginning of the excitation pulse cycle.

\section{Waveguides}

The following waveguides, each with a length of $300 \mathrm{~mm}$. were evaluated:

- Solid copper, with outside diameters of $1.6,2.4$, and $3.2 \mathrm{~mm}$

- Hollow copper, with diameters of $1.6,2.4,3.2$ and $6.4 \mathrm{~mm}$

- Solid aluminum, with diameters of 2.4 and $6.4 \mathrm{~mm}$

- Hollow aluminum, with diameters of $1.6,2.4,3.2$, and $6.4 \mathrm{~mm}$

- An aluminum waveguide of $1.6 \mathrm{~mm}$ OD with a length of $6 \mathrm{in}$.

The hollow aluminum waveguide of $3.2 \mathrm{~mm}$ OD worked the best.

\section{The key equation for calculating viscosity from acoustic measurements}

According to the test data, when the diameter is between 1.6 and $3.2 \mathrm{~mm}$, the viscosity exhibits the following relationship that is the fundamental equation used to calculate viscosity:

$$
\begin{gathered}
\nu=18(\Delta t / t)^{2} \omega \mathrm{a}^{2} \quad \text { (for copper) } \\
\nu=2(\Delta t / t)^{2} \dot{\omega} \mathrm{a}^{2} \quad \text { (for aluminum) }
\end{gathered}
$$


where $v$ denotes kinematic viscosity; $\Delta \mathrm{t}$ is the time difference of the times of propagation in air and in the viscous medium; $\omega$ is the wave frequency (angular velocity) or its reciprocal, the wave period; and a is the characteristic dimension of the cross section. With a fixed, there are then three time variables to be measured. Note the sensitivity of viscosity to the time measurements.

\section{Two-transducer transmission mode measurements}

Different electrical configurations of possible transducers, rods, and waveguides were also identified. There were advantages to going from one transducer towards two or four. Transmission mode measurements require separate transducers for transmit'and receive (see Figure 4 for the two-transducer option). The receive transducer never sees the transmit pulse. This mode simplifies the receiver measurement process substantially, since there is no large transmit pulse to attenuate. The raw, receive transducer output is about $140 \mathrm{mV}$ p-p open circuit.

However, two separate (in both space and time) measurements of time are required, and the differ--rce between them is calculated before being used to calculate the viscosity. Any .. - ared difference between measured values has the potential for degradation in accuracy; particularly when the measured values are close to one another.

\section{Four-transducer transmission mode measurements}

It is possible to measure directly the differential flight time, $\Delta t$, if four transducers are used. The same transmit pulse is supplied to two identical transmit transducers. The wave propagates down two identical rods to two identical waveguides. When both waveguides are in air, the receive wave trains should be identical; if not, this can be compensated for. Then, one waveguide is inserted in the viscous medium under test, and the difference in time is measured directly. This method is not likely to be feasible until the other difficulties mentioned above are dealt with. Nonetheless, we show how they can be resolved to make this approach feasible. For accuracy, it is the preferred approach, but may not be as accurate at probe bulk. 
Transmitting

transducers

Waveguides

a.

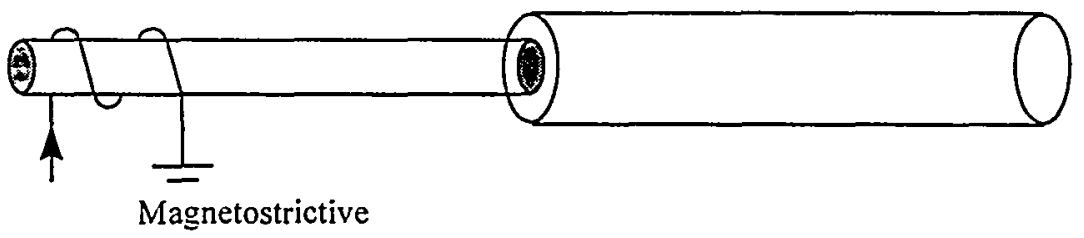

b.

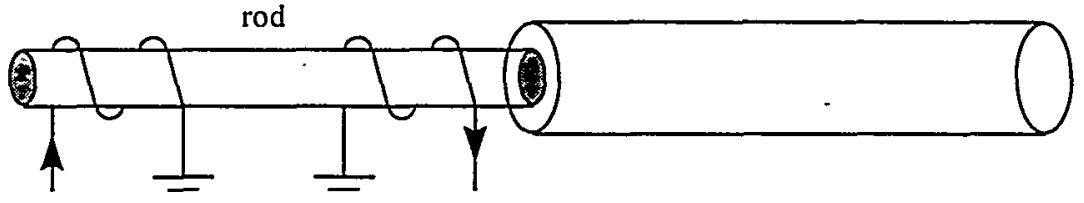

Transmitting

Receiving transducers transducers

Waveguides

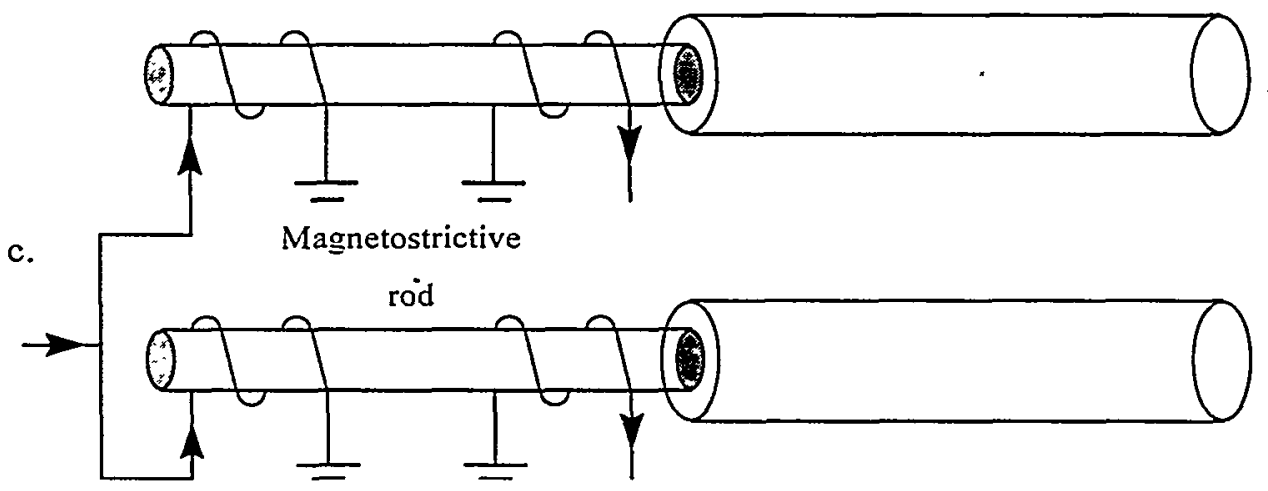

Figure 4. Configurations in transducers, rods, and waveguides.

\section{Error analysis when measuring with an oscilloscope}

Accurate values for viscosity requires that all measured variables be obtained with precision and accuracy. An ordinary analog oscilloscope cannot measure $\Delta t$, $t$, or $\omega$ with sufficient precision for viscosity instrumentation. It is even difficult to achieve repeatable results with a digital Time Domain Reflectometer (TDR).

If the waveguide's length is cut in half, both $\Delta t$ and $t$ are cut in half. Unfortunately, their ratio, while independent of the waveguide's length, is small, typically around one percent for glycerin at room temperature. This is a differential flight time of around two microseconds on a $300-\mathrm{mm}$ waveguide. To measure this time difference with around one percent accuracy implies measuring with $10 \mathrm{nS}$ precision. Cutting the waveguide's length in half doubles the possible error or requires measurement with $5 \mathrm{nS}$ precision to maintain the accuracy of around one percent. In the simple configuration of Figure 4, this time difference is obtained from the difference of separate time measurements from different wave trains obtained from the two viscous media by successive immersions. 
Another reason for the difficulty in obtaining accurate values is the difficulty of identifying the beginning of a wave train by visual inspection. This is complicated by the dramatic effect of damping on the wave trains. Since the 5055PR has continuously variable damping, it is also difficult to achieve repeatability. Repeatability would be improved by a switchable damping resistor.

Reflective mode measurements require a complex transmitter/receiver. The difficulty in processing received millivolts at the same terminal which, microseconds before, had hundreds of volts resulted in a 5055PR that gave inconsistent results for different attenuator settings. These inconsistencies were resolved under transmission mode measurements.

\section{FY97 research in acoustic electronics}

The associated research in acoustic electronics was for a laboratory instrument that was to be used in proximity to the acoustic probe. It allowed for direct measurement of roundtrip flight time and the differential time due to viscous drag. It also can switch to measure the period of each cycle in the wave train. Each cycle period is approximately ten microseconds. The wave frequency is the reciprocal of this period. These measurements are all required for calculation. For repeatability, the instrument can also measure the period of the sync pulses plus the pulse width of hold-on and delay-on. Time can be measured with four precisions: 10, 100, and 1000 nS.

The instrument also had two analog coax cable drivers to send analog or digital signals to a twochannel oscilloscope and switches to select the signals to go to each channel. The back panel holds seven BNC jacks and a power strip.

Electronic research has resulted in validated circuits for the following:

- Suppression of the transmit pulse waveform, even if already attenuated, plus all of the ware'. trains after the first two desired reflections

- Detection of the point in time when each of the two pulse trains begins (positive slope of the first positive cycle of successive pulse trains) by a method that is automated (not dependent on human skill), digital, robust, repeatable, and accurate

- Generation of a digital gate signal whose width is the accurate time difference between these two beginnings (this is the round-trip flight time)

- The measurement of the time of this gate width with $10 \mathrm{nS}$ resolution

- The direct measurement of the differential time $\Delta t$ due to viscous drag, if the four-transducer configuration is used.

This instrument was designed to measure automatically and display in turn one of the three needed time delay values. These time values were to be read and written down. Then, the viscosity could be calculated off-line. The principle on which it worked was to have the instrument select automatically the voltage reference points, then measure the time difference between these points automatically using an electronic counter.

Further details on both the oscillating and acoustic projects appear in Section 2.0 and in the FY96 Year-End Report. 


\subsection{FY97 ACCOMPLISHMENTS AND PROJECT STATUS}

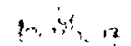

\section{CONTINUATION UP TO MARCH, 1997}

\section{Measurement of viscosity using an oscillating cylinder}

This year both projects were independently conducted through March. Dr. Dillion, however, assisted with some preliminary cylinder drive electronics design and testing. A low-frequency power amplifier was designed and built to drive a coil with a moving internal rod core. The internal rod in turn drove the cylinder. However, the voice coil approach proved unsuccessful. The displacement could not easily be held constant or stable. the relationship between the drive voltage and displacement was not linear, the conversion between coil current and force was not easy to calibrate, and too much audio power was required.

\section{Acoustic probe structures}

Some structures to house the acoustic probe(s) were investigated. A promising two-transducer structure is shown below as Figure 5. This structure has the advantage of isolating the $350 \mathrm{~V}$ excitation pulse supplied to the left (transmit) transducer from the millivolt signals generated by the receive transducer on the right. However, the design and construction of such a structure proved difficult. The difficulty was in providing a good seal and sufficient mechanical strength in support of the transducers, rod, and waveguide while not dampening the acoustic waves.

Isolating the transmit and receive transducers permits the use of a simple but high performance receive preamplifier located in the probe housing. The preamplifier can drive by a lowimpedance source a possibly long line with high-level signals. to minimize the effect of noise. This preamplifier could be designed with sharp cut-off below $30 \mathrm{KHz}$, to reduce $60 \mathrm{~Hz}$ hum pickup. Such a preamplifier was built and was used for measurement and, therefore, did yield proof of concept.

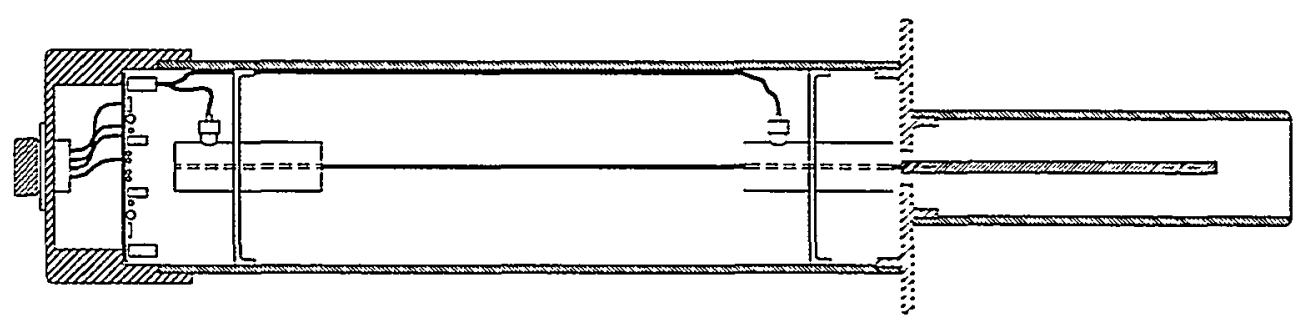

Figure 5. A promising acoustic probe assembly.

\section{Acoustic electronics}

By March, the acoustic counter instrument had been constructed and tested as much as it could be without a working acoustic probe. 


\section{THE NEW REQUIREMENTS IN MARCH, 1997}

At a March ORNL meeting, definitive requirements were given for the first time specifying the requirements for the evaluation on-site of various approaches to the measurement of viscosity. Explicit in these requirements was that each approach include automated and unattended data acquisition, calculation, and data logging. This implied for the first time that the need was to develop a whole automated instrumentation system. In addition, this system was required to be functional and delivered in a few weeks.

\section{DECISIONS MADE IN MARCH}

In response to these requirements the following decisions were made:

- Change from a research mode with emphasis on investigating the feasibility of new and innovative methods to measure viscosity. These research activities were not complete, but the results' at this time demonstrate the promise of both the acoustic and oscillating cylinder approaches.

- Change into a development mode to provide an operational system with basic capability for field tests as soon as possible.

- Since the data logging and computer configurations would be the same for both the acoustic and oscillating approaches, design a joint system that will support both the acoustic and oscillating cylinder methods. Design the system in its entirety, but so that the implementation can be staged to provide a basic capability for tests as soon as possible, with fuller features to follow.

- Due to the short time frame, the base capability will incorporate the features most readily available, hence, which can be implemented most quickly.

\section{THE BASE CAPABILITY VISCOSITY INSTRUMENTATION SYSTEM}

\section{Features of the probes}

The base capability instrumentation system is shown at the left of Figure 6 . 


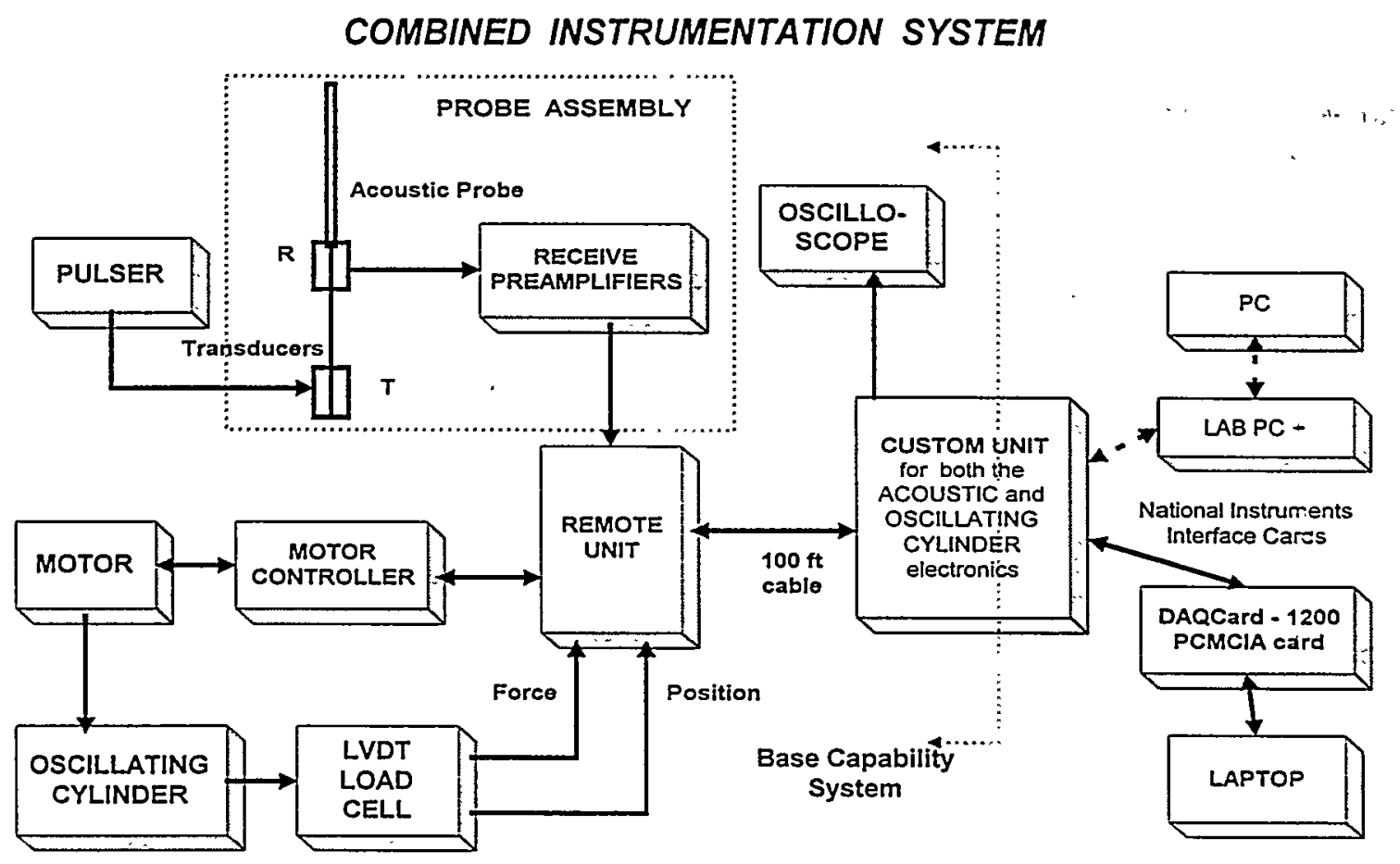

Figure 6. The complete automated viscosity instrumentation system.

Features of the oscillating cylinder sub-system:

- A variable DC motor controller and a DC-motor is used to actuate the oscillating cylinder rather than a voice-coil since it is the approach that can be implemented most quickly. It also implies a cylinder position that can be known with high precision. The motor controller and its power supply are mounted at the motor. with only low-powered signals running between it and the electronics.

- The position of the cylinder is sensed by a Linear Variable Differential Transformer (LVDT).

- The shear force needed to move the cylinder in the viscous medium is sensed by a pressure transducer.

- The motor controller includes a precise digital readout of RPM. Knowing the gear reduction ratio enables the angular velocity of the oscillating cylinder to be calculated with high accuracy.

- A digital oscilloscope with ensemble averaging capability is required to recover clean signals.

\section{Structure of the oscillating cylinder}

The side view of the structure of the prototype oscillating cylinder is diagrammed in Figure 7. Figure 8 is a top-view photograph. An AC electric motor turns the crank gear through a belt drive. The crank arm, $\mathrm{A}$, is attached to the crank gear two inches from its center of rotation. Arm $\mathrm{B}$ transmits the motion through a pivot point to Arm C, which is attached to the moving cylinder. 


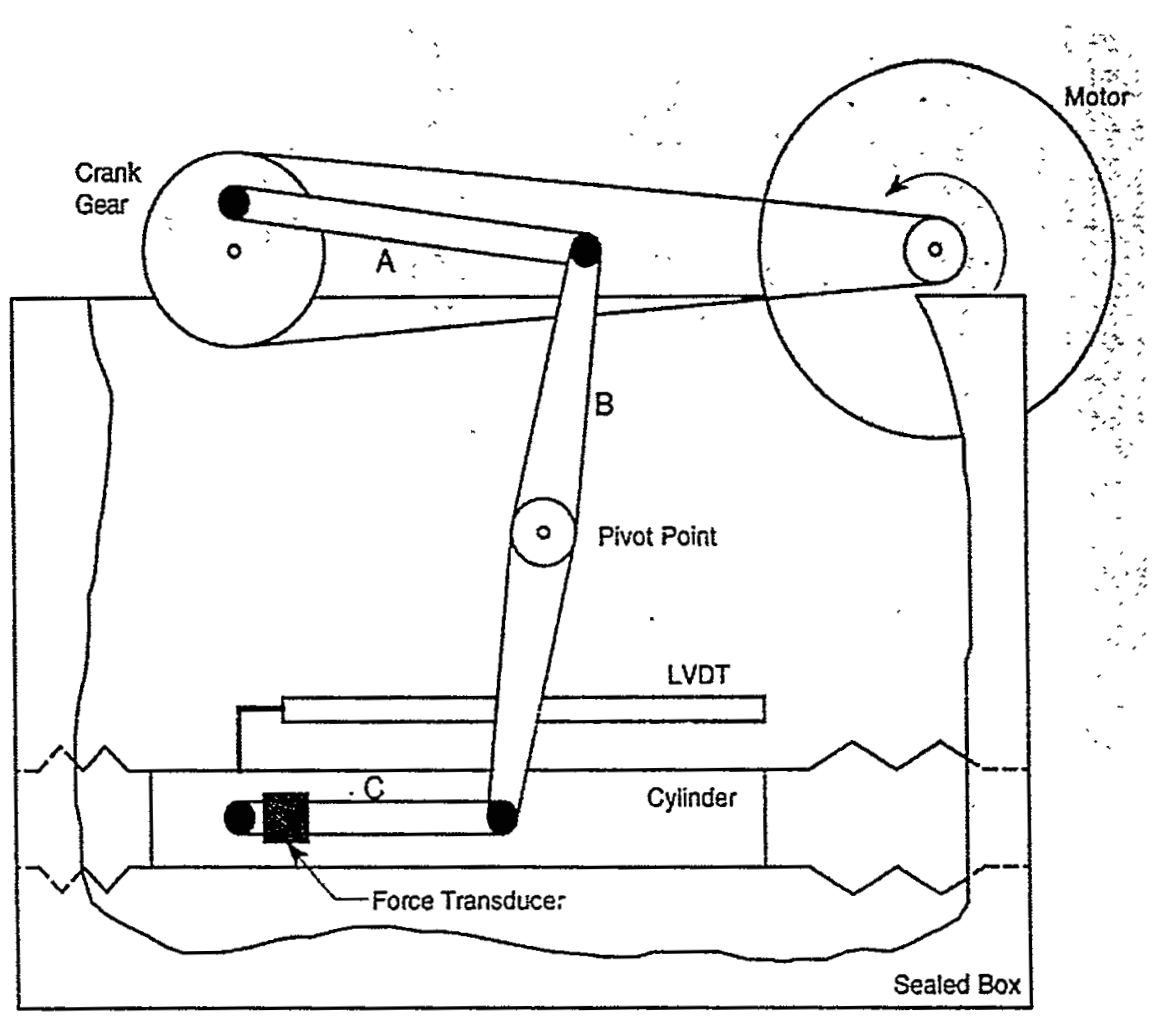

Figure 7. Illustration of the prototype oscillating cylinder viscometer.

The motion of the cylinder is guided by a linear bearing assembly. The force that moves the cylinder is measured with a strain gauge force transducer located in Arm C. The motion of the cylinder is measured with a Linear Variable Displacement Transducer (LVDT), located adjacent to the cylinder. These components are contained within a sealed, open-top aluminum box. The connection between the cylinder and the box is accomplished with a sealed bellows.

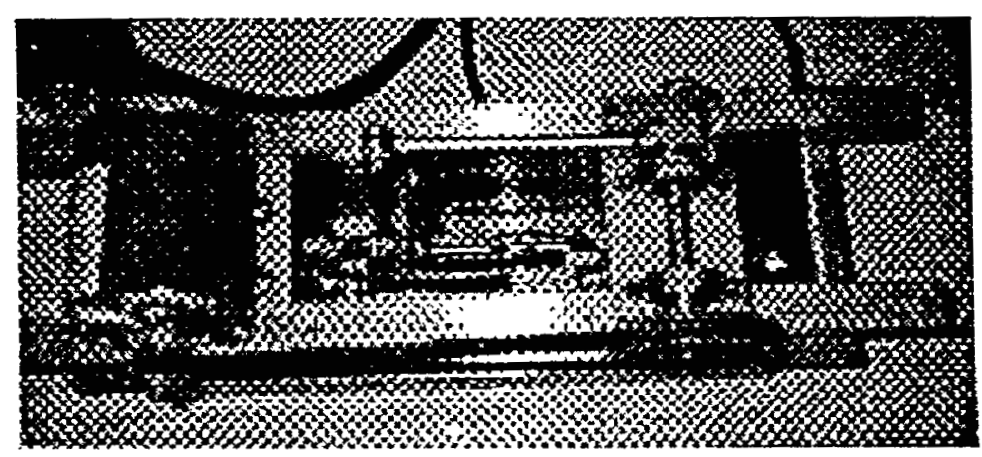

Figure 8. Top View of the oscillating cylinder structure. 


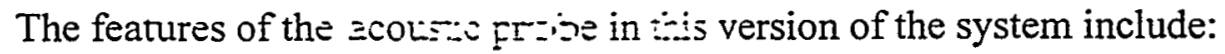

- A two transducer str_aur: $=$ useci. jut without a housing.

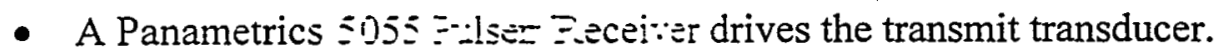

- A $30 \mathrm{X}$ preamp $:$ ier $\because 0 \mathrm{0s}=\cong$ the :eceived signal before sending it to the oscilloscope.

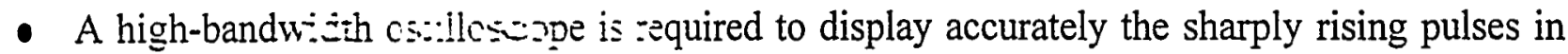
the received plise tra-s.

\section{System electronics}

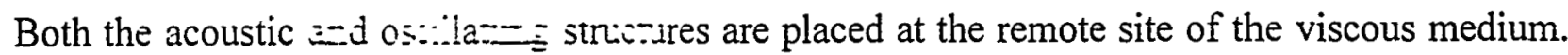
At this site. one rezote $=0 x=2$ - 25 ses electronics and connectors. It requires only one either short or long cable $: 0 \mathrm{~g}$ : 3 acis $:>$ a 0 . $t$ trol site where a custom enclosure and oscilloscope are located (see Figure 5 .

In a custom enclos:-a t:-: $:= \pm$ iditic:al electronics, including drivers for an oscilloscope. This

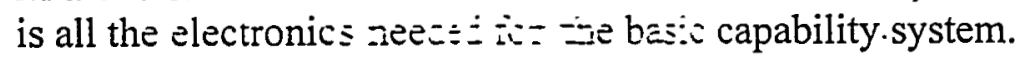

The basic capabi: $: ;:$ : $:$ ras instructed, and it works. As such, it is sufficient to

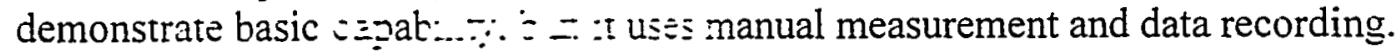

\section{AN AUTOMATED VISCOS, Y INSTRUMENTATION SYSTEM}

\section{The computer}

The more complete suteacquisition interface var $:-0, \because a t i c=\vdots$ Instruments (NI). The computer additions are shown on the right of Figure $\vdots$ TH $\vdots$. viscous media. It $F=5$ s 1 .

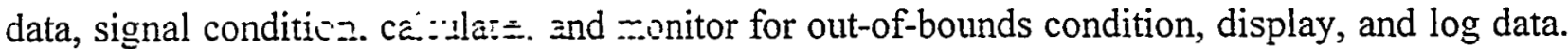
Most of this softwera has :eer - - -itter and debugged.

\section{The custom enclosure}

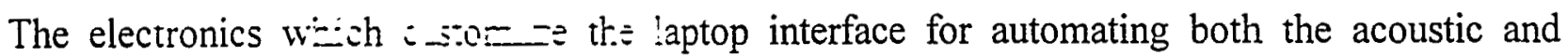
oscillating cylinder neas :-aran is sused in this custom enclosure. This includes the high-

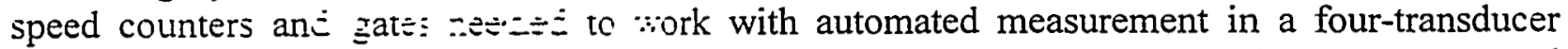
system. It runs on shc $-: 3:=0$ : $:=$ laptop's PCMCIA interface card. The connectors and electronics are des: $\equiv$ nec $: .2 \ldots=$ the $:$ istom unit could also be used with a larger desktop

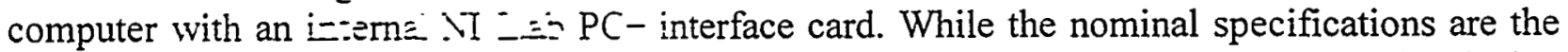

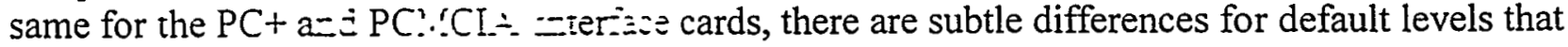

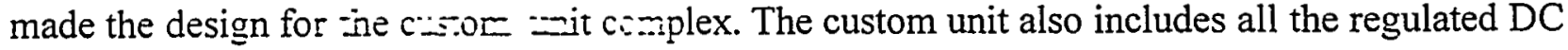
voltages needed, $\mathrm{pl}$ - sw: sies.

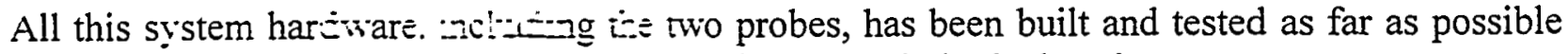
without having a fo $=$-tra-sive $=$ covs: $:$ i probe assembly in the housing. 


\section{PROJECT STATUS}

\section{Acoustic method}

We have completed our proof of the concept of measuring viscosity by acoustics. There were recurring apparatus limitations. These limitations prevented automated data acquisition, but sufficient acoustic time delay data has been obtained manually from representative solutions. This data has been used to calculate viscosity. and the results check with good accuracy from 5 $\mathrm{cP}$ to $2000 \mathrm{cP}$ on several mixtures-sugar, glycerin, and glycerol-across a broad temperature range. Non-Newtonian fluids can also be measured for particle sizes of less than one millimeter.

A robust four-transducer probe assembly still needs to be developed.

The electronics hardware for an automated instrumentation system has been constructed. However, substantial additional effort and corresponding funding will be required for software development and testing to complete a stable automated instrument.

\section{Oscillating cylinder method}

We have completed our proof of the concept of measuring viscosity using an oscillating cylinder. The force and displacements transducers and their signal conditioners work, as observed on a storage oscilloscope. With only limited time available, a manual approach was used for data acquisition and recording. All the required averaged force and displacement waveforms were captured and documented using a camera. Data was read and recorded manually from the screen and camera pictures for various solutions and mixtures with various cylinder oscillation frequencies. From this manual data, the viscosity was calculated using MATHCAD and Bessel function equations from fluid mechanics. The process works.

However, the mass and power of the present prototype oscillating structure is too large for the opposing viscous drag to modify sufficiently to obtain laboratory-quality precision. A reduced mass, second-generation structure is called for.

To produce a stable automated instrument some LabView programs will need to be developed. In addition, some means must be found to either link these programs to MATHCAD so that data is transferred automatically, or to embed corresponding calculations within LabView. 


\subsection{PROOF OF CONCEPT FOR THE OSCILLATING CYLINDER METHOD}

\section{EXPERIMENTAL LIQUIDS}

The properties of some liquids tested are presented in Table 1.

Table 1.

Thermophysical properties of the experimental fluids

\begin{tabular}{||l|c|c|}
\hline Adjacent Fluid & Density $\left(\mathrm{g} / \mathrm{cm}^{3}\right)$ & Viscosity (cPs) \\
\hline water & 0.987 & 1 \\
\hline $25 \%$ sugar-75\% water & 1.1 & 2.42 \\
\hline $40 \%$ sugar-60\% water & 1.1765 & 6.1625 \\
\hline $50 \%$ sugar-50\% water & 1.2295 & 10.27 \\
\hline $60 \%$ sugar-40\% water & 1.28 & 45.46 \\
\hline $45 \%$ sugar-45\% water-10\% sand & 1.25 & 24.673 \\
\hline
\end{tabular}

The first five data from the table are from "The Manufacturing of Sugar Products," by G. Nicolescu. The last information on the multi-component fluid sugar-water-sand was provided from previous experiments developed at Oak Ridge National Laboratories.

\section{WAVEFORMS}

\section{Introduction}

The goal was to prove the feasibility of measuring the viscosity of an adjacent fluid by an oscillating cylinder. According to the theory developed last year, with the mass $\mathrm{m}$ and the displacement fixed, viscosity can be calculated if three variables are measured: the angular velocity $\omega$, the force $x$ the cylinder exerts on the viscous medium, and the phase lag between them.

The accuracy of the calculated viscosity depends on the accuracy with which these measured values are determined. In addition, since force is implied by voltage from a load cell, calibration is required to interpret this voltage as the force $\mathrm{x}$. The calibration can be extended to include the calculation of the term $m \omega^{2} \mathrm{x}$ that is proportional to $\mathrm{x}$. Therefore, the key factors affecting accuracy are the accuracy of this term and the measurement of phase angle. A least-squares fit will be used to come up with mathematical models for both, and the correlation for each fit is an objective measure of the validity-hence, accuracy of each. Raw data on which these linear fits 
were performed were obtained from the waveforms. Waveforms follow for force and position of some tested liquids.

\section{The need for ensemble averaging}

A substantial noise was detected in the force waveform but was eliminated by using ensemble averaging over 150 cycles. The LabView software was not completed sufficiently to include its capability for ensemble averaging for noise reduction. In order to prove the feasibility of this approach, a Hewlett Packard $500 \mathrm{MHz}$ storage oscilloscope was used. Figure 9 shows both the noisy shear force and displacement transducer waveforms in air. The force signal is not stable and varies within a certain range. A closer look at both waveforms is presented in Figure 10. In Figure 11, the force waveform was ensemble averaged over 150 cycles by the oscilloscope.

\section{Comparing waveforms in air and water}

The waveforms obtained in air and in the first tested fluid (water) are compared in Figures 12, 13. The force peak amplitude is higher in water than in air. Frequencies in Figures 12, 13 correspond to the same electronic settings. Most likely due to the non-sinusoidal nature of the force waveform, the frequencies are close to each other in value, but never the same. The displacement waveform remained in the same range of $2.750 \mathrm{~V}-2.781 \mathrm{~V}$ for all the tested liquids.

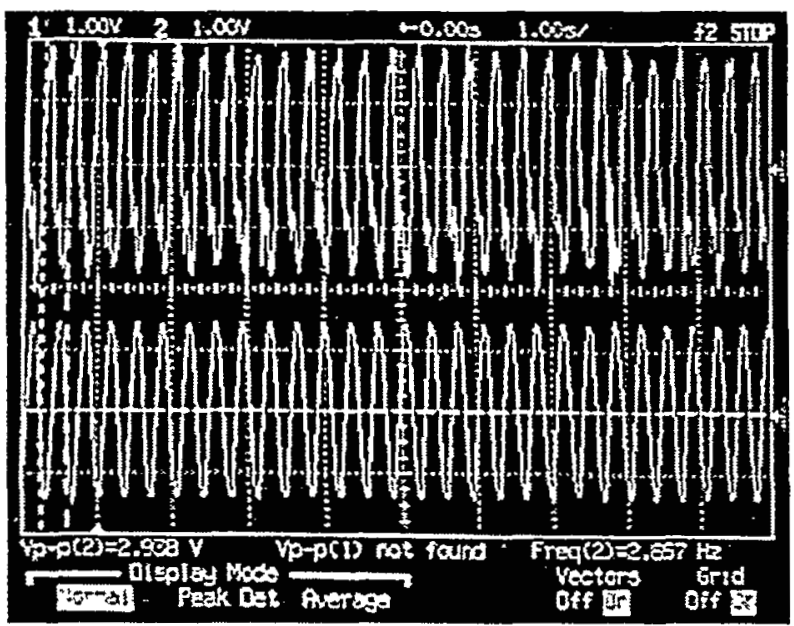

Figure 9. Waveforms in air at $2.849 \mathrm{~Hz}$. 


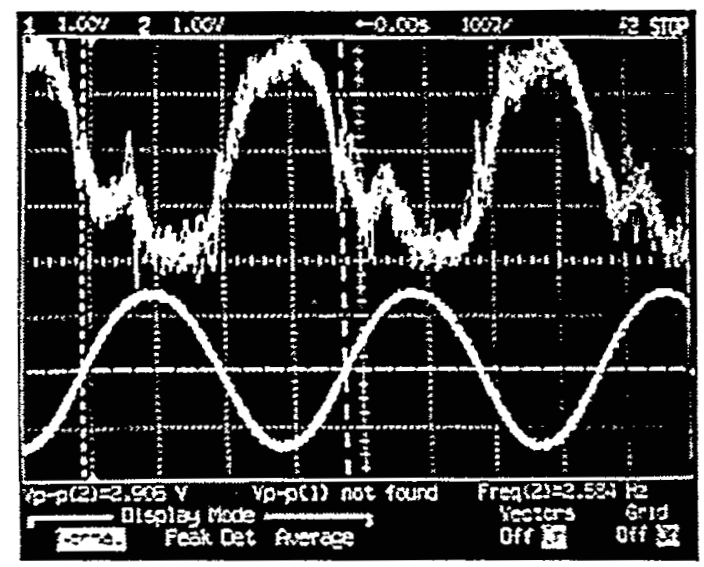

Figure 10. Detail of the waveforms for a frequency of $2.849 \mathrm{~Hz}$.

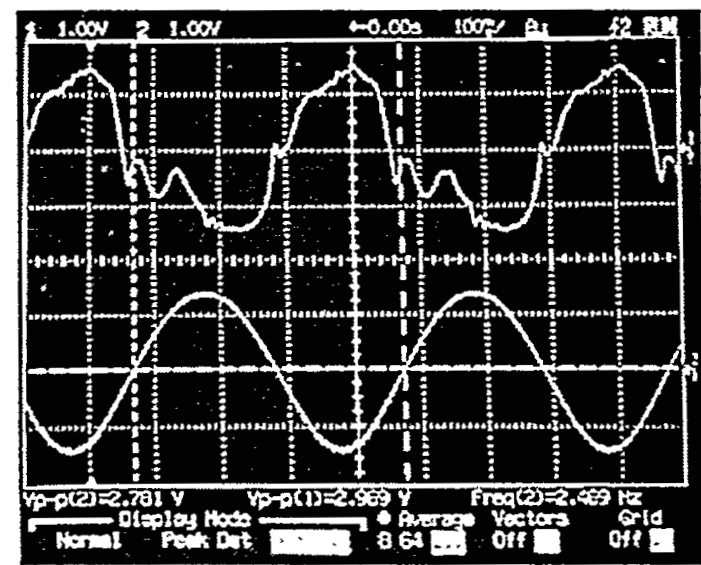

Figure 11. The same waveforms as shown in Figure 10, but using ensemble averaging.

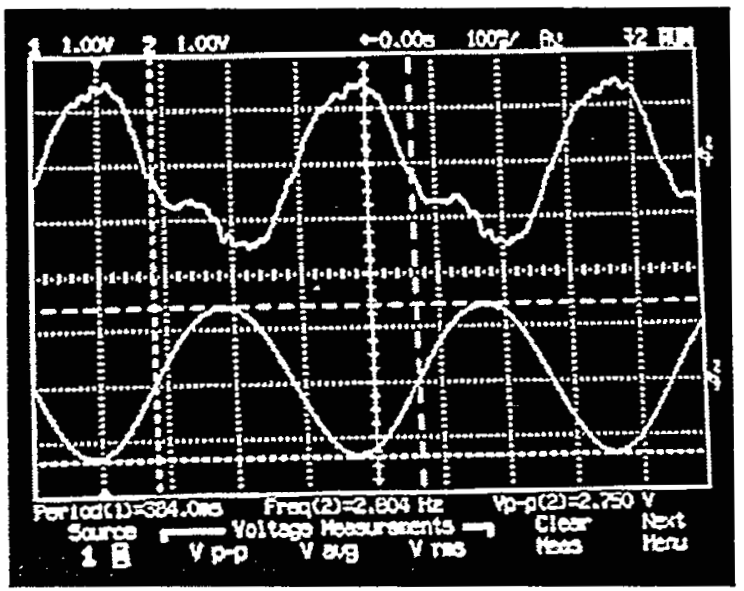

Figure 12. Waveforms in air for $2.604 \mathrm{~Hz}$. 


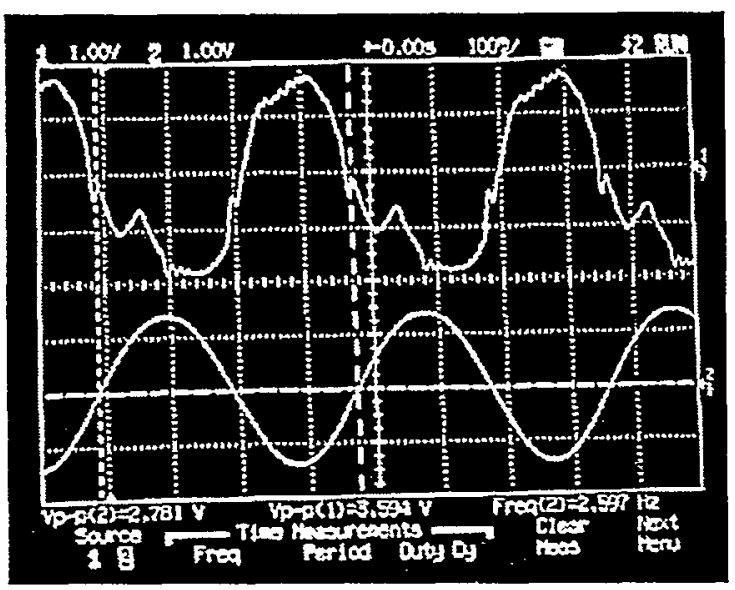

Figure 13. Waveforms in water for $2.604 \mathrm{~Hz}$.

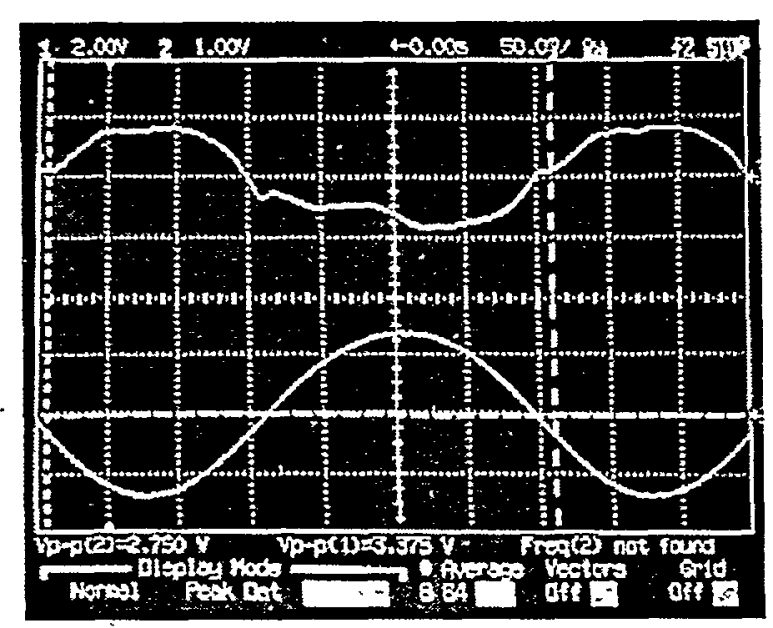

Figure 14. Waveforms in air for $2.750 \mathrm{~Hz}$.

\section{The effect of frequency on waveshape}

Figures 14, 15 represent waveforms obtained in air for two different frequencies: $2.813 \mathrm{~Hz}$ and $2.750 \mathrm{~Hz}$. The force waveforms change with the frequency of oscillation. The waveforms become more stable as the frequency increases. and the signal can be trigged more easily if the frequency of oscillation is higher than $2.5 \mathrm{~Hz}$. 


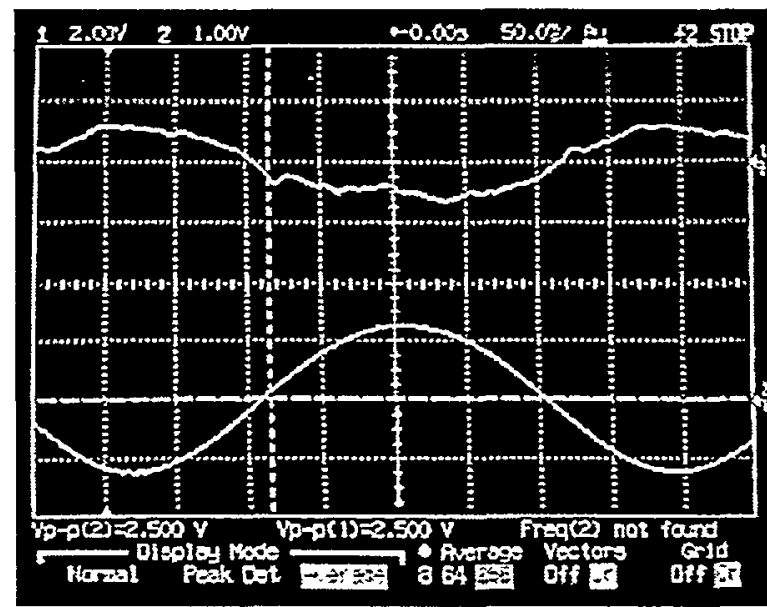

Figure 15. Waveforms in air for $2.813 \mathrm{~Hz}$.

\section{EXPERIMENTAL RESULTS}

\section{Calibration}

The calibration of the device is done in air, where viscous fluid forces are negligible. The force amplitude is represented through $m \omega^{2} \mathrm{x}$. By using a least square-approximation one obtains a straight line with the corresponding equation and correlation factor. The equation obtained from the calibration $y=7.7824 x+3.6504$, is used later for calculating the measured force $(N)$. In Figure 16 , the $\mathrm{x}$ value is replaced by the force value $(\mathrm{V})$, which is the voltage displared on the oscilloscope screen.

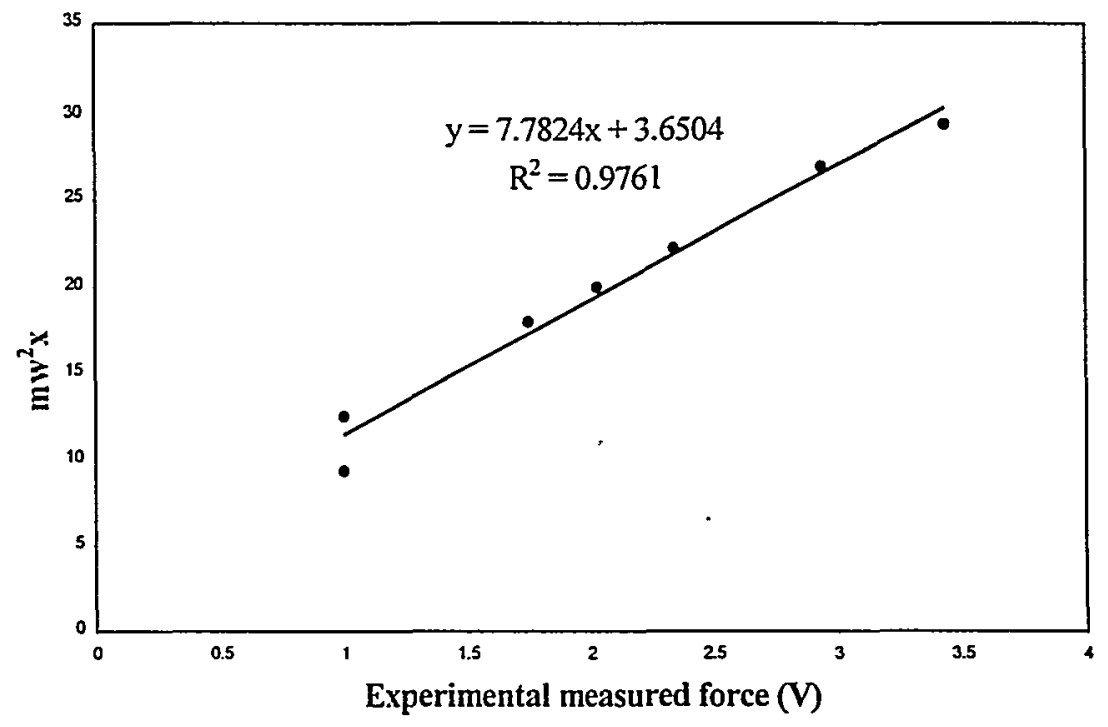

Figure 16. Calibration in air. 
The obtained curve fit is linear for a force corresponding to a $0.5-3.5 \mathrm{~V}$ range. In the experimentally calculated force it is assumed that this approximation can be extended for magnitudes greater than $3.5 \mathrm{~V}$.

Table 2.

Experimental data for calibrating the oscillating cylinder sensor in air

\begin{tabular}{|c|c|}
\hline Force $(\mathrm{V})$ & $\mathrm{m} \omega^{2} \mathrm{x}(\mathrm{N})$ \\
\hline 1.0 & 9.330943 \\
\hline 1.0 & 12.5116 \\
\hline 1.75 & 17.97802 \\
\hline 2.031 & 19.98008 \\
\hline 2.344 & 22.21299 \\
\hline 2.938 & 26.93487 \\
\hline 3.438 & 29.45601 \\
\hline
\end{tabular}

In Table $2, \mathrm{~m}^{2} \mathrm{x}$ represents the calculated experimental force using the calibration provided data. This value will be referred to as the 'measuring force'.

\section{Measured data in water}

After obtaining the calibration diagram, the device is immersed in 40 liters of water. The fluid dynamic effects at the extremities of the moving cylinder are considered negligible. Table 3 shows the force in volts obtained from the oscilloscope, the measured, and the predicted force in Newtons. By considering the density, viscosity and frequency of cylinder movement, the force amplitude and the phase angle are predicted with accuracy. The measured experimental force is obtained by using the calibration curve with the $\mathrm{X}$ value replaced by the force amplitude. The predicted force amplitude was obtained by using a Mathematica program (see Figure 17). 
Table 3.

Force peak amplitude and the corresponding frequencies for water as the adjacent fluid

\begin{tabular}{|c|c|c|c|}
\hline Frequency $(\mathrm{Hz})$ & Reading force $(\mathrm{V})$ & Measured force $(\mathrm{N})$ & Predicted force $(\mathrm{N})$ \\
\hline 1.98 & 1.625 & 16.2968 & 14.078 \\
\hline 2.105 & 1.937 & 18.72491 & 15.9062 \\
\hline 2.227 & 2.219 & 20.91955 & 17.8062 \\
\hline 2.347 & 2.594 & 23.83795 & 18.7629 \\
\hline 2.469 & 2.969 & 26.75635 & 19.7796 \\
\hline 2.538 & 3.063 & 27.48789 & 20.8049 \\
\hline 2.597 & 3.188 & 28.46069 & 22.5025 \\
\hline 2.66 & 3.438 & 30.40629 & 23.6711 \\
\hline 2.725 & 3.625 & 31.8616 & 24.8103 \\
\hline 2.841 & 4.125 & 35.7528 & 26.03947 \\
\hline 2.976 & 4.5 & 38.6712 & 27.8067 \\
\hline 3.091 & 5 & 42.5624 & 30.3708 \\
\hline
\end{tabular}

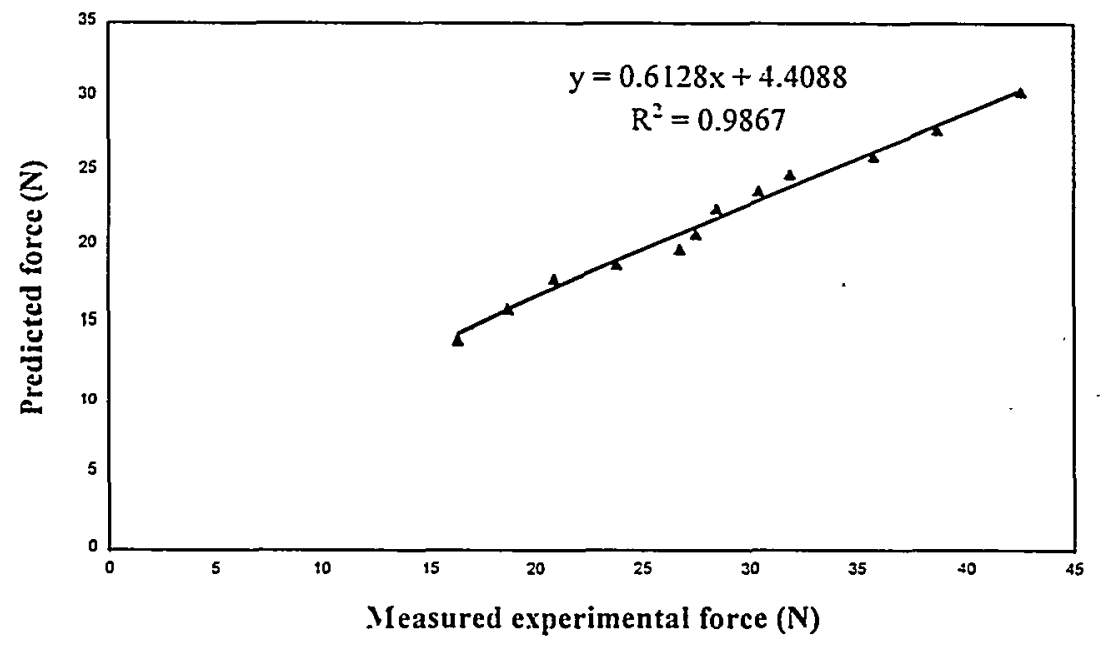

Figure 17. Predicted force versus measured force for water.

\section{Data for $25 \%$ sugar mixtures}

The experimental fluids are mixtures with the same properties and behavior as the waste tank slurries. 
Their initial aqueous mixtures were designed with sucrose instead of sugar. Due to the high cost, the sucrose was replaced with sugar. For a $60 \%$ sugar- $-40 \%$ water, $80 \mathrm{lbs}$. of sugar was needed to acquire the desired percentage.

The next adjacent experimental fluid is $25 \%$ sugar- $75 \%$ water. Table 4 shows the data for the measured force obtained from the calibration equation. The predicted force obtained from the Mathematica program is plotted versus the measured force in Figure 18.

Table 4.

Experimental data for $25 \%$ sugar $-75 \%$ water

\begin{tabular}{|c|c|c|c|}
\hline Frequency $(\mathrm{Hz})$ & Reading force $(\mathrm{V})$ & Measured force $(\mathrm{N})$ & Predicted force (N) \\
\hline 2.237 & 2.344 & 21.89235 & 17.905 \\
\hline 2.358 & 2.688 & 24.56949 & 18.8691 \\
\hline 2.481 & 2.938 & 26.51509 & 22.034 \\
\hline 2.532 & 3.188 & 28.46069 & 22.485 \\
\hline 2.604 & 3.313 & 29.43349 & 22.9511 \\
\hline 2.66 & 3.438 & 30.40629 & 23.601 \\
\hline 2.732 & 3.625 & 31.8616 & 24.7977 \\
\hline 2.849 & 4.125 & 35.7528 & 26.0183 \\
\hline 2.976 & 4.625 & 39.644 & 27.8683 \\
\hline 3.077 & 5.000 & 42.5624 & 30.3622 \\
\hline 3.145 & 5.125 & 43.5352 & 32.799 \\
\hline 3,268 & 5.625 & 47.4264 & 34.6676 \\
\hline
\end{tabular}

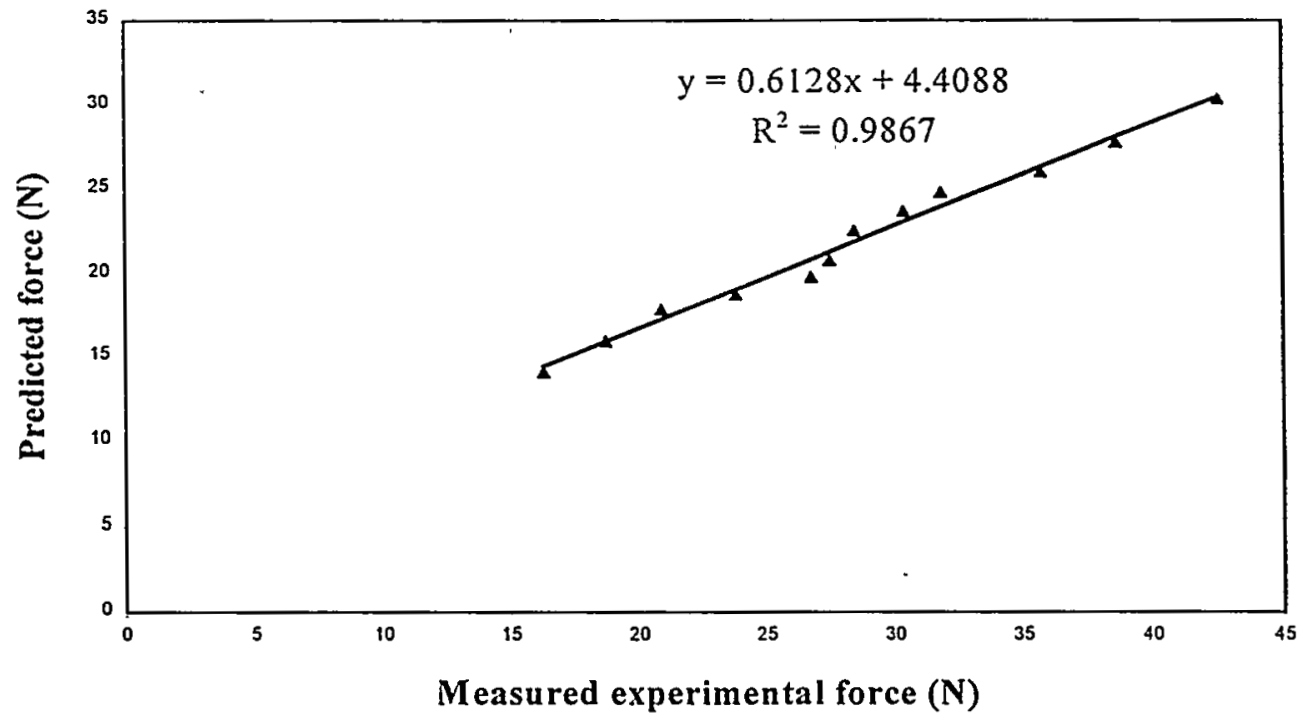

Figure 18. Predicted force versus experimental force for $25 \%$ sugar- $75 \%$ water solution. 


\section{Results for $40 \%$ sugar mixtures}

The next experimental fluid measured was $40 \%$ sugar-60\% water. In Figure 19, the predicted force is represented versus the experimental force (obtained using the calibration curve obtained in air).

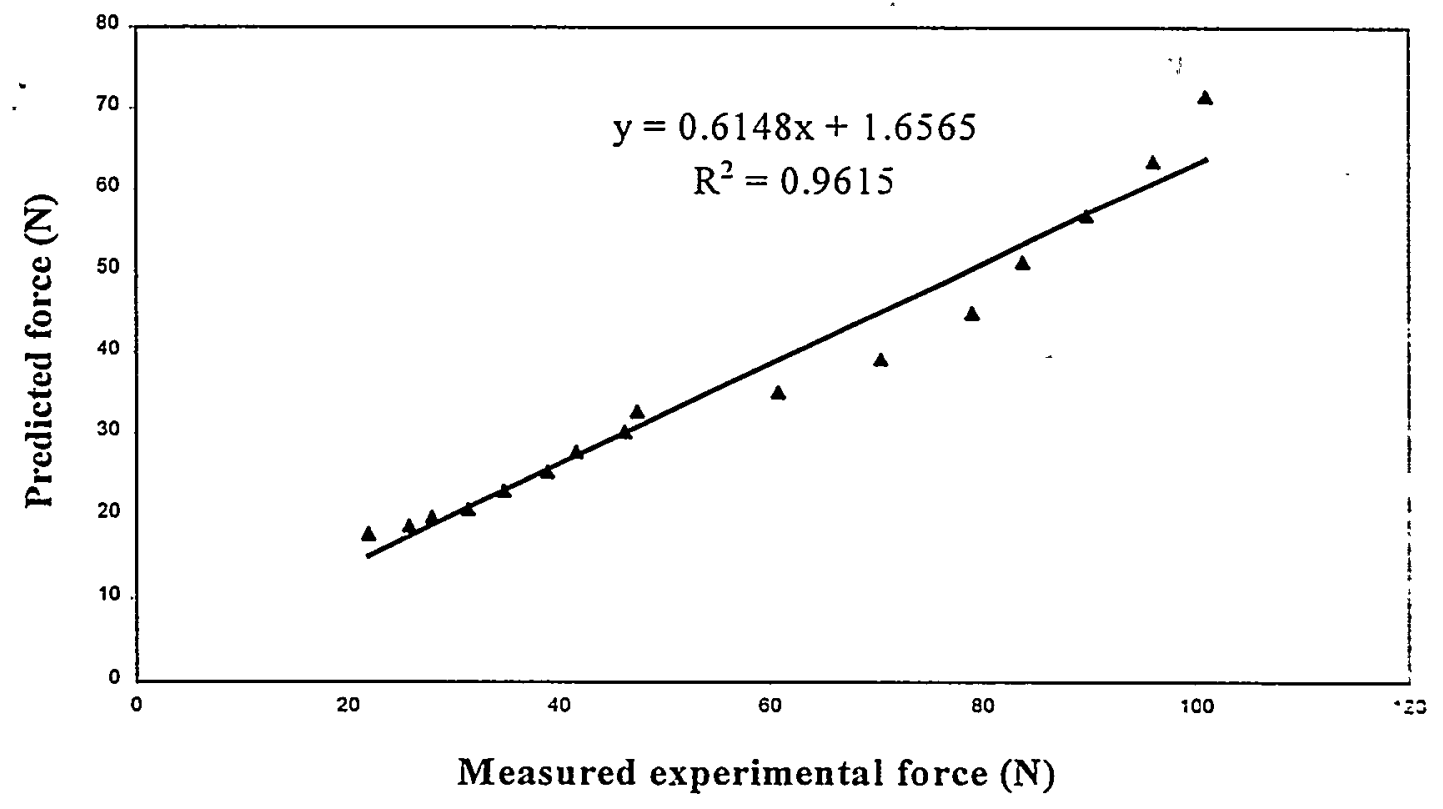

Figure 19. Predicted force versus measured force for $40 \%$ sugar- $60 \%$ water solution.

\section{Results for $50 \%$ sugar}

The magnitude of the peaks corresponding to the force signal in the $40 \%$ sugar- $60 \%$ water and $50 \%$ sugar- $50 \%$ water are different. It can be seen that as the frequency increases the peak amplitude corresponding to the more concentrated aqueous solution is bigger in magnitude than the one in the lower concentrated solution. Figure 20 is the plot. 


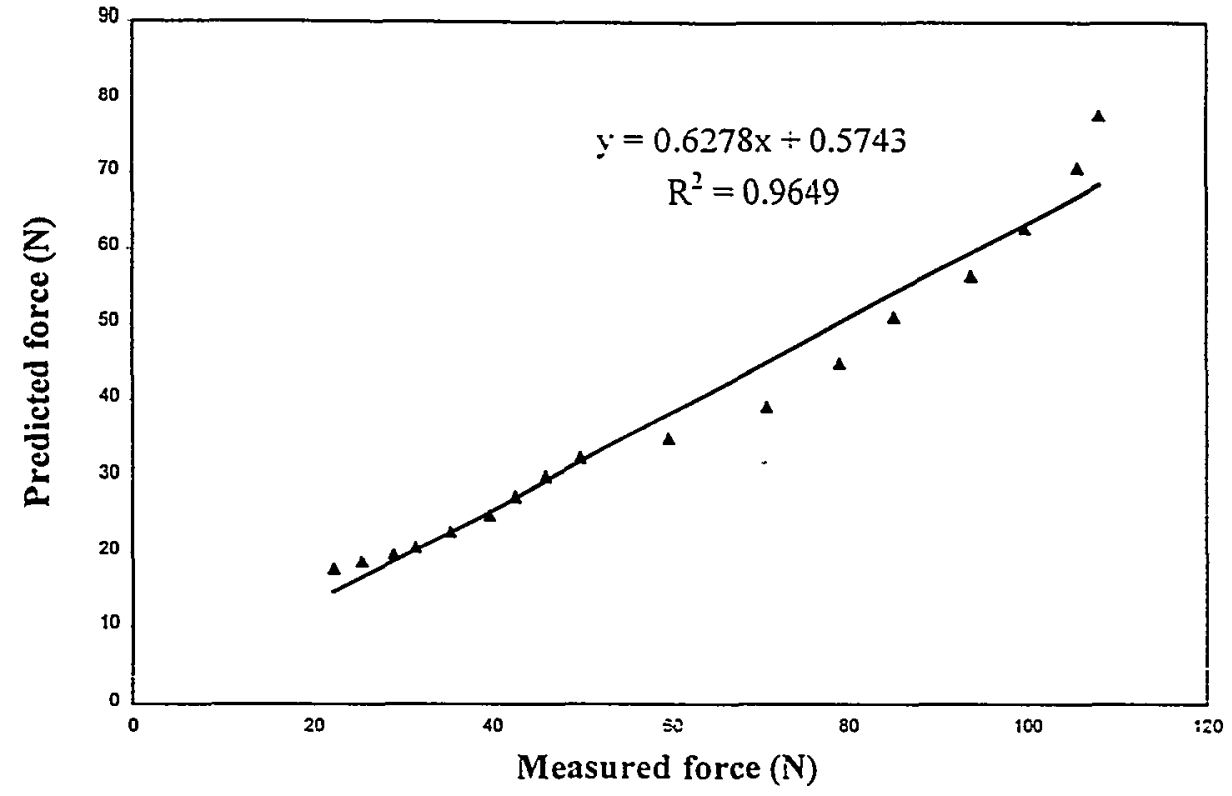

Figure 20. Predicted force versus measured force for a $50 \%$ sugar-50\% water solution.

\section{Data for $60 \%$ sugar}

The next experimental fluid is a $60 \%$ sugar- $-40 \%$ water solution. See Table 5 and its plot Figure 21. The sugar particles in this solution were not completely dissolved because this solution is supra-saturated. There is a phase change between this solution and the $45 \%$ sugar $-45 \%$ water$10 \%$ sand (presented in the next section).

Table 5.

Experimental data for $60 \%$ sugar $-40 \%$ water

\begin{tabular}{|c|c|c|c||}
\hline Frequency $(\mathrm{Hz})$ & Reading force $(\mathrm{V})$ & Heasured force $(\mathrm{N})$ & Predicted force $(\mathrm{N})$ \\
\hline 2.237 & 2.563 & 23.59669 & 17.2314 \\
\hline 2.358 & 2.844 & 25.78355 & 18.1407 \\
\hline 2.481 & 3.406 & 30.15725 & 19.1695 \\
\hline 2.604 & 4.000 & 34.78 & 20.1457 \\
\hline 2.732 & 4.437 & 38.18091 & 22.2751 \\
\hline 2.849 & 4.937 & 42.07211 & 24.5559 \\
\hline 2.976 & 5.375 & 45.4808 & 26.8984 \\
\hline 3.077 & 5.875 & 49.372 & 29.3263 \\
\hline 3.125 & 6.406 & 53.50445 & 31.7093 \\
\hline
\end{tabular}


Table 5.

Experimental data for $60 \%$ sugar $-40 \%$ water (Continued)

\begin{tabular}{|c|c|c|c|}
\hline Frequency $(\mathrm{Hz})$ & Reading force $(\mathrm{V})$ & Measured force $(\mathrm{N})$ & Predicted force $(\mathrm{N})$ \\
\hline 4.04 & 10.31 & 83.88694 & 49.5325 \\
\hline 4.228 & 10.63 & 86.37731 & 54.7151 \\
\hline 4.556 & 12.66 & 102.1756 & 59.486 \\
\hline 4.773 & 13.44 & 108.2459 & 67.1034 \\
\hline
\end{tabular}

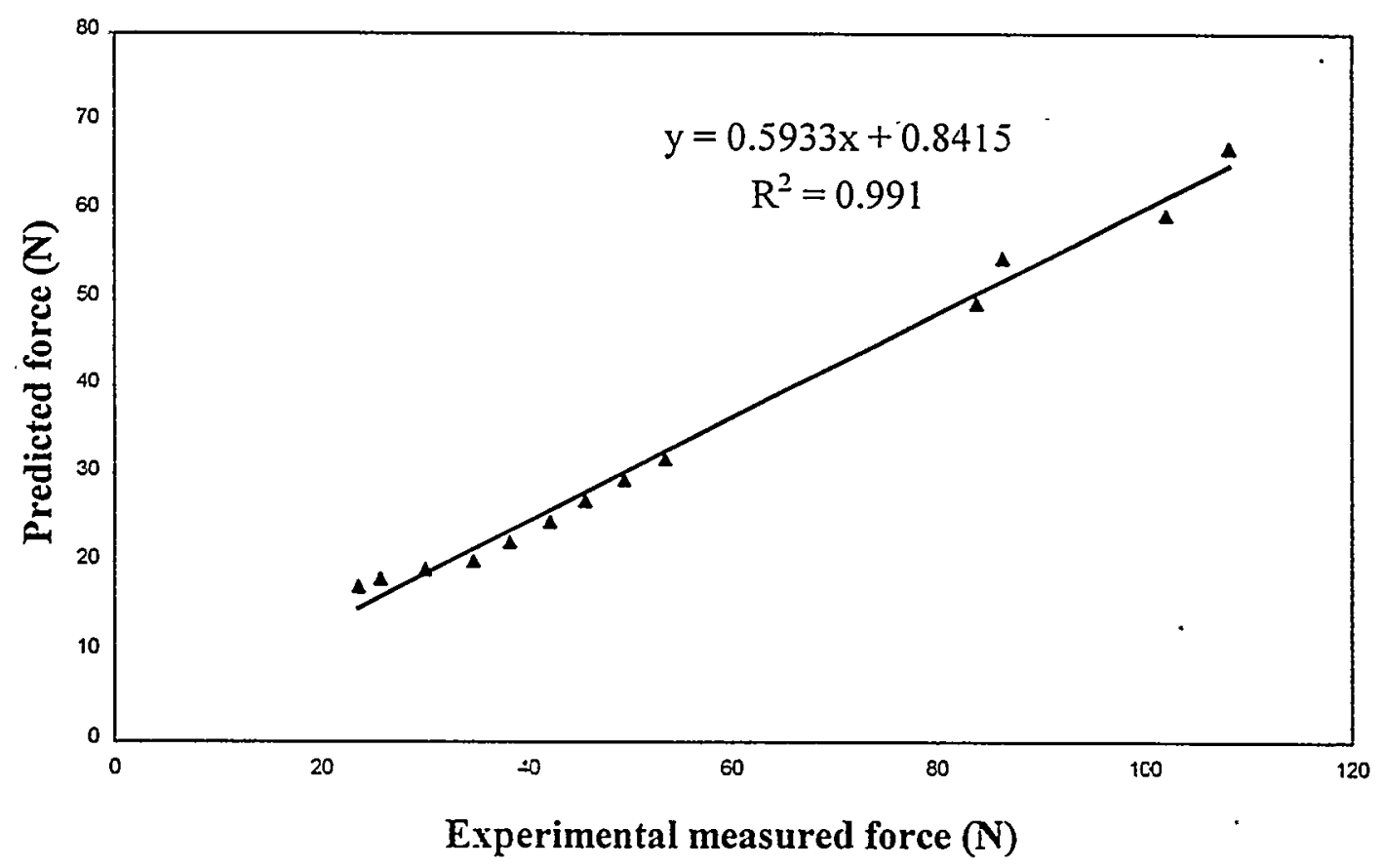

Figure 21. Predicted force versus measured force for $60 \%$ sugar $-40 \%$ water solution.

\section{Data for $25 \%$ sugar, $45 \%$ water, and $10 \%$ sand}

The last experimental solution is $45 \%$ sugar $-45 \%$ water $-10 \%$ sand. See Table 6 and its plot, Figure 22. This solution is a multi-component phase fluid. During the measurements, the solution was permanently mixed manually to maintain the sand particles as a suspension within the sugarwater solution. 
Table 6.

Experimental data for $45 \%$ sugar- $45 \%$ water- $10 \%$ sand

\begin{tabular}{|c|c|c|c|}
\hline Frequency $(\mathrm{Hz})$ & Reading force $(\mathrm{V})$ & Measured force $(\mathrm{N})$ & Predicted force $(\mathrm{N})$ \\
\hline 2.358 & 3.188 & 28.46069 & 19.4894 \\
\hline 2.481 & 3.625 & 31.8616 & 20.4905 \\
\hline 2.604 & 4.000 & 34.78 & 21.5916 \\
\hline 2.732 & 4.687 & 40.12651 & 22.6462 \\
\hline 2.849 & 5.062 & 43.04491 & 24.955 \\
\hline 2.976 & 5.562 & 46.93611 & 27.3238 \\
\hline 4.367 & 11.72 & 94.86013 & 55.4449 \\
\hline 4.566 & 12.81 & 103.3429 & 62.0909 \\
\hline
\end{tabular}

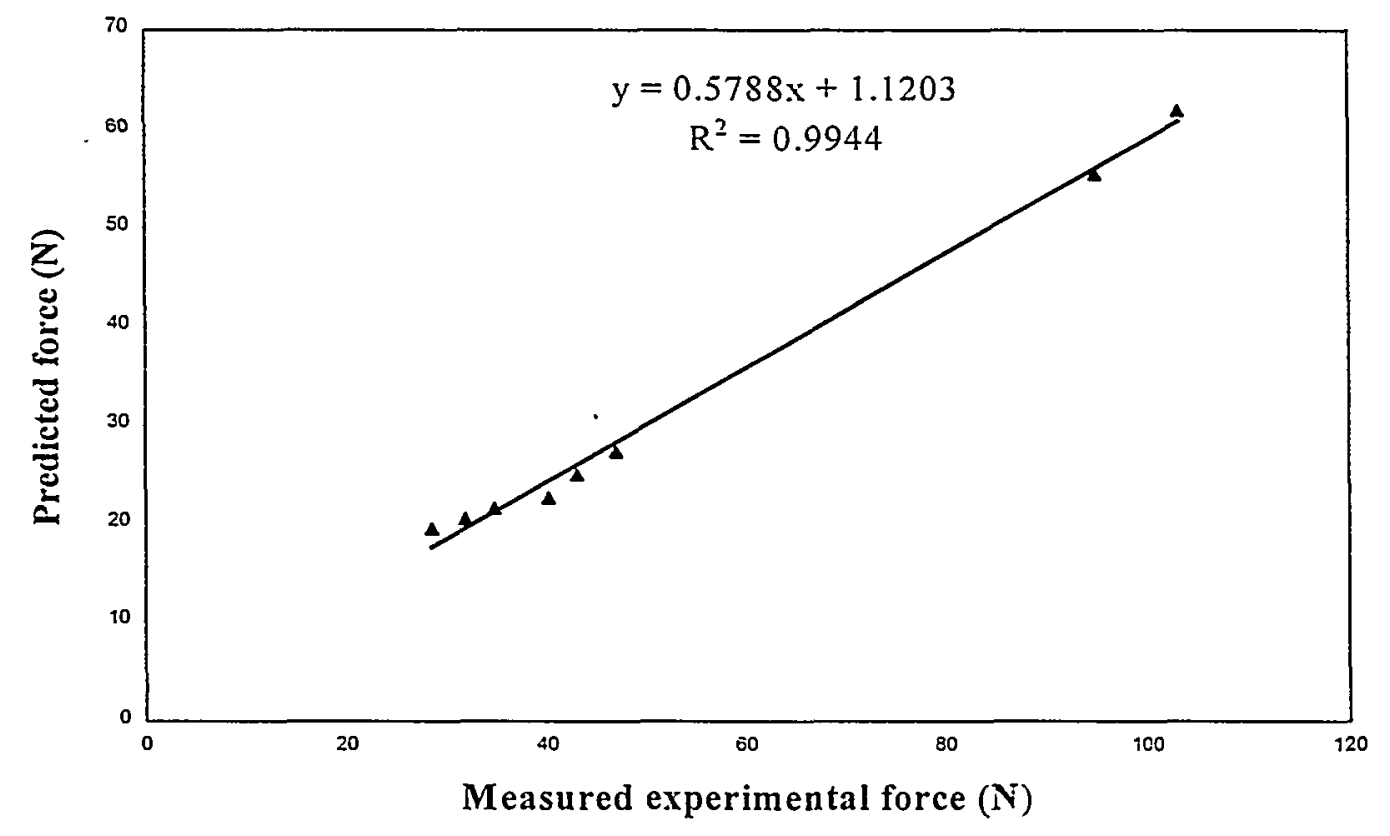

Figure 22. Predicted force versus experimental measured force for $45 \%$ sugar$45 \%$ water $-10 \%$ sand solution.

\section{PHASE ANGLES}

\section{Introduction}

Dr. Moore's theoretical derivations predicted phase shifts between the force and displacements that vary with viscosity. Such phase shifts were found to occur, but the correlations are weak for 
low viscosities. Figures $23-28$ present the predicted and calibrated (calculated) phase angles for the various solutions tested.

Phase angles for water

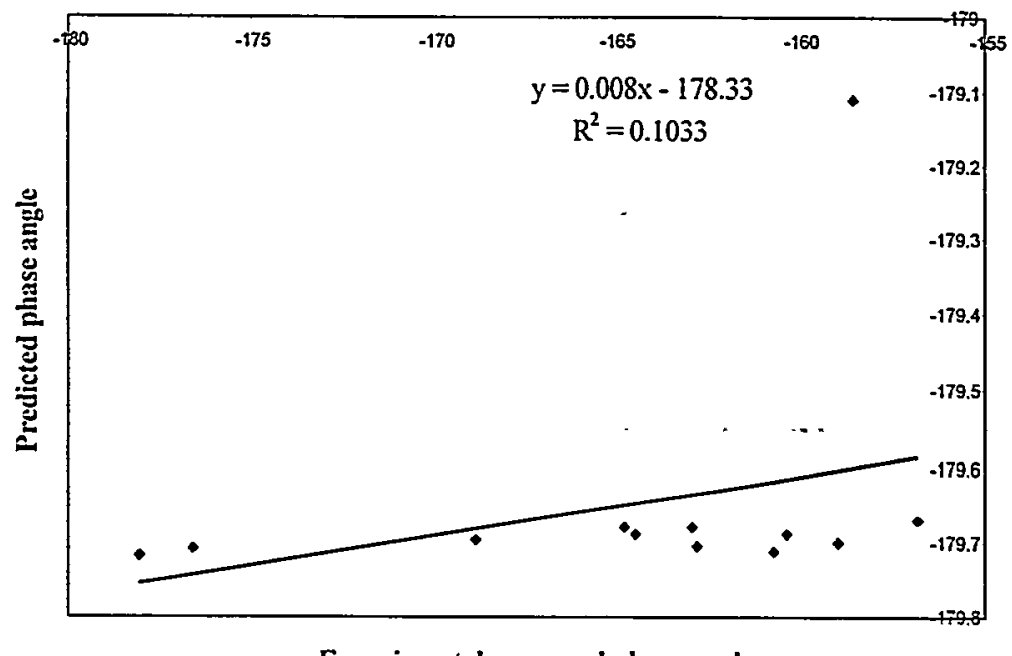

Experimental measured phase angle

Figure 23. Predicted phase angle versus measured phase angle for water.

Phase angles for $25 \%$ sugar

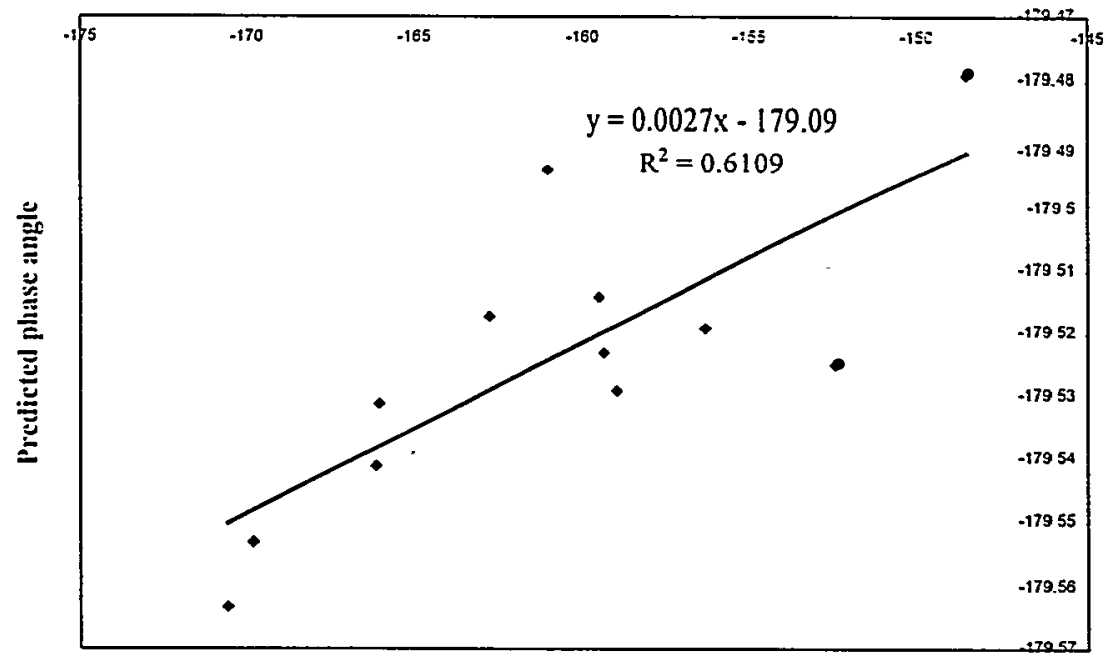

Measured experimental phase angle

Figure 24. Predicted phase angle versus experimental phase angle for $25 \%$ sugar- $75 \%$ water solution. 
Phase angles for $40 \%$ sugar

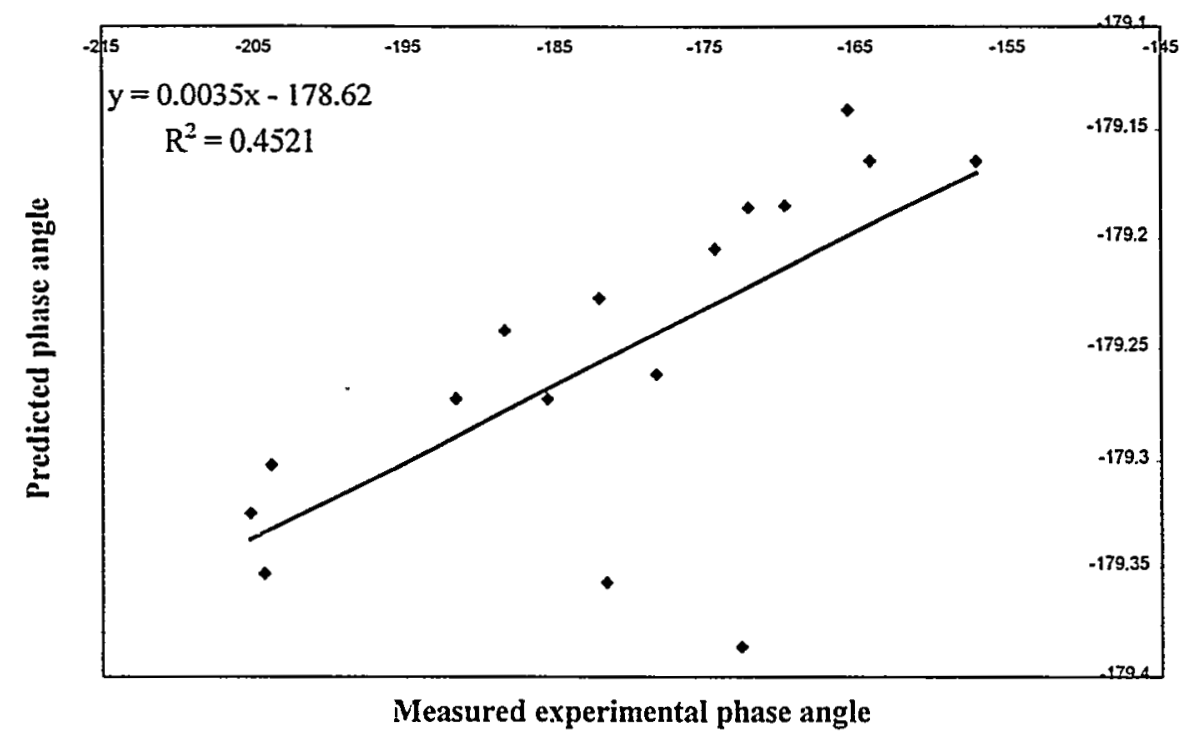

Figure 25. Predicted phase angle versus measured angle for $40 \%$ sugar- $60 \%$ water solution

Phase angles for $50 \%$ sugar :

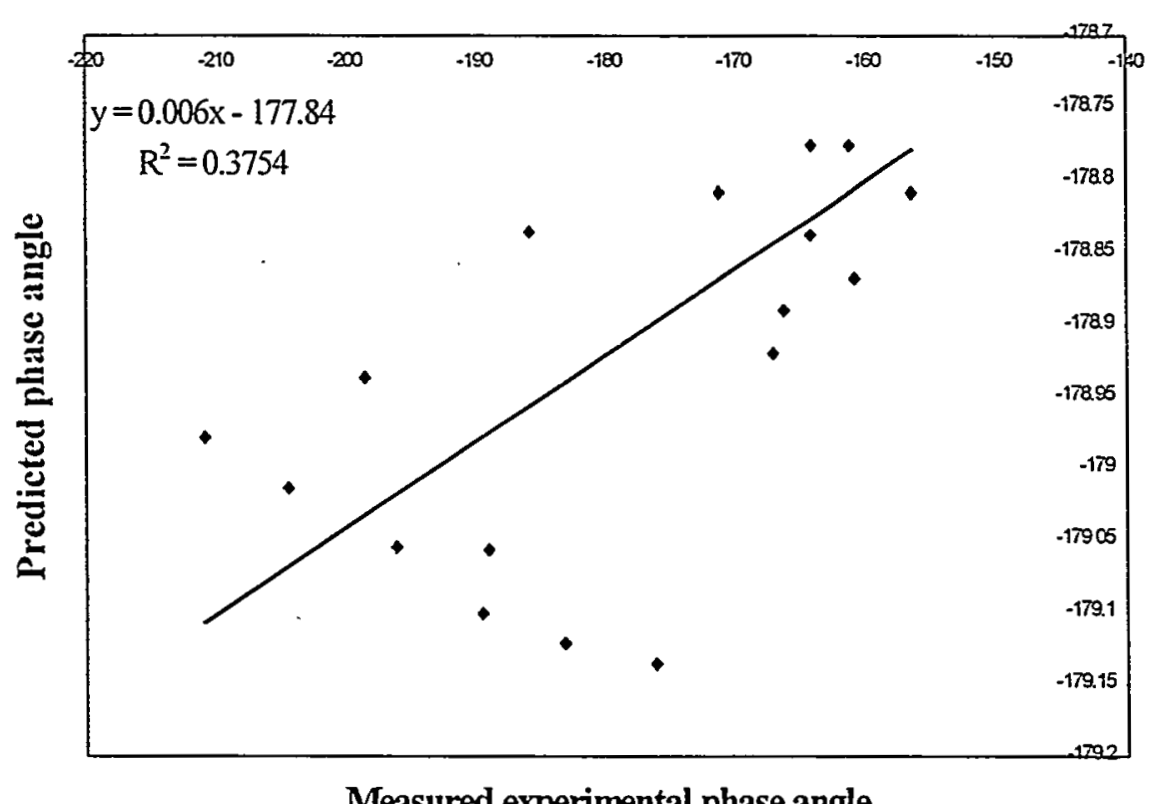

Measured experimental phase angle

Figure 26. Predicted phase angle versus measured phase angle for $\mathbf{5 0} \%$ sugar $-\mathbf{5 0} \%$ water solution. 
Phase angles for $60 \%$ sugar

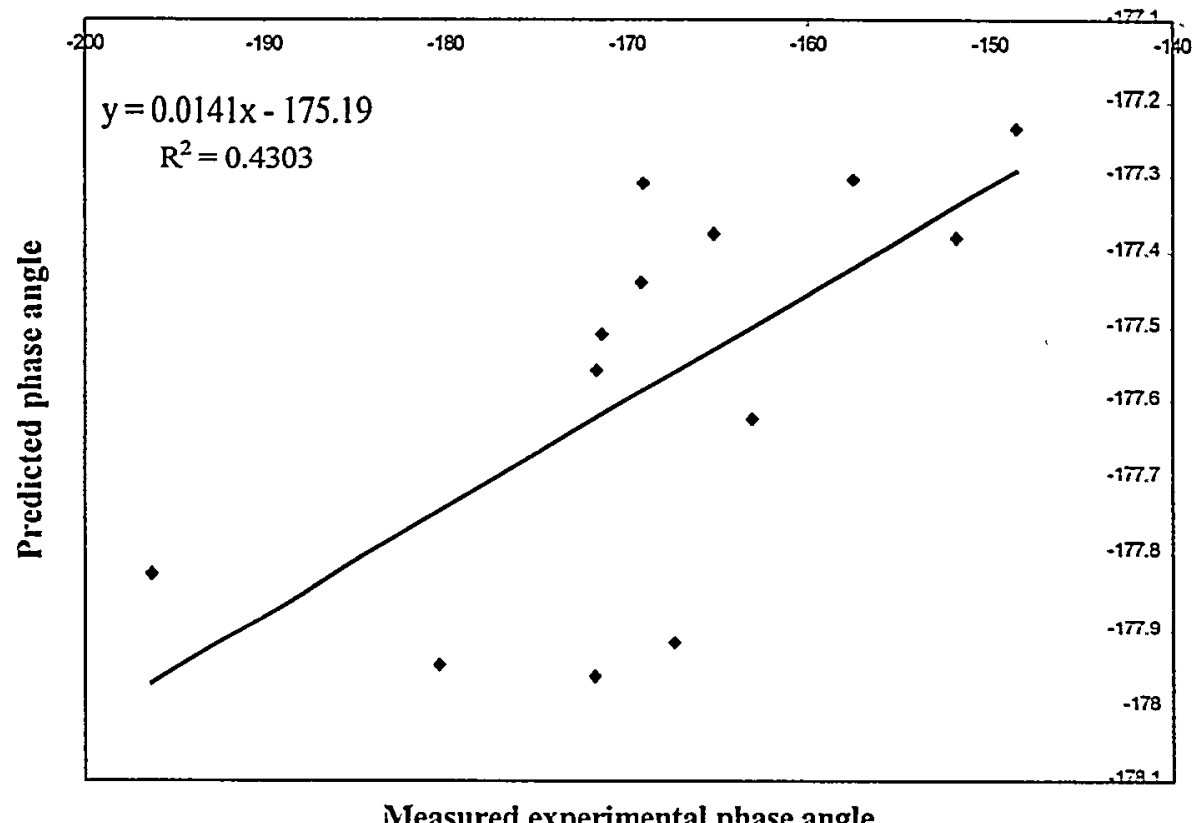

Figure 27. Predicted phase angle versus measured phase angle for $60 \%$ sugar $-40 \%$ water solution.

Table 7 compares the calculated and predicted phase angles for $45 \%$ sugar, $45 \%$ water, and $10 \%$ sand.

Table 7.

Predicted and calculated phase angles for $45 \%$ sugar $-45 \%$ water $-10 \%$ sand solution

\begin{tabular}{|c|c|}
\hline Calculated phase angle & Predicted phase angle \\
\hline-152.798 & -178.32 \\
\hline-156.303 & -178.274 \\
\hline-154.678 & -178.362 \\
\hline-157.363 & -178.319 \\
\hline-158.974 & -178.36 \\
\hline-160.704 & -178.404 \\
\hline-180.794 & -178.669 \\
\hline-189.032 & -178.659 \\
\hline
\end{tabular}




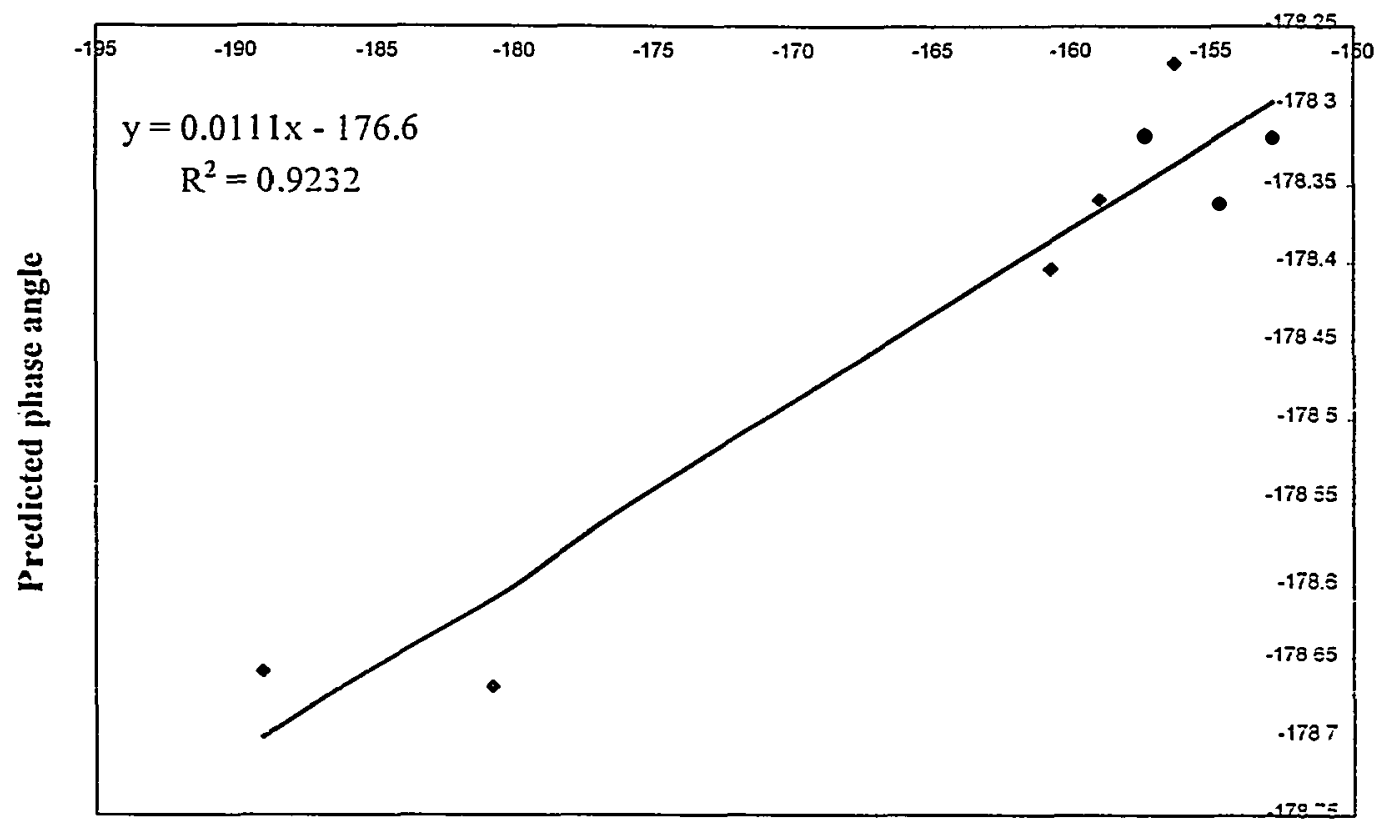

Measured experimental phase angle

Figure 28. Predicted phase angle versus measured phase angle for $45 \%$ sugar$45 \%$ water $-10 \%$ sand solution.

\section{Summary Results}

The results for force, displacement amplitudes and phase lag for the different solutions tested are summarized in Tables 8,9 .

Table 8.

Comparative measured-predicted force results for the fluids measured

\begin{tabular}{|l|c|c|}
\hline \multicolumn{1}{|c|}{ Solution } & Linear fit Measured-Predicted Force & Correlation factor \\
\hline $25 \%$ sugar - 75\% water & $0.6307 x+4.2311$ & 0.9775 \\
\hline $40 \%$ sugar - 60\% water & $0.6148 x+1.6565$ & 0.9615 \\
\hline $50 \%$ sugar - 50\% water & $0.6278 \mathrm{x}+0.5743$ & 0.9649 \\
\hline $60 \%$ sugar - 40\% water & $0.5933 \mathrm{x}-0.8415$ & 0.9911 \\
\hline $45 \%$ sugar - $45 \%$ water - $10 \%$ sand & $0.5788 x+1.1203$ & 0.9944 \\
\hline
\end{tabular}


Table 9.

Comparative measured-predicted phase lag results for the fluids measured

\begin{tabular}{|l|c|c|}
\hline \multicolumn{1}{|c|}{ Solution } & Linear fit Measured-Predicted Phase lag & Correlation factor \\
\hline $25 \%$ sugar - 75\% water & $0.0027 \mathrm{x}-179.09$ & 0.6109 \\
\hline $40 \%$ sugar $-60 \%$ water & $0.0035 \mathrm{x}-178.62$ & 0.4521 \\
\hline $50 \%$ sugar - 50\% water & $0.0060 \mathrm{x}-177.84$ & 0.3754 \\
\hline $60 \%$ sugar - $40 \%$ water & $0.0141 \mathrm{x}-175.19$ & 0.4303 \\
\hline $45 \%$ sugar - $45 \%$ water $-10 \%$ sand & $0.0111 \mathrm{x}-176.60$ & 0.9232 \\
\hline
\end{tabular}




\subsection{CONCLUSIONS}

\section{OSCILLATING CYLINDER DESIGN}

The prototype of the oscillating cylinder viscometer succeeded in predicting the force necessary to move the cylinder in a viscous medium. There was a clear dependence of the force on the frequency of the movement, as was predicted by the theory. This design will be able to accurately measure fluid viscosities; provided some design changes are made.

Suggested design changes for the next version include measures to reduce the noise generated by the force transducer and making the moving cylinder carriage much lighter. In the prototype experiments, the noise from the force transducer was reduced by ensemble averaging. Although this technique was successful, the time required to make a single measurement is on the order of one minute. This may need to be reduced for some applications. The ability of this design to measure viscosity will be significantly enhanced if the mass of the moving cylinder carriage is reduced. The mass of the prototype design was too large to allow a large phase angle to develop between the applied force and the resulting displacement. Neither of these design changes is difficult to overcome.

Finally, some distinct advantages of this design must be noted. It was considered desirable to be able to measure the viscosities of slurry mixtures that are being pumped from one storage facility to another. This viscometer is ideal for such an application, because it measures the force necessary to move the fluid as a whole. It measures a sample volume of fluid that is similar in size to the pipeline used to convey the slurry mixtures. Therefore, the values of viscosity obtained with the oscillating cylinder design will be more applicable than those obtained with ultrasonic methods that only measure a sample volume within a few millimeters of the probe. 


\subsection{PROOF OF CONCEPT FOR THE ACOUSTIC VISCOMETER}

\section{EXPERIMENTAL PROCEDURES}

\section{System configuration}

While all the electronic hardware was constructed, only the basic system capability to the left of the dotted line in Figure 6 was used for proof of concept. A four-transducer configuration was used. Data was read off the Tektronix TDR and recorded manually. As Figure 29 indicates, time measurements were made at the peak amplitude of the first pulse in each of the second and third wavetrains on the received waveform. This TDR had storage and sweep magnification to increase the precision of time measurement

\section{Calibration}

The first fluids considered were water and a solution of $25 \%$ sugar- $75 \%$ water. After evaluating the results obtained from a computer program. it was concluded that an acoustic viscometer as described in [H1] would be able to take measurements for a viscosity higher than $5 \mathrm{cPs}$. In addition, calibration was considered necessary by the literature. The results imply a calibration factor of 10 for a viscosity higher than $500 \mathrm{cPs}$.

\section{Solutions}

Several sucrose-water solutions with different concentrations of sucrose were considered. See Table 10. The viscosity for these fluids can be found in Perry's Chemical Engineer Handbook, 6 ed, page 3-254. Solutions 4, 5, and 6 were studied mainly for seeing if the waveguide sensor data are valid for a multi-phase component fluid. The obtained data were compared with the data provided by CTPSM Instrument Developers and the existing literature.

Table 10.

Some experimental fluids

\begin{tabular}{|c|c|c|c|c|c||}
\hline Number & Sugar \% & Water \% & Kaolin \% & Sand \% & Gravel \% \\
\hline 1 & 40 & 60 & 0 & 0 & 0 \\
\hline 2 & 50 & 50 & 0 & 0 & 0 \\
\hline 3 & 60 & 40 & 0 & 0 & 0 \\
\hline 4 & 45 & 45 & 10 & 0 & 0 \\
\hline 5 & 45 & 45 & 7.5 & 2.5 & 0 \\
\hline 6 & 10 & 45 & 45 & 7.426 & 0.099 \\
\hline
\end{tabular}




\section{Experimental tasks}

Tasks used to determine viscosity by acoustic means were as follows:

- Calibration of the waveguides in air.

- Recording the time values (CS1) in air for the second peak for both waveguides.

- Insertion of the waveguide 1 (the shorter waveguide) in a confined space (in this case a 750 $\mathrm{ml}$ cylinder) containing the fluid to be measured.

- Reading again the time value (CS2) of the second peak for Waveguide 1 in the solution of interest.

- Calculation of $\Delta t(\mathrm{CS} 2-\operatorname{CS} 1)$.

- Calculating the viscosity of the fluid.

\section{EXPERIMENTAL DATA}

\section{Waveforms}

Figure 29 shows typical waveforms for the four-mode transducer configuration. The first two peaks are the peaks of interest. The first peak corresponds to the interface between delay line and waveguide. The second peak corresponds to the reflection at the end of the waveguide. To prove these two peaks are the ones of interest, the time between them and the published torsional speed ( $3015 \mathrm{M} / \mathrm{S}$ ) implies a calculated propagated distance that is double the length of the aluminum waveguide. This is expected for a round-trip.

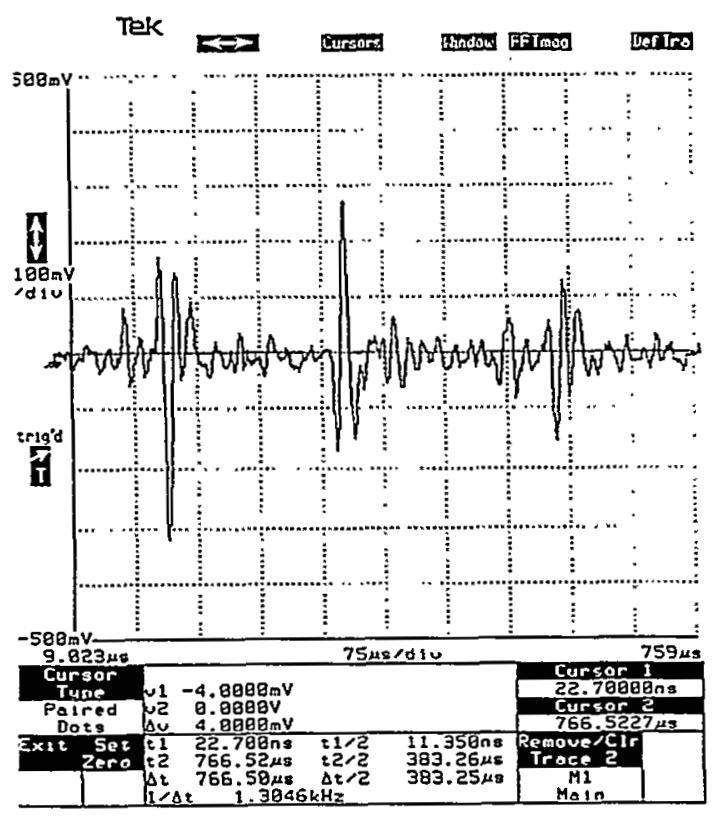

Figure 29. Waveforms in the fourtransducer transmission mode. 
To improve the precision of measurement, the sweep can be expanded. Figures 30 and 31 show expanded displays of peaks in air and glycerin, respectively:

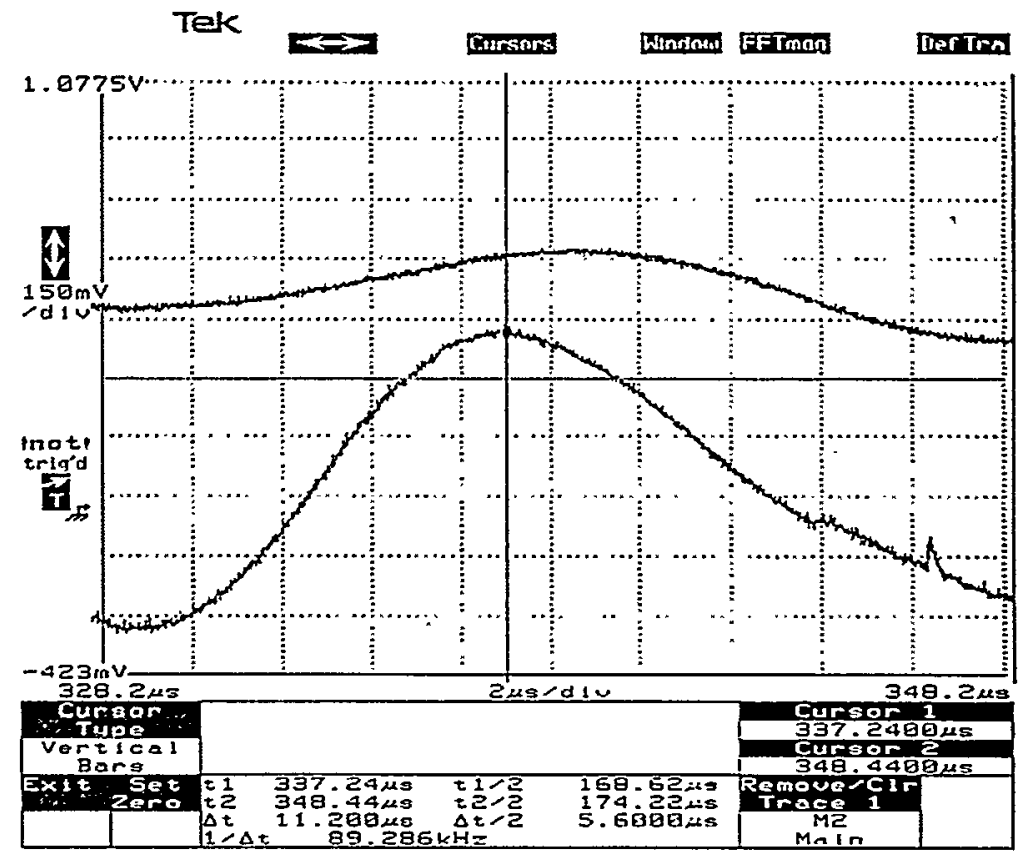

Figure 30. Detail of the second peak in air.

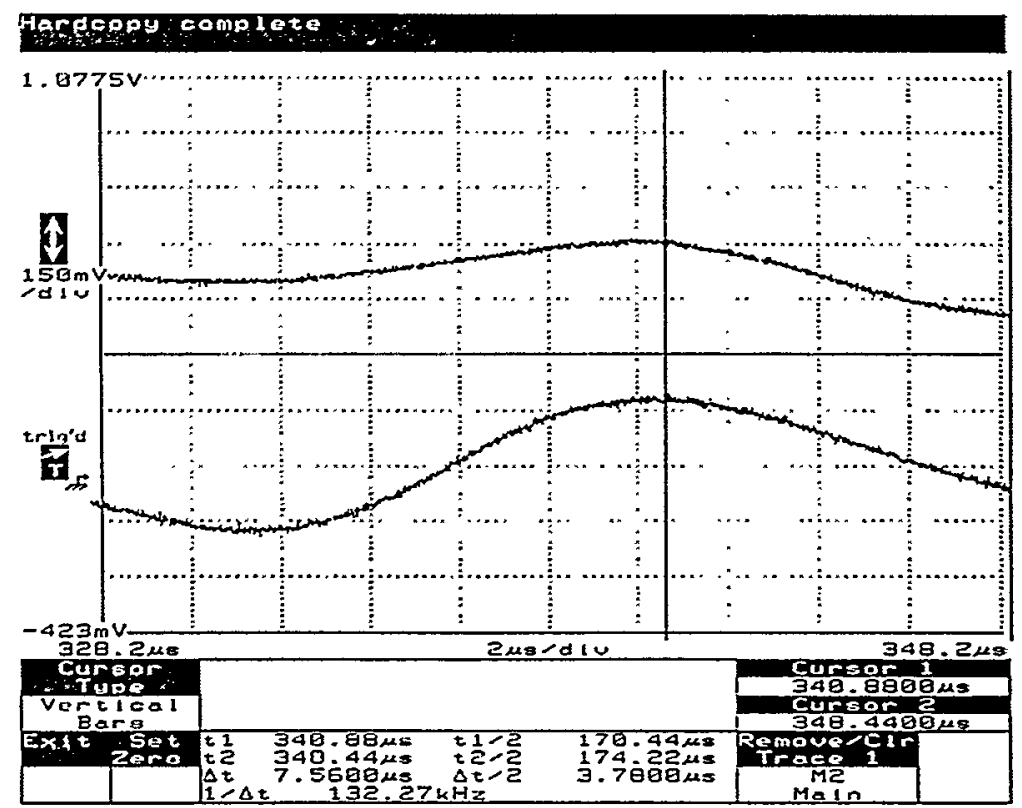

Figure 31. Detail of the second peak in glycerin at $45^{\circ} \mathrm{C}$. 


\section{Initial tests of sucrose-water solutions at room temperature}

Table 11 shows $\Delta t$ for various solutions. The position CS1 corresponding to the reference peak in air is needed for calculating the ratio $I_{f} / I_{s}$.

Table 11.

Initial results for water and sucrose-water solutions

\begin{tabular}{|c|c|c|c|c|c|c|c|}
\hline Sugar (\%) & Water (\%) & Kaolin (\%) & Sand (\%) & Gravel (\%) & $\overline{D \text { Delta } \tau(\mu s)}$ & Conditions & measurement \\
\hline \multirow{6}{*}{0} & \multirow{6}{*}{100} & \multirow{6}{*}{0} & \multirow{6}{*}{0} & \multirow{6}{*}{0} & \multirow{6}{*}{.04} & 3 & $\mu \mathrm{s} / \mathrm{div}$ \\
\hline & & & & & & 150 & $\mathrm{mv} / \mathrm{div}$ \\
\hline & & & & & & 333.6 & MP \\
\hline & & & & & & 333.64 & $\mathrm{CS} 1$ \\
\hline & & & & & & 333.72 & CS2 \\
\hline & & & & & & $20 \mathrm{~ns}$ & Acc \\
\hline \multirow{6}{*}{62} & \multirow{6}{*}{38} & \multirow{6}{*}{0} & \multirow{6}{*}{0} & \multirow{6}{*}{0} & \multirow{6}{*}{2.68} & 3 & $\mu \mathrm{s} / \mathrm{div}$ \\
\hline & & & & & & 150 & $\mathrm{mv} / \mathrm{div}$ \\
\hline & & & & & & 333.6 & MP \\
\hline & & & & & & 333.64 & CS1 \\
\hline & & & & & & 336.32 & CS2 \\
\hline & & & & & & $20 \mathrm{~ns}$ & Acc \\
\hline \multirow{6}{*}{70} & \multirow{6}{*}{30} & \multirow{6}{*}{0} & \multirow{6}{*}{0} & \multirow{6}{*}{0} & \multirow{6}{*}{2.88} & 3 & $\mu \mathrm{s} / \mathrm{div}$ \\
\hline & & & & & & 150 & $\mathrm{mv} / \mathrm{div}$ \\
\hline & & & & & & 333.6 & MP \\
\hline & & & & & & 333.64 & $\mathrm{CS} 1$ \\
\hline & & & & & & 336.52 & CS2 \\
\hline & & & & & & $20 \mathrm{~ns}$ & Acc \\
\hline
\end{tabular}

The first solution presented in Table 11 is for Solution 1. The time difference air-liquid is about 1 $\mu \mathrm{s}$. Calculated results do not correspond with the value found in the literature. Several other solutions were investigated: $10 \%$ sucrose- $90 \%$ water, $20 \%$ sucrose- $80 \%$ water, $10 \%$ glycerine$90 \%$ water, $15 \%$ glycerine- $85 \%$ water. The conclusion was that this device has a lower usable limit of 5-7 cPs.

A very good correspondence to literature data was obtained for a $50 \%$ sucrose- $50 \%$ water solution and for a $60 \%$ sucrose- $-40 \%$ water solution. Figure 32 shows the curves obtained for Solutions 1,2 , and 3 . 


\section{Temperature sensitivity of sucrose}

\section{for solutions 1, 2, and 3 (sugar-water solutions)}

After taking the measurements at room temperature, the solution was heated to $50^{\circ} \mathrm{C}$. The solubility of sucrose increases as the temperature increases (see Tables 12 and 13). Table 14 calculated the kinematic viscosity for solutions 1,2 and 3.

Table 12.

How the solubility of sucrose increases with temperature

\begin{tabular}{|l|l|l|l|l|l||}
\hline $\begin{array}{c}\text { Temperature } \\
\left({ }^{\circ} \mathrm{C}\right)\end{array}$ & $\begin{array}{l}\text { Dissolved sucrose in } \\
\mathbf{1 0 0} \mathrm{ml} \text { water }(\mathrm{g})\end{array}$ & $\begin{array}{c}\text { Temperature } \\
\left({ }^{\circ} \mathrm{C}\right)\end{array}$ & $\begin{array}{l}\text { Dissolved sucrose in } \\
\mathbf{1 0 0} \mathrm{ml} \text { water }(\mathrm{g})\end{array}$ & $\begin{array}{l}\text { Temperature } \\
\left({ }^{\circ} \mathrm{C}\right)\end{array}$ & $\begin{array}{l}\text { Dissolved sucrose } \\
\text { in } \mathbf{1 0 0 ~} \mathrm{ml} \text { water }(\mathrm{g})\end{array}$ \\
\hline 0 & 179.2 & 35 & 228.4 & 70 & 320.5 \\
\hline 5 & 184.7 & 40 & 238.1 & 75 & 339.9 \\
\hline 10 & 190.5 & 45 & 248.8 & 80 & 362.1 \\
\hline 15 & 197.0 & 50 & 260.4 & 85 & 386.8 \\
\hline 20 & 208.9 & 55 & 273.1 & 90 & 415.7 \\
\hline 25 & 211.4 & 60 & 287.3 & 95 & 448.6 \\
\hline 30 & 219.5 & 65 & 302.9 & 100 & 487.2 \\
\hline
\end{tabular}

Table 13

Raw data (shift in peak position) as a function of temperature for solutions 1,2 , and 3

\begin{tabular}{|c|c|c|c|}
\hline Temperature $\left({ }^{\circ} \mathrm{C}\right)$ & $\begin{array}{c}\text { Solution 1 } \\
\text { Cursor position }(\mu \mathrm{s})\end{array}$ & $\begin{array}{c}\text { Solution 2 } \\
\text { Cursor position }(\mu \mathrm{s})\end{array}$ & $\begin{array}{c}\text { Solution 3 } \\
\text { Cursor position }(\mu \mathrm{s})\end{array}$ \\
\hline 55 & 540.42 & 540.46 & 540.54 \\
\hline 54 & 540.24 & 540.40 & 540.50 \\
\hline 53 & 540.06 & 540.16 & 540.42 \\
\hline 52 & 540.05 & 540.10 & 540.38 \\
\hline 50.5 & 540.03 & 540.05 & 540.32 \\
\hline 49.5 & 540.00 & 540.049 & 540.22 \\
\hline 48.7 & 539.94 & 540.047 & 540.16 \\
\hline 46 & 539.92 & 540.045 & 540.12 \\
\hline 45 & 539.70 & 540.04 & 540.06 \\
\hline 44 & 539.68 & 540.04 & 540.02 \\
\hline 43 & 539.58 & 539.86 & 540.00 \\
\hline
\end{tabular}


Table 13.

Raw data (shift in peak position) as a function of temperature for solutions 1,2 , and 3 (Continued)

\begin{tabular}{|c|c|c|c|}
\hline Temperature $\left({ }^{\circ} \mathrm{C}\right)$ & $\begin{array}{c}\text { Solution 1 } \\
\text { Cursor position }(\mu \mathrm{s})\end{array}$ & $\begin{array}{c}\text { Solution 2 } \\
\text { Cursor position }(\mu \mathrm{s})\end{array}$ & $\begin{array}{c}\text { Solution 3 } \\
\text { Cursor position }(\mu \mathrm{s})\end{array}$ \\
\hline \hline 42 & 539.54 & 539.74 & 539.94 \\
41 & 539.44 & 539.72 & 539.92 \\
\hline 38 & 539.34 & 539.68 & 539.90 \\
\hline 37 & 539.24 & 539.62 & 539.90 \\
\hline 35.5 & 539.14 & 539.56 & 539.88 \\
\hline 30 & 539.06 & 539.44 & 539.86 \\
\hline 22 & 538.18 & 538.08 & 539.00 \\
\hline
\end{tabular}

Table 14.

Calculated kinematic viscosity for solutions 1,2 and 3

\begin{tabular}{||c|c|c|c||}
\hline $\begin{array}{c}\text { Temperature } \\
\left({ }^{0} \mathrm{C}\right)\end{array}$ & $\begin{array}{c}\text { Solution 1 } \\
v(c \mathrm{St})\end{array}$ & $\begin{array}{c}\text { Solution } 2 \\
v(\mathrm{cSt})\end{array}$ & $\begin{array}{c}\text { Solution } 3 \\
v(c \mathrm{St})\end{array}$ \\
\hline $5.50 \mathrm{E}+01$ & $7.10 \mathrm{E}+01$ & $9.90 \mathrm{E}+01$ & $1.10 \mathrm{E}+02$ \\
\hline $5.40 \mathrm{E}+01$ & $6.40 \mathrm{E}+01$ & $8.80 \mathrm{E}+01$ & $1.10 \mathrm{E}+02$ \\
\hline $5.30 \mathrm{E}+01$ & $6.10 \mathrm{E}+01$ & $7.80 \mathrm{E}+01$ & $1.00 \mathrm{E}+02$ \\
\hline $5.20 \mathrm{E}+01$ & $5.70 \mathrm{E}+01$ & $7.80 \mathrm{E}+01$ & $1.00 \mathrm{E}+02$ \\
\hline $5.10 \mathrm{E}+01$ & $5.40 \mathrm{E}+01$ & $.7 .70 \mathrm{E}+01$ & $9.60 \mathrm{E}+01$ \\
\hline $5.00 \mathrm{E}+01$ & $5.20 \mathrm{E}+01$ & $7.50 \mathrm{E}+01$ & $9.00 \mathrm{E}+01$ \\
\hline $4.90 \mathrm{E}+01$ & $4.60 \mathrm{E}+01$ & $7.20 \mathrm{E}+01$ & $8.70 \mathrm{E}+01$ \\
\hline $4.60 \mathrm{E}+01$ & $4.40 \mathrm{E}+01$ & $7.10 \mathrm{E}+01$ & $8.50 \mathrm{E}+01$ \\
\hline $4.50 \mathrm{E}+01$ & $4.00 \mathrm{E}+01$ & $6.00 \mathrm{E}+01$ & $8.10 \mathrm{E}+01$ \\
\hline $4.40 \mathrm{E}+01$ & $3.70 \mathrm{E}+01$ & $5.90 \mathrm{E}+01$ & $7.90 \mathrm{E}+01$ \\
\hline $4.30 \mathrm{E}+01$ & $3.50 \mathrm{E}+01$ & $5.50 \mathrm{E}+01$ & $7.80 \mathrm{E}+01$ \\
\hline $4.20 \mathrm{E}+01$ & $3.20 \mathrm{E}+01$ & $5.30 \mathrm{E}+01$ & $7.50 \mathrm{E}+01$ \\
\hline $4.10 \mathrm{E}+01$ & $3.10 \mathrm{E}+01$ & $4.80 \mathrm{E}+01$ & $7.40 \mathrm{E}+01$ \\
\hline $3.80 \mathrm{E}+01$ & $2.90 \mathrm{E}+01$ & $4.40 \mathrm{E}+01$ & $7.30 \mathrm{E}+01$ \\
\hline $3.70 \mathrm{E}+01$ & $2.70 \mathrm{E}+01$ & $4.00 \mathrm{E}+01$ & $7.30 \mathrm{E}+01$ \\
\hline $3.60 \mathrm{E}+01$ & $2.50 \mathrm{E}+01$ & $3.70 \mathrm{E}+01$ & $7.20 \mathrm{E}+01$ \\
\hline $3.00 \mathrm{E}+01$ & $2.30 \mathrm{E}+01$ & $3.40 \mathrm{E}+01$ & $7.10 \mathrm{E}+01$ \\
\hline $2.20 \mathrm{E}+01$ & $3.10 \mathrm{E}+00$ & $9.90 \mathrm{E}+00$ & $3.40 \mathrm{E}+01$ \\
\hline
\end{tabular}


The peak shift was measured from the oscilloscope screen. This raw data was logged manually. Then a Fortran program calculated the viscosity.

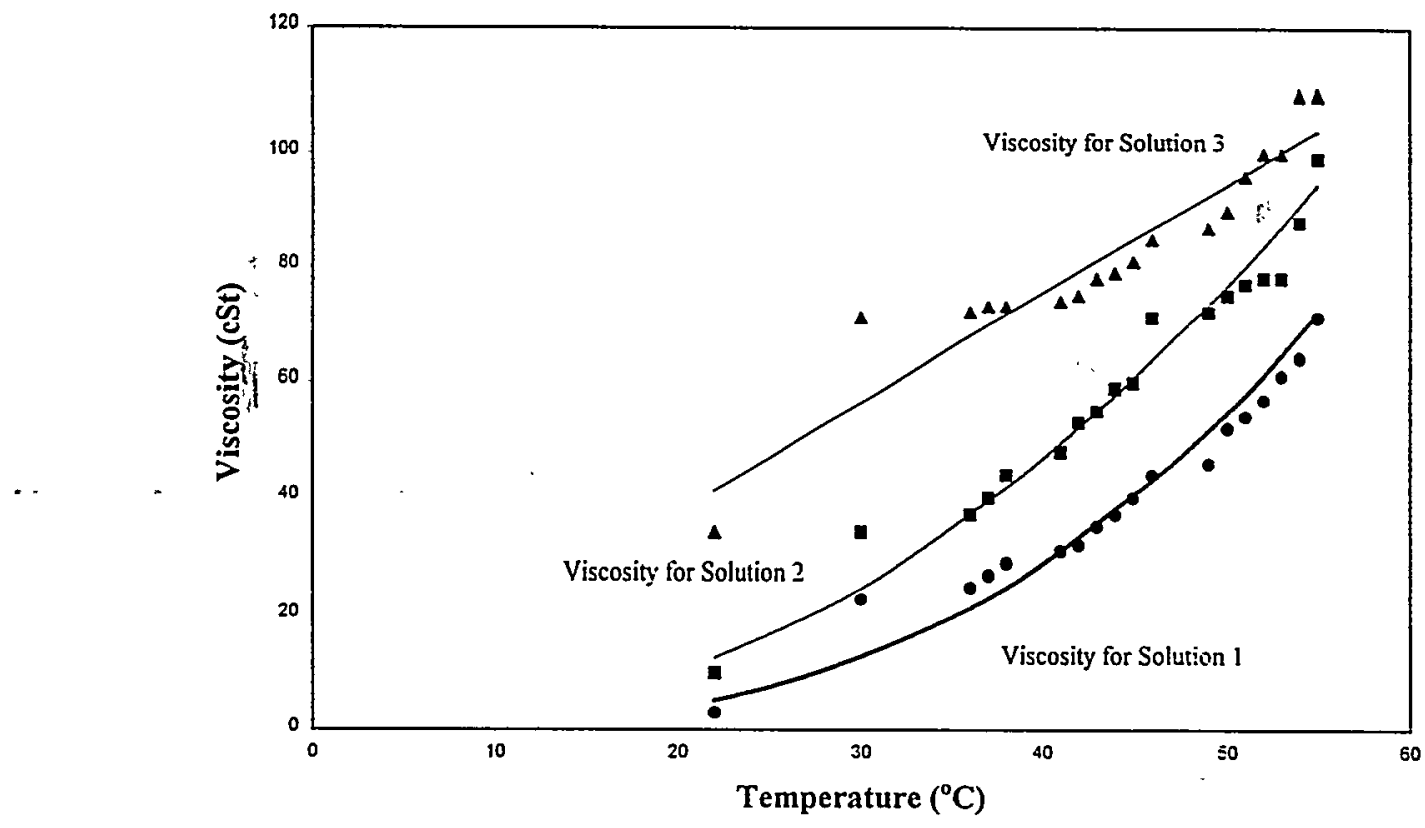

Figure 32. Kinematic viscosity for Solutions 1, 2, and 3 for temperatures from $20^{\circ} \mathrm{C}-50^{\circ} \mathrm{C}$.

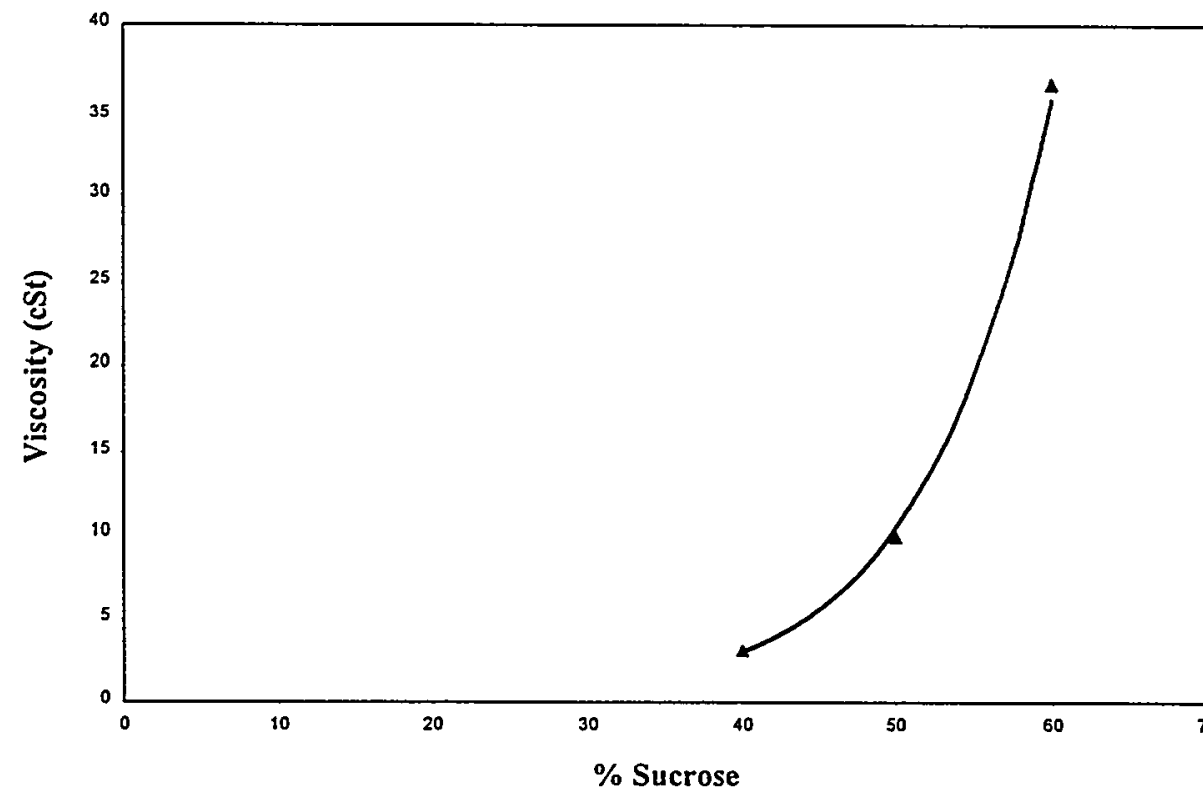

Figure 33 . The effect of $\%$ sucrose on the viscosity of Solutions 1,2 , and 3. 
Note this interesting phenomenon: the viscosity increased as the temperature increased. The reason was that small sucrose particles were in suspension. In addition, during the experiments it was observed that sugar particles were deposited on the waveguides surfaces. This deposition was hard to remove.

After evaluating the experimental data and comparing the results with the existent data, it was concluded that Solution 1 represents the lower range of viscosity for this device.

The data for Solution 1 was close to data in the literature $(5.238 \mathrm{cSt})$. The lower range for this viscometer was determined to be $5-7 \mathrm{cSt}$. A $40 \%$ (weight percent) sucrose solution weighing 500 grams contained 200 grams of sucrose and 300 grams of water.

\section{Multi-component fluids}

The results for Solution 4 (sugar, kaolin, and water) are presented in Table 15. The corresponding plot appears in Figure 34. Solution 4 was a multi-component fluid because the clay particles could not be dissolved. As the solution was heated up, the particles of sugar dissolved in the water. Solution 4 is a multi-phase component fluid. A comparison of these results with published data shows this acoustic sensor is capable of measuring the viscosity without taking into consideration a second phase existing as a suspension. The sand particle size was less than $5 \mu \mathrm{m}$. When the sucrose is completely dissolved the percent solids are estimated to be around $10 \%$.

Table 15

Viscosity as a function of temperature for solution 4

\begin{tabular}{|c|c|}
\hline Temp ( $\left.{ }^{0} \mathrm{C}\right)$ & Sol. \# 4 v(cSt) \\
\hline $5.50 \mathrm{E} \div 01$ & $1.20 \mathrm{E}+02$ \\
\hline $5.40 \mathrm{E} \div 01$ & $1.20 \mathrm{E}+02$ \\
\hline $5.30 \mathrm{E}+01$ & $1.20 \mathrm{E}+02$ \\
\hline $5.20 \mathrm{E}+01$ & $1.20 \mathrm{E}+02$ \\
\hline $5.10 \mathrm{E}+01$ & $1.20 \mathrm{E}+02$ \\
\hline $5.00 \mathrm{E}+01$ & $1.10 \mathrm{E}+02$ \\
\hline $4.90 \mathrm{E}+01$ & $1.10 \mathrm{E}+02$ \\
\hline $4.60 \mathrm{E}+01$ & $1.20 \mathrm{E}+02$ \\
\hline $4.50 \mathrm{E}+01$ & $1.00 \mathrm{E}+02$ \\
\hline $4.40 \mathrm{E}+01$ & $1.00 \mathrm{E}+02$ \\
\hline $4.30 \mathrm{E}+01$ & $1.00 \mathrm{E}+02$ \\
\hline $4.20 \mathrm{E}+01$ & $1.20 \mathrm{E}+02$ \\
\hline
\end{tabular}


Table 15

Viscosity as a function of temperature for solution 4 (Continued)

\begin{tabular}{|c|c|}
\hline Temp $\left.{ }^{0} \mathrm{C}\right)$ & Sol. \#4 v(cSt) \\
\hline $4.10 \mathrm{E}+01$ & $1.10 \mathrm{E}+02$ \\
\hline $3.80 \mathrm{E}+01$ & $1.00 \mathrm{E}+02$ \\
\hline $3.70 \mathrm{E}+01$ & $8.80 \mathrm{E}+01$ \\
\hline $3.60 \mathrm{E}+01$ & $7.50 \mathrm{E}+01$ \\
\hline $3.00 \mathrm{E}+01$ & $7.30 \mathrm{E}+01$ \\
\hline $2.20 \mathrm{E}+01$ & $4.20 \mathrm{E}+01$ \\
\hline
\end{tabular}

According to previous tests performed at ORNL and Hanford, the viscosity was $12.5 \mathrm{cSt}$, if the sucrose was completely dissolved. A solution of $50 \%$ sucrose $-15 \%$ water has a viscosity of $12.55 \mathrm{cSt}$. The presence of sand particles and probably sucrose particles generates some differences. See Figure 35 for a comparison between Solution 2 and 4 showing the effect of particles. There is a clear difference, both at room and high temperatures. It can be concluded that this device would be capable of sensing presence of particles less than $5 \mu \mathrm{m}$.

Another solution (7) was also tested, with the sand particles mixed in the sucrose water mixture. The sand did not have any influence in modifying the viscosity. The viscosity for solution 6 was found to be $42.7 \mathrm{cSt}(54.459 \mathrm{cPs})$. Glycerin and glycerol solutions were also studied and the results were very close to the available data. For Solution 5, the density of the fluid was calculated to be $1275.2 \mathrm{~kg} / \mathrm{m}^{3}$ and the kinematic viscosity of $42.7068 \mathrm{cSt}$. This result did not coincide to the result obtained by CTPSM Instrument Developers. However, the result was encouraging because it showed that the instrument was capable of detecting existing solids. For multiphase component fluids with particle size above $5 \mu \mathrm{m}$, like Solutions 5 and 6 , the design and the shape of the waveguide' cross section should be modified.

\section{Viscosity of Glycerin}

Data for glycerin was obtained for room temperature and for temperatures up to $50^{\circ} \mathrm{C}$. Figures 36 and 37 show typical waveforms. The waveform in glycerin has lower amplitude than the one in air. 


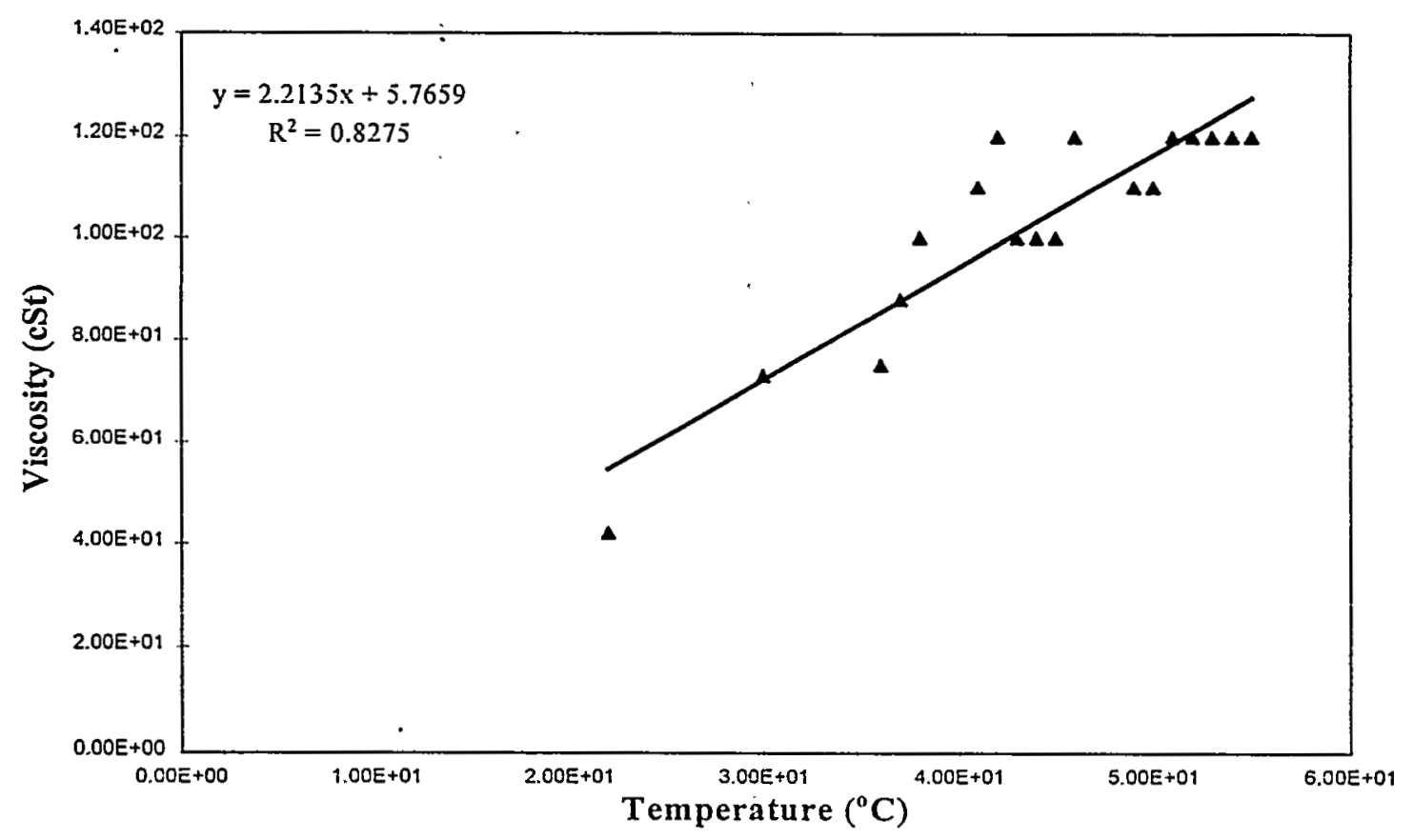

Figure 34. Viscosity (cSt) versus temperature $\left({ }^{\circ} \mathrm{C}\right)$ for Solution 4.

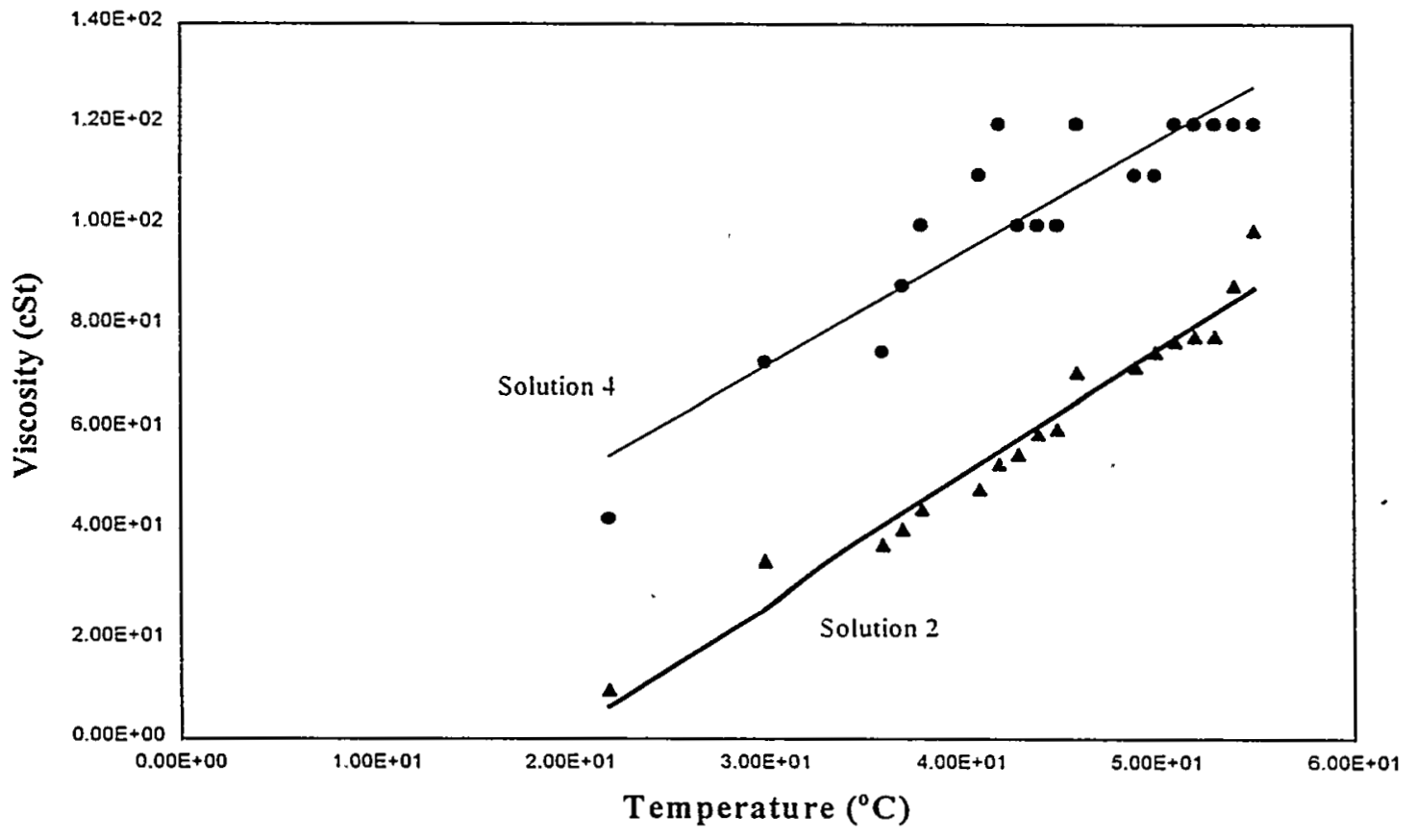

Figure 35. Comparison between the viscosities of solutions 2 and 4 . 
Tables 16 and 17 give the raw and calculated data, respectively, and Figure 38 shows the plot. These results are in agreement with published data. In Table 16, the time value at the second peak is for the waveguide immersed in the glycerin. The reference (first) peak position was $336.02 \mu$ s and the first waveguide peak position (in air) was $323.52 \mu$ s. The reference peak is the cursor position in air of the waveguide to be emerged in the experimental fluid. This value is necessary for further calculation for the kinematic riscosity. According to the results, the viscosity of glycerin decreased as the temperature increased. This demonstrates that this sensor is valid for measurements involving liquids or liquids mixtures (glycerol solutions). For all mixtures, a $650-\mathrm{ml}$ cylinder was used. The smaller the space around the waveguide, the better the accuracy of the results.

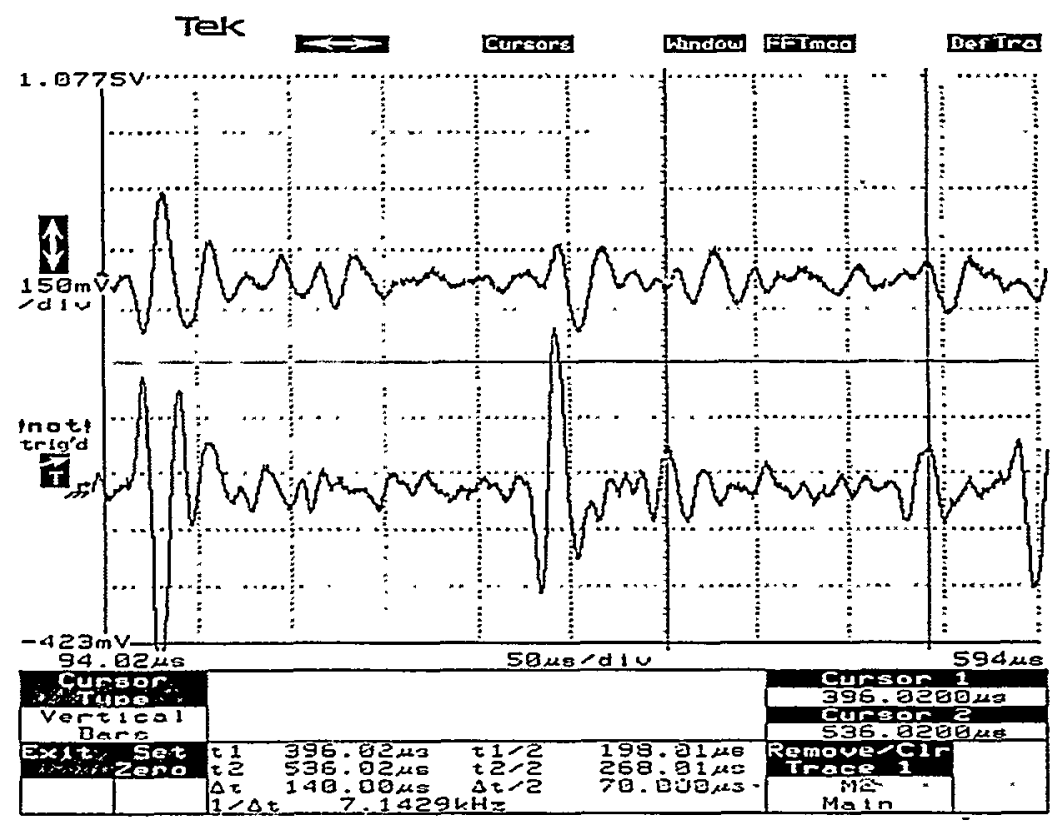

Figure 36. Waveforms when both waveguides are in air. 


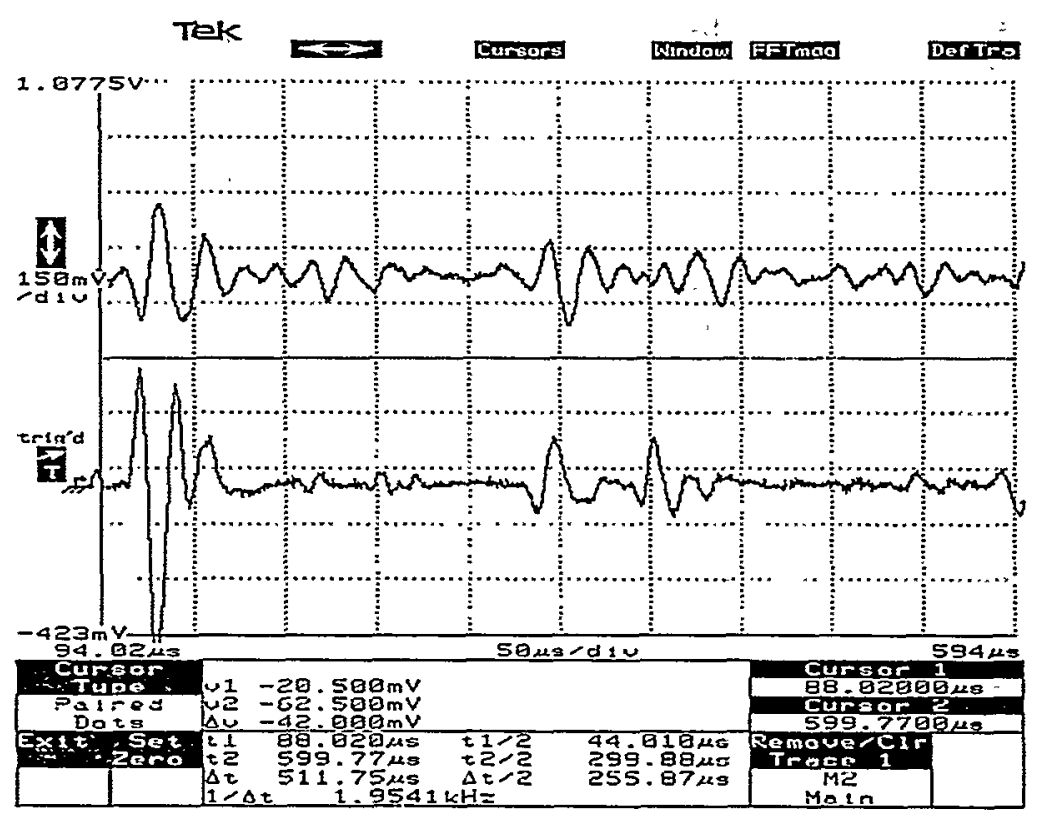

Figure 37. Waveforms when waveguide 1 is in air and waveguide 2 is in Glycerin at $20^{\circ} \mathrm{C}$.

Table 16.

Raw data as a function of temperature for $68 \%$ glycerin $-32 \%$ water solution

\begin{tabular}{|c|c|}
\hline Cursor position $(\mu \mathrm{s})$ & Temperature $\left({ }^{\circ} \mathrm{C}\right)$ \\
\hline 340.44 & 45 \\
\hline 340.48 & 44 \\
\hline 340.64 & 43 \\
\hline 340.68 & 42 \\
\hline 340.68 & 41 \\
\hline 340.70 & 40 \\
\hline 340.72 & 38 \\
\hline 340.76 & 37 \\
\hline 340.80 & 36 \\
\hline 340.84 & 35 \\
\hline 340.96 & 34 \\
\hline 341.30 & 30 \\
\hline 342.96 & 20 \\
\hline
\end{tabular}


Table 17.

Calculated viscosity versus the temperature for $68 \%$ glycerin- $32 \%$ water solution

\begin{tabular}{|c|c|}
\hline Temperature $\left.{ }^{\circ} \mathrm{C}\right)$ & Viscosity (cSt) \\
\hline $4.50 \mathrm{E}+01$ & $4.96 \mathrm{E}+02$ \\
\hline $4.40 \mathrm{E}+01$ & $4.98 \mathrm{E}+02$ \\
\hline $4.30 \mathrm{E}+01$ & $5.00 \mathrm{E}+02$ \\
\hline $4.20 \mathrm{E}+01$ & $5.00 \mathrm{E}+02$ \\
\hline $4.10 \mathrm{E}+01$ & $5.10 \mathrm{E}+02$ \\
\hline $4.00 \mathrm{E}+01$ & $5.10 \mathrm{E}+02$ \\
\hline $3.80 \mathrm{E}+01$ & $5.20 \mathrm{E}+02$ \\
\hline $3.70 \mathrm{E}+01$ & $5.30 \mathrm{E}+02$ \\
\hline $3.60 \mathrm{E}+01$ & $5.40 \mathrm{E}+02$ \\
\hline $3.50 \mathrm{E}+01$ & $5.40 \mathrm{E}+02$ \\
\hline $3.40 \mathrm{E}+01$ & $5.70 \mathrm{E}+02$ \\
\hline $3.00 \mathrm{E}+01$ & $6.50 \mathrm{E}+02$ \\
\hline $2.00 \mathrm{E}+01$ & $1.10 \mathrm{E}+03$ \\
\hline
\end{tabular}

As seen in Table 16, changes in time are small. Still, Table 17 shows they produce a significant difference in viscosity. This is because viscosity varies as the square of $\Delta t$. Data with less randomness could be obtained with a temperature-controlled bath and a permanently homogenization process. 


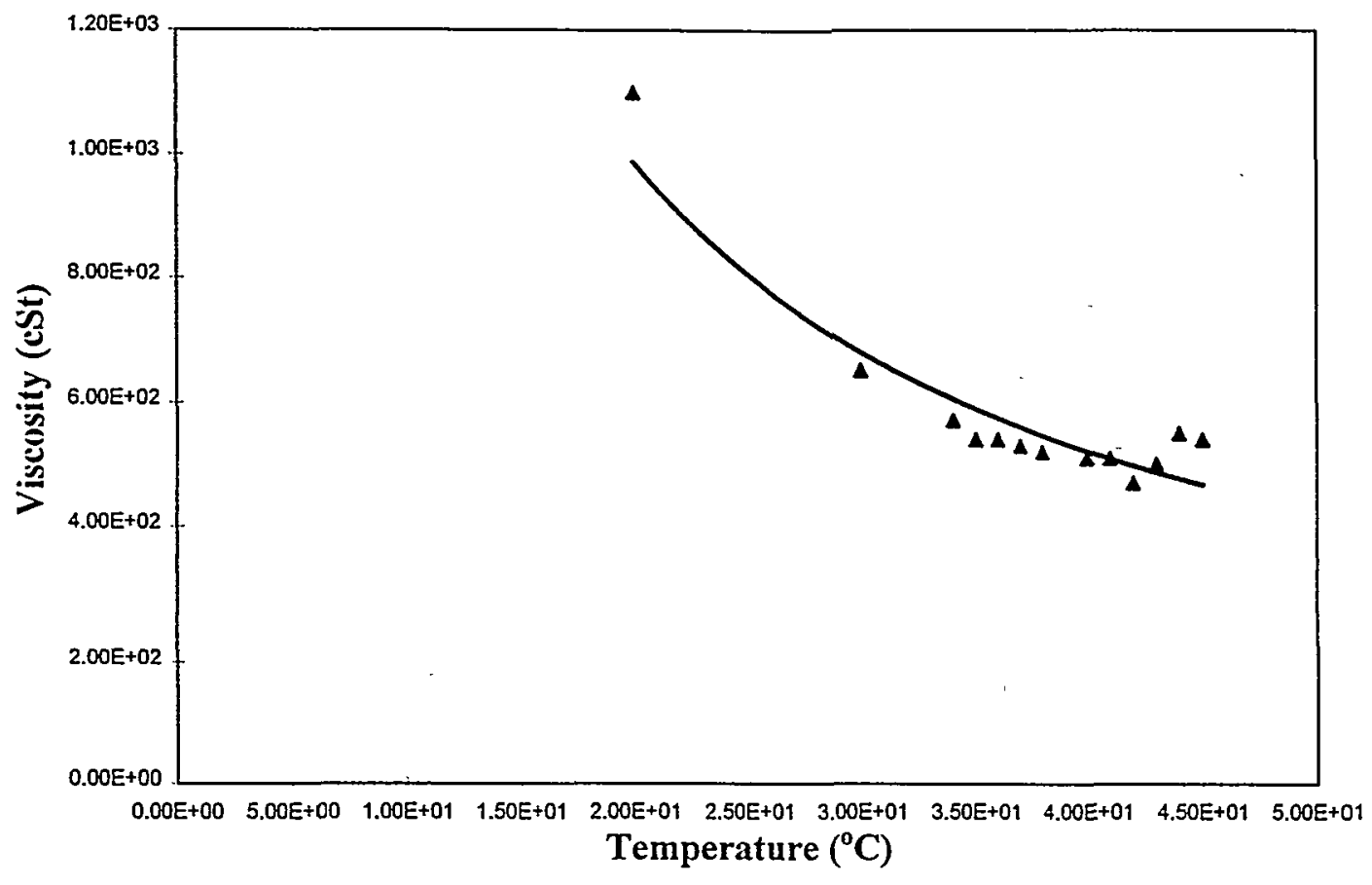

Figure 38. Viscosity (cSt) versus temperature $\left({ }^{\circ} \mathrm{C}\right)$ for Glycerin.

\section{Viscosity of Glycerol}

Glycerol $\left(\mathrm{CH}_{2} \mathrm{OHCHOHCH} 2 \mathrm{OH}\right)$ solutions were measured. Tables 18 and 19 present the raw and calculated data respectively. Figure 39 is the plot. As the temperature increases, the viscosity of the solutions decreases. A solution of $68 \%$ glycerin- $32 \%$ water is close to the range of this apparatus; the change is viscosity is very small. The experimental data obtained for temperatures higher than room temperatures are compared with the results reported by Jin Oh Kim (1989, page 196).

Table 18.

Raw data of glycerol solutions versus temperatures

\begin{tabular}{|c|c|c|c|}
\hline \hline Temperature $\left({ }^{\circ} \mathrm{C}\right)$ & $\begin{array}{c}\mathbf{6 8 \% G - 3 2 \% W} \\
\text { Cursor Position }\end{array}$ & $\begin{array}{c}\mathbf{8 0 \% G - 2 0 \% W} \\
\text { Cursor Position }\end{array}$ & $\begin{array}{c}\mathbf{9 2 \% G - 8 \% W} \\
\text { Cursor Positions }\end{array}$ \\
\hline 50 & 342.1 & 342.24 & 345.46 \\
\hline 45 & 342.12 & 342.4 & 345.48 \\
\hline 40 & 342.16 & 343.08 & 345.50 \\
\hline 35 & 342.18 & 344.3 & 345.58 \\
\hline 30 & 342.24 & 344.46 & 345.68 \\
\hline 20 & 342.42 & 345.02 & 346.42 \\
\hline
\end{tabular}


The symbol ' $G$ ' represents glycerin and the symbol ' $W$ ' represents water. The results obtained at room temperature agree with published data. The viscosity of $68 \%$ glycerin- $32 \%$ water solution remained almost the same as the temperature increased. This was due to the low viscosity of this solution. As the percent glycerin increases, the viscosity increased in magnitude. This made the variation of this parameter more visible as the temperature varied between $20^{\circ} \mathrm{C}$ and $50^{\circ} \mathrm{C}$.

Table 19.

Calculated viscosity as a function of temperature for glycerol.

\begin{tabular}{|c|c|c|c|}
\hline Temperature $\left({ }^{\circ} \mathrm{C}\right)$ & $\begin{array}{c}\text { Solution } \\
68 \% \mathrm{G}-32 \% \mathrm{~W} \\
v(\mathrm{cSt})\end{array}$ & $\begin{array}{c}\text { Solution } \\
80 \% \mathrm{G}-20 \% \mathrm{~W} \\
v(\mathrm{cSt})\end{array}$ & $\begin{array}{c}\text { Solution } \\
92 \% \mathrm{G}-8 \% \mathrm{~W} \\
v(\mathrm{cSt})\end{array}$ \\
\hline $5.00 \mathrm{E}+01$ & $8.20 \mathrm{E}+00$ & $9.50 \mathrm{E}+00$ & $1.60 \mathrm{E}+02$ \\
\hline $4.50 \mathrm{E}+01$ & $8.40 \mathrm{E}+00$ & $1.10 \mathrm{E}+01$ & $1.70 \mathrm{E}+02$ \\
\hline $4.00 \mathrm{E}+01$ & $8.80 \mathrm{E}+00$ & $1.90 \mathrm{E}+01$ & $1.70 \mathrm{E}+02$ \\
\hline $3.50 \mathrm{E}+01$ & $9.00 \mathrm{E}+00$ & $3.80 \mathrm{E}+01$ & $1.80 \mathrm{E}+02$ \\
\hline $3.00 \mathrm{E}+01$ & $9.50 \mathrm{E} \div 00$ & $4.10 \mathrm{E} \div 01$ & $1.90 \mathrm{E}+02$ \\
\hline $2.00 \mathrm{E}+01$ & $1.10 \mathrm{E}+01$ & $5.30 \mathrm{E}+01$ & $3.00 \mathrm{E} \div 02$ \\
\hline
\end{tabular}

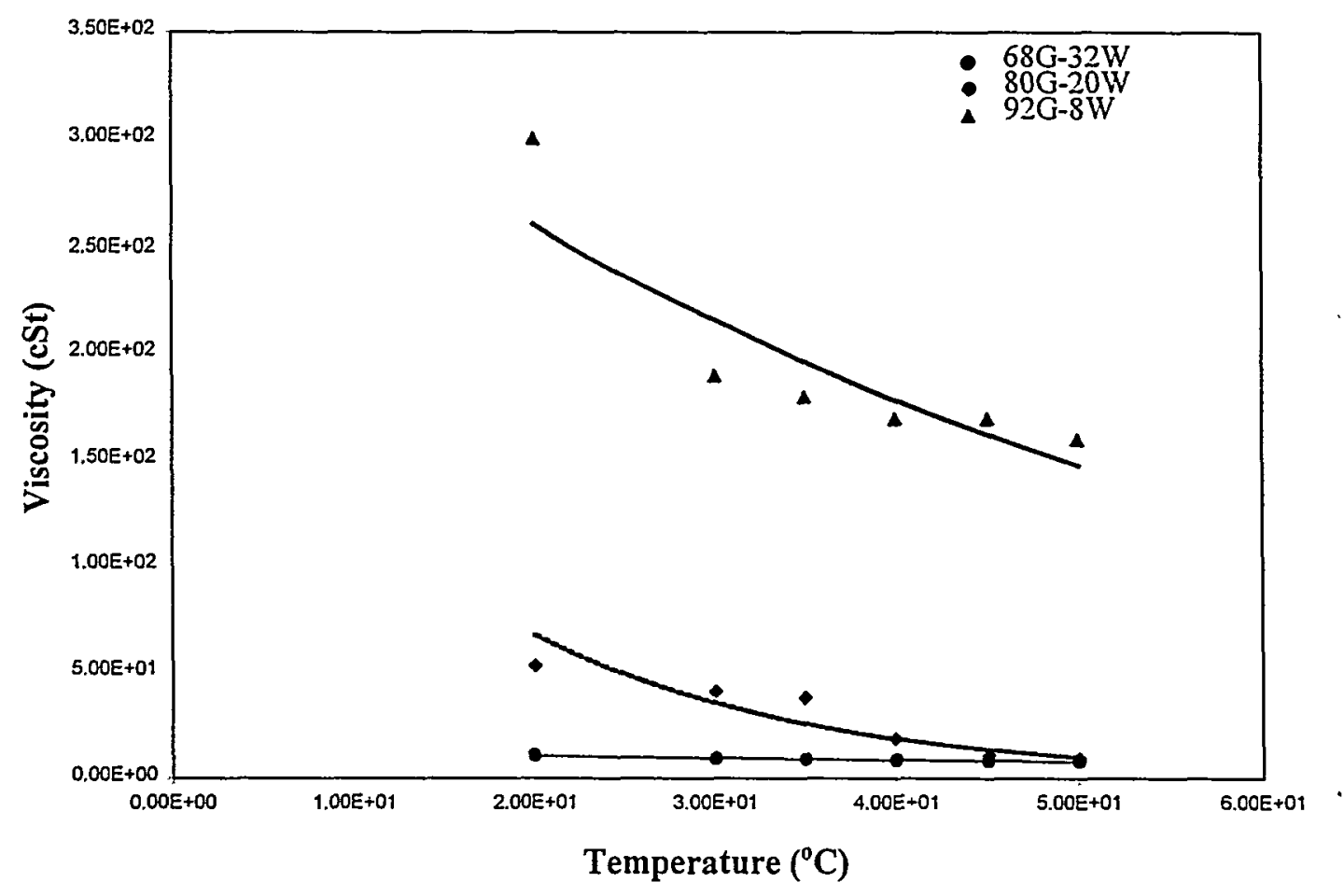

Figure 39. Viscosity (CSt) versus temperature $\left({ }^{\circ} \mathrm{C}\right.$ ) for different glycerol solutions. 


\section{Summary Data}

Summary results for the principal experimental fluids are presented in Table 20, with comparison to the data from Perry's Chemical Handbook. The symbols used are "G"-glycerin; "W"-water; "S"-sucrose.

\section{CONCLUSIONS}

Both reflective and transmission mode testing have been conducted with both torsional and longitudinal acoustic waves. A four-transducer version works the best. The design uses the difference in transmission between two equivalent rods, one of which is immersed in the fluid to be tested. The rods are excited by the same pulse into the magnetostrictive transducers. The difference in the time of flight is directly measurable. This difference is due to the retardation caused by the viscous drag on the rod immersed in the fluid. This time difference can be related to the viscosity and density of the fluid, as predicted by Kim and Bau (1989).

Table 20.

Summary of experimental data for the tested solutions, compared to published data

\begin{tabular}{|c|c|c|c||}
\hline Liquids & Density $\left(\mathrm{x10}^{3} \mathrm{~kg} / \mathrm{m}^{3}\right)$ & Published data for $v(\mathrm{cSt})$ & Experimental data for $v(\mathrm{cSt})$ \\
\hline Water & 0.982 & 1.005 & - \\
\hline $40 \% \mathrm{~S}-60 \% \mathrm{~W}$ & 1.17 & 5.238 & 3.2 \\
\hline $50 \% \mathrm{~S}-50 \% \mathrm{~W}$ & 1.2295 & 12.55 & 9.9 \\
\hline $60 \% \mathrm{~S}-40 \% \mathrm{~W}$ & 1.2864 & 45.46 & $34.0-47.4$ \\
\hline Glycerin & 1.2611 & 1181.3 & 1100 \\
\hline $68 \% \mathrm{G}-32 \% \mathrm{~W}$ & 1.1755 & 11.73 & $11.0-13.24$ \\
\hline $80 \% \mathrm{G}-20 \% \mathrm{~W}$ & 1.2085 & 49.57 & 53.00 \\
\hline $92 \% \mathrm{G}-8 \% \mathrm{~W}$ & 1.2404 & 310.0 & $300.0-374.1$ \\
\hline
\end{tabular}

Acoustic tests were successful on the following solutions:

- sucrose-water solutions above $7 \mathrm{cPs}$

- sugar, kaolin, and water mixtures

- glycerin solutions

- glycerol solutions

While the results obtained manually on the base capability system have more randomness than published data, the trends are good, and they are sufficient to prove the concept of an acoustic method. The automated system described in the next section when implemented completely will provide improved repeatability, precision, and accuracy. 


\subsection{FLORIDA INTERNATIONAL UNIVERSITY'S AUTOMATED VISCOSITY INSTRUMENTATION SYSTEM}

\section{REQUIREMENTS}

\section{Principles}

Incorporate two independent and innovative approaches to the measurement of viscosity. One approach is to use an acoustic pulse whose propagation along a probe is retarded by the viscous medium in which it is inserted. The other approach is to measure the mechanical interaction of a cylinder oscillating in the viscous medium.

\section{The acoustic approach}

Use a four-transducer configuration with two waveguides, one in air and the other in the viscous medium under test. Measure the round trip and differential flight time directly and automatically. Calculate the viscosity automatically.

\section{The oscillating cylinder approach}

Measure automatically the shear force and cylinder displacement using electronic sensors and signal conditioners. Calculate the viscosity automatically.

\section{Test and control sites}

Place the acoustic and oscillating cylinder sensors at a remote site adjacent to the viscous media under test, along with a remote junction box housing local signal conditioners, DC regulators, and line drivers. Link this by a cable that could be quite long to a larger electronics complex in a control room.

\section{Computer control}

Control and process instrumentation data using an IBM compatible computer such as a laptop in the control room, with a commercial instrumentation card. Use another enclosure that will customize the interface between this card and the remote electronics. plus provide DC power supplies, and support diagnostic circuits.

The processing of data is to include automated data acquisition, calculation, data logging, data display, and system monitoring.

\section{Computer software}

Use National Instrument's LabView software, running as an application under Windows 95, and possibly other specialized mathematical programs. 


\section{PHYSICAL DESCRIPTION}

\section{Physical configuration}

The system's physical configuration shown before in Figure 6 is repeated in this section for convenience as Figure 40. Items to the left of the cable are placed at the remote site in the room with the tanks and piping. A long shielded cable carries only low-level signals for control, instrumentation, and DC power. Items to the right of the cable are to be placed in the control room. The unit customizes (via the cable) the remote site to the National Instruments instrumentation interface card. All data is acquired through this card. The oscilloscope is used only for setup and monitoring. The custom unit is designed so that the laptop and PCMCIA card can be placed on top of it, with the oscilloscope behind. However, a rack-mount installation is possible. Unregulated plus and minus DC power is sent to the remote unit where local regulators supply precise and noise-free plus and minus voltages to all electronics there and in the probe assembly.

\section{Probe assembly}

The assembly includes the transducers, probes, receive preamplifier, and the cylindrical housing. The probes are inserted in the tank holding the viscous medium. In this (generation three) system, an external commercial pulser is used. Generation four's probe assembly will house also the high-power pulser output circuit, driven by a low-level signal from the custom unit.

\section{Motor controller}

The motor controller is a commercial AC Inverter (Model 1C93C) from Dayton. The 3-phase $207-\mathrm{v} 60 \mathrm{~Hz} \mathrm{AC}$ power is supplied directly at the remote site to this inverter. It, in turn, controls the motor through the modified AC it sends to the motor. Three-phase power is used because it is more effective and efficient for speed control. This inverter offers sophisticated control and, in turn, communicates by low-powered signals with the control room. A set of low-powered slowly varying digital signals can be and is used to set basic operating modes for the motor. The speed of the motor can be adjusted over a range of about 2 to 30 Hertz. 


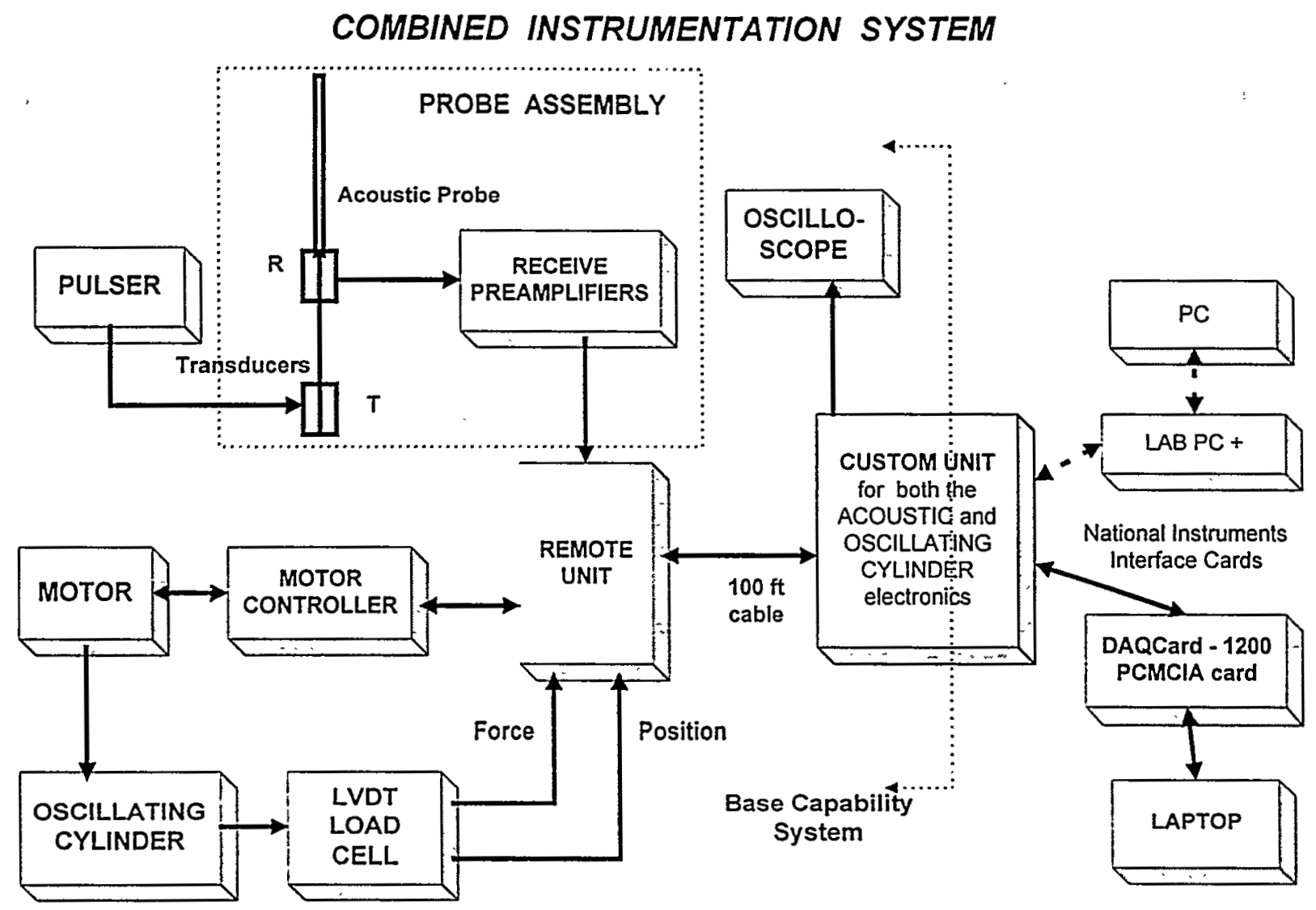

Figure 40. The FIU/HCET automated viscosity instrumentation system.

\section{Motor}

The industrial standard 1/3 HP AC motor is coupled to the oscillating cylinder.

\section{Oscillating cylinder and transducers}

The oscillating cylinder is immersed in the viscous medium under test. In the same structure is a Linear Variable Differential Transformer (LVDT), attached to the cylinder that senses the cylinder position. In addition, a Load Cell is interposed between the motor and the cylinder to sense force.

\section{Remote unit}

The oscillating cylinder electronics of the remote unit includes the signal conditioners for LVDT and Load Cell outputs, supplying high-level analog signals $\mathrm{P}$ (position) and $\mathrm{F}$ (force) to the long cable. Acoustic electronics in the remote unit consists of a receiver that drives the pulser's sync input with a pulse when it receives one pulse from the custom unit. Each sync pulse supplied to the pulser causes one transmit pulse to be sent to the transmit transducer. This, in turn, generates 
one acoustic wave, which is sent on the long cable back to the custom unit, where high-speed circuits capture one value of raw data at a time, but automatically.

\section{Custom unit acoustic electronics}

The custom unit includes:

- DC power supplies of $+5,+9 \mathrm{~V},+16 \mathrm{~V},-5 \mathrm{~V},-9 \mathrm{~V}$, and $-16 \mathrm{~V}$ for its own and all the remote electronics.

- Simple digital line drivers between the low-current digital signals from the NI instrumentation card and the long cable.

- Sophisticated acoustic electronics for processing the received acoustic pulse signals to give the digital data required which the instrumentation card and computer can at its leisure calculate the viscosity. This includes the Fastcard that is described in last year's report.

- Electronics that processes the force $(F)$ and position $(P)$ signals to give continuous values indicating peak amplitude, period, and time-shift.

- Circuits for waveform and DC voltage monitoring.

The custom unit in the fourth generation version will also contain a high-voltage power supply and low-powered pulser circuits, including the driver to a high-power pulse output circuit in the probe assembly. It might also include a commercially available oscilloscope sub-system. There is sufficient room in the enclosure for these.

\section{FUNCTIONAL DESCRIPTION}

\section{See Appendix}

Appendix B contains additional details on the system electronics. The details below are included because they help in the understanding of the software.

\section{Digital counter function allocation for the instrumentation card}

See what is denoted Figure 41 for the connection of instrumentation card circuits to the custom and remote units. Counter B's three 16-bit counters are used as follows:

- B0 measures directly the time difference between the oscillating cylinder's zero crossings of position and force, counting one-half microsecond pulses.

- Bl measures one half the period of oscillation of the cylinder in counts of one-half microsecond pulses.

- B2 measures the remainder of the time of one of the three quantities needed for viscosity calculation in counts of one microsecond per clock pulse. Hardware counters in the custom unit preceding B2 measure the lower two digits of count of time in units of 10 and $100 \mathrm{nS}$. 


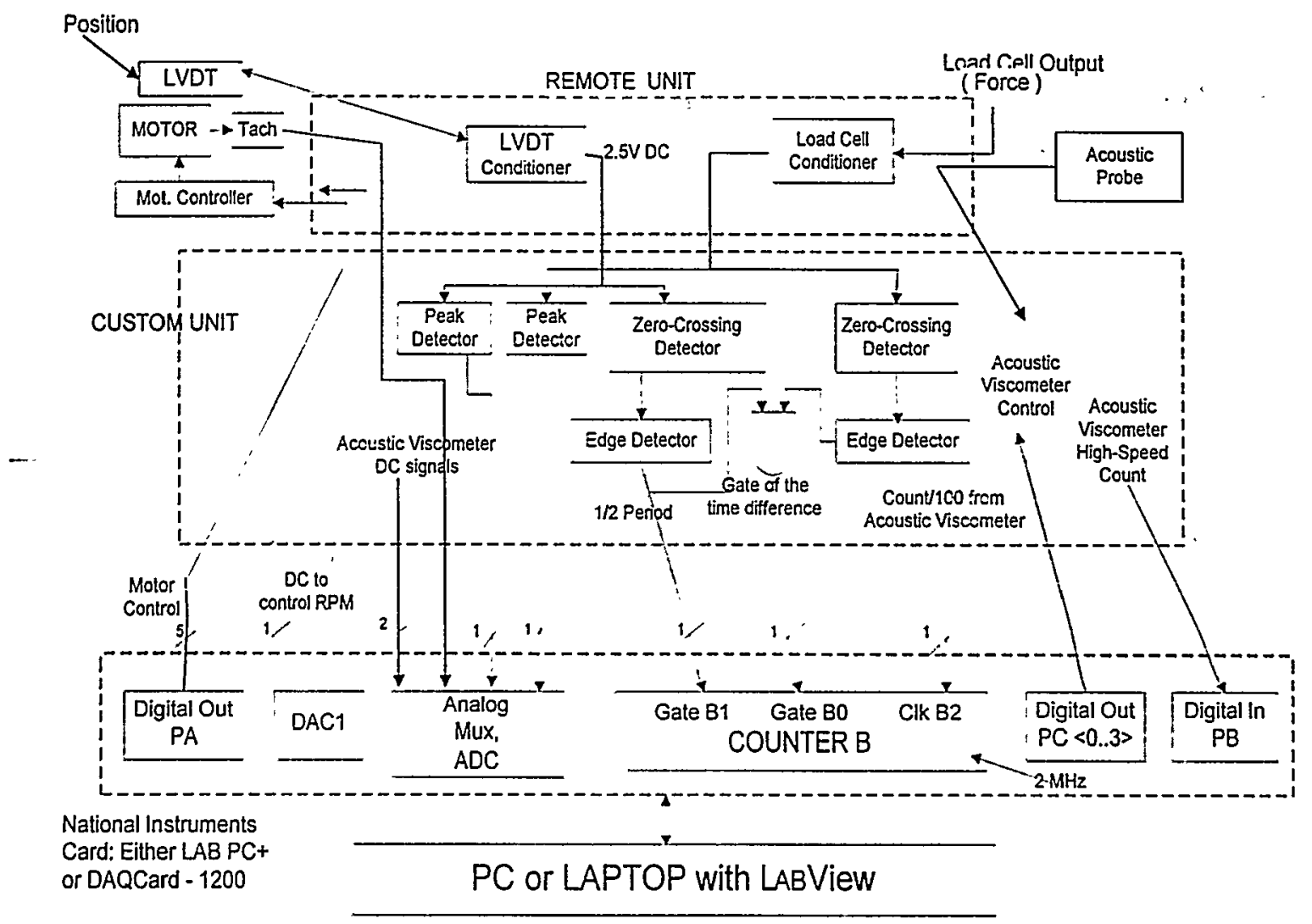

Figure 41. Signal flow for the automated instrument.

\section{Parallel digital function allocation for the instrumentation card}

The parallel capability of the instrumentation card. is based..on Intel's classic 24-bit Peripheral Parallel Interface (PPI) chip, the 8255A. In this system its three digital ports are allocated as follows:

- Port A (i.e., PA) is not now used.

- $\mathrm{PB}$ is used in input mode 0 only to pick up quickly one value from one of the three 8-bit fast counters in the custom unit.

- There are two separate parts of PC, whose functions depend on the mode selected for PA and PB. Since mode 0 (simple input without handshaking) is selected for PA and PB, then PC $\langle 7 . .0\rangle$ is free to be used for independent purposes. Note that these bits can be independently set (logic one, or a high) or reset (logic zero or a low).

$\mathrm{PC} 1$ and $\mathrm{PC} 0$ are encoded to specify the counter address of the acoustic quantity whose time is to be digitally measured: 
Table 21.

How to select the time quantity to be measured

\begin{tabular}{cll}
\hline PC1,0 & Q & \multicolumn{1}{c}{ QUANTITY } \\
\hline 00 & & No measurement of time is performed \\
01 & $\mathrm{Q}(1)$ & Differential flight time $\Delta t$ \\
10 & $\mathrm{Q}(2)$ & Round-trip flight time $\mathrm{T}$ \\
11 & $\mathrm{Q}(3)$ & Wave-train period \\
\hline
\end{tabular}

This is the address of one of the three 8-bit-high-speed counters in the custom unit, each of which contains two digits of one count of time. Hence, to select the time quantity to be measured, send the appropriate byte out to port PC.

The function of PC2 is to control the acquisition of one time measurement value. It is described in the Appendix. PC5, PC4, and PC3 are yet unspecified.

The upper two bits PC7, PC6 of PC are used to generate individually the two software inverted control signals going to the motor controller to individually control the two control terminals of the motor controller.

\section{ACOUSTIC DATA ACQUISITION, REDUCTION, ANALYSIS, LOGGING, AND DISPLAY}

\section{Data acquisition}

Acoustic data acquisition is a joint software and hardware process. The hardware collects raw time counts with high precision. The precision is such that three bytes are needed to portray one measured time value.

Software selects the three acoustic quantities in turn. Let us begin with Q(1). Software then: a) signals the hardware to trigger one pulse train, b) wait a while (TIME DELAY) for counts to accumulate, and c) read the three bytes from the counters. These three bytes are stored in main memory in a temporary one-dimensioned array.

This process is repeated for the other two quantities, $Q(2), Q(3)$; as detailed below.

\section{Data reduction}

Each of these three bytes of one quantity is converted into a 32-bit-integer-type measurement quantity. From these three 32-bit numbers (defined as one scan), one double-precision floatingpoint value of viscosity is calculated. This single calculated value is stored in another temporary main memory one-dimensioned array called VISC of length IMAX.

Then the process is repeated as fast as possible IMAX times, to give IMAX scans of the computed values of viscosity and fill the array VISC. 


\section{Data analysis}

One set of the statistics of viscosity (mean, standard deviation, minimum, and maximum) are calculated from the entire array of values in VISC. These values in one set are converted to ASCII text and stored in main memory in the one-dimensioned string array REC. Date and time stamp and measured values of threshold voltage are also stored in REC. In the next generation system, temperature and radiation level would also be added.

\section{Data logging}

REC is appended to a hard disk file as one record.

The entire process above is repeated at scheduled points in time. This requires an additional timed delay.

\section{Summary of processes}

While the final need mentioned above is for a process that results in systematic data logging, there are three other processes required for setup. test, etc. The four processes with their features are summarized in the table below. The adjust process is used when the system is first powered up, check power supply voltages, and to adjust the delay times and threshold voltages while monitoring waveforms on the oscilloscope. The test process is used to check for the production of raw data, thus verifying the low-level hardware processes. The single-step process checks also for the proper functioning of the software, or to just obtain one value of calculated viscosity. The full process includes all functions.

Table 22.

The four processes of the acoustic virtual instrument

\begin{tabular}{lcccc}
\hline \multicolumn{1}{c}{ FEATURE } & ADJUST & TEST & SINGLE-STEP & FULL \\
\hline L (Case index) & 1 & 2 & 3 & 4 \\
Trigger mode & Repetitive & Single & Single & Repetitive \\
Raw data acquisition & No & Yes & Yes & Yes \\
Raw data display & No & Yes & Yes & No \\
Data reduction & No & No & Yes & Yes \\
Data analysis & No & No & No & Yes \\
Data logging & No & No & No & Yes \\
\hline
\end{tabular}




\section{Algorithms}

Algorithms for all four of these processes are expressed in pseudo-code in Appendix C.

Pseudo-code is used below because it is a convenient way to clearly present iterative processes without use of a particular programming language. It is probably the place to begin for those more familiar with computer programming than with LabView. In addition, it presents an alternative discussion to that embedded in the LabView virtual instruments (vis), if there is any question as to what the vis are doing. However, the pseudo-code requires and defines some variables that LabView handles internally and automatically.

\section{TOP LEVELS OF THE LABVIEW}

\section{SOFTWARE FOR THE VIRTUAL ACOUSTIC INSTRUMENT}

\section{Introduction}

National Instrument's (NI) LabView v 4.1 was used to write a series of programs which turn the hardware described above into an acoustic viscometer virtual instrument (vi). It implements the algorithms in Appendix C. The programs are over half completed. Only some top-level programs are included below. These are included to show the potential power of the instrument, and as graphic documentation of the algorithms. A corresponding program for an oscillating cylinder has not yet been written.

\section{LabView software principles}

Each Virtual Instrument (vi) in LabView is high level self-documenting software with a front panel, signal flow diagram, and associated routines. It is likely that one signal flow diagram will include lower-level "vi"s, down ultimately to a subset from the set of vis available for each of NI's instrumentation cards. A compiler translates this high-level software into run-time code. The Front Panel handles all input and output for the "vi".

Each signal flow diagram shows how its corresponding front panel inputs are processed to yield that front panel's outputs. Note it is NOT properly a control flow-chart. Transfer of control is implicit; there is not a single "token" which is located at only one point and progresses a step at a time through the diagram as do the tokens in the board game Monopoly. As soon as conditions permit, any operation shown can commence, and this might be independent of another operation. In other words, usually operations run in parallel. However, sequential constraints can be imposed, if needed. The virtual instruments below are presented with little comment. The complete documentation can be made available to those with a need to know. 


\section{Some front panels and signal flow diagrams}
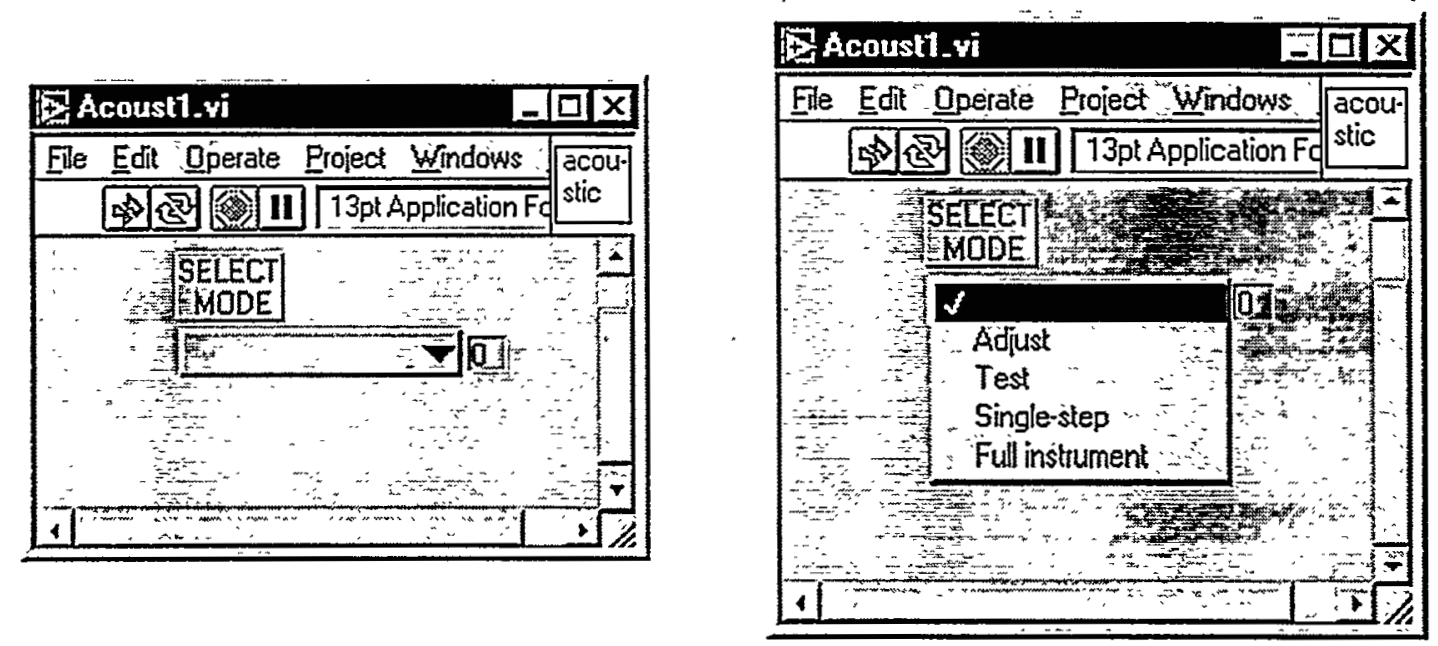

Figure 42. Selecting process options from the top-level panel of the virtual instrument.

The top-level instrument runs continually. When the mouse clicks on the select mode bar in the left panel in Figure 42, the four process options shown on the right appear. When one process is selected, its program will be launched and its panel will appear showing only those inputs (controls) and outputs (indicators) for that process. The Figure 42 panel has only one control, and no indicators. Its diagram counterpart is shown in Figure 43. Only part of the diagram is shown because the top-level instrument includes what would be called in computer science a case statement. Only one of the cases can be and is shown at a time.

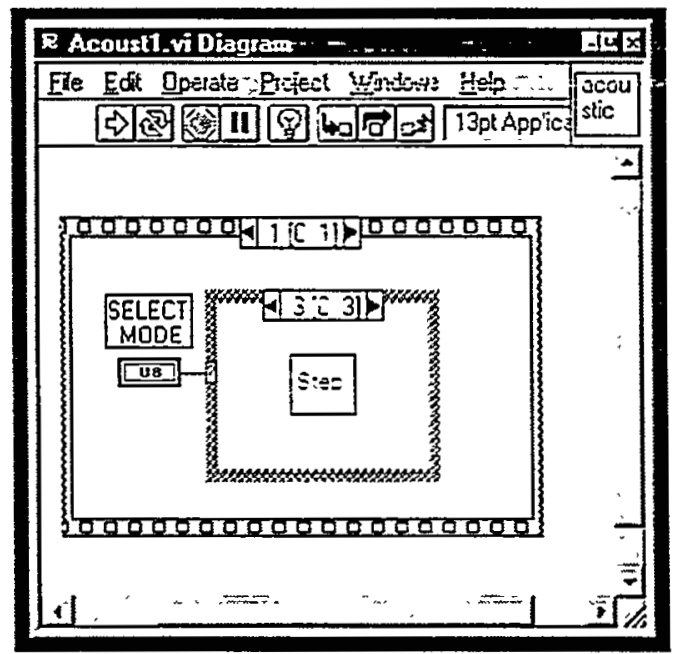

Figure 43. Part of the signal flow diagram for the top-level instrument. 
Selecting the "Full Instrument" option on the Figure 42 panel causes Figure 44 to appear. This is the operational panel after some initial settings are made.

Selecting the "Adjust" option on Figure 42 causes the Adjust sub-instrument panel of Figure 44 to appear. Adjust is used while DC threshold voltages are adjusted manually using the custom unit's potentiometers. The Figure 45 panel has two outputs (indicators)-showing the exact current value of the two threshold voltages. This instrument will run until the "return" button is pressed.

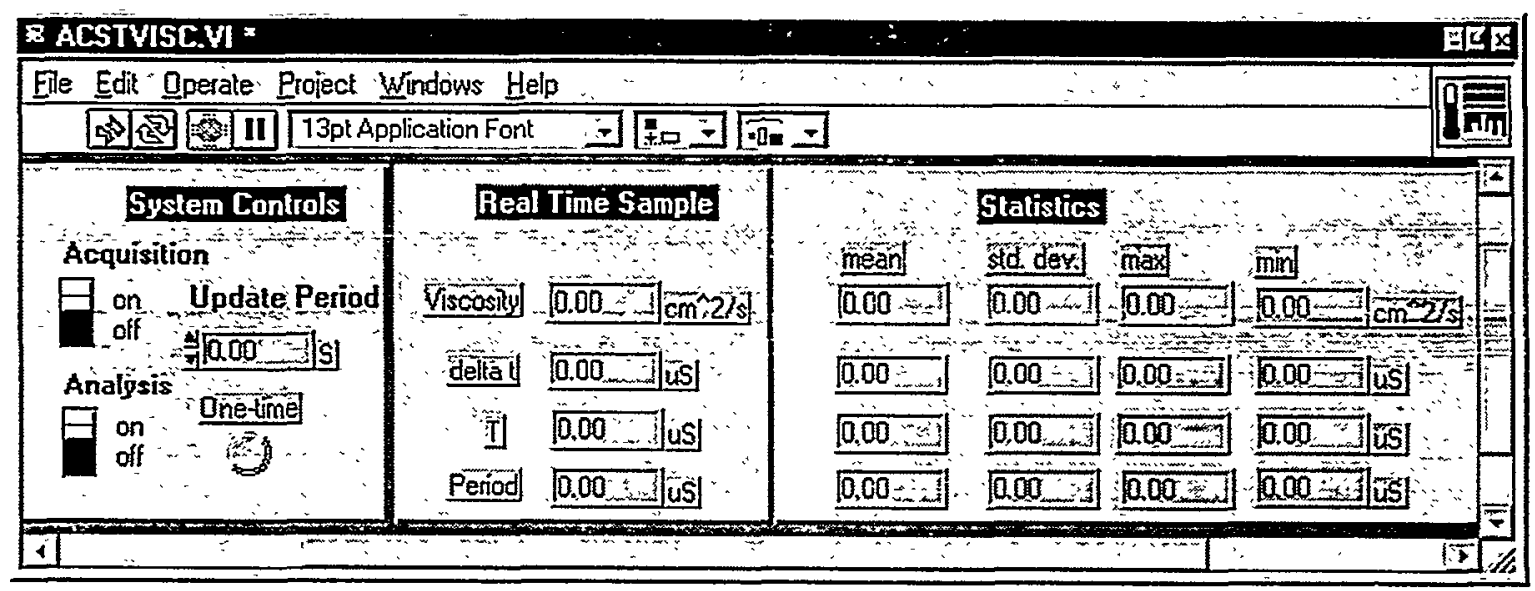

Figure 44. Front panel for the Full Instrument sub-sub vi.

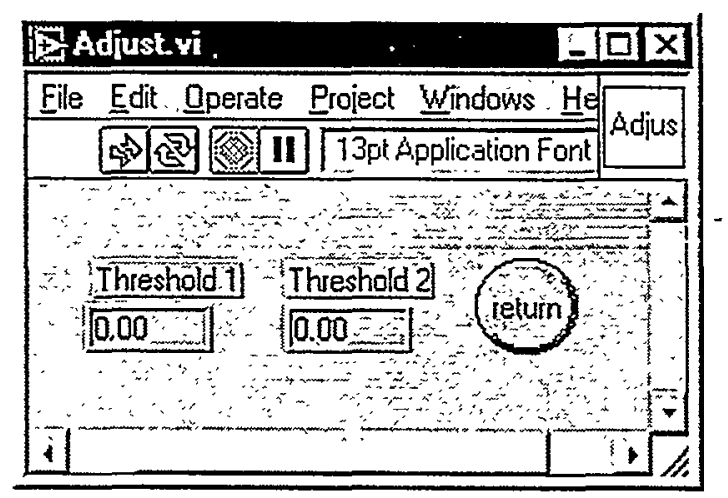

Figure 45. The Adjust sub-instrument panel.

Selecting the "Single Step" option on Figure 42 causes the Step sub-instrument panel of Figure 46 to appear. Step is used to obtain and display (output) only one calculated value of viscosity. The diameter of the waveguide and the calibration constant must first be supplied (input) by the operator. Every time the one-test button is pressed, the three time values are read and viscosity is calculated. The Step signal flow diagram is given in Figure 47. 


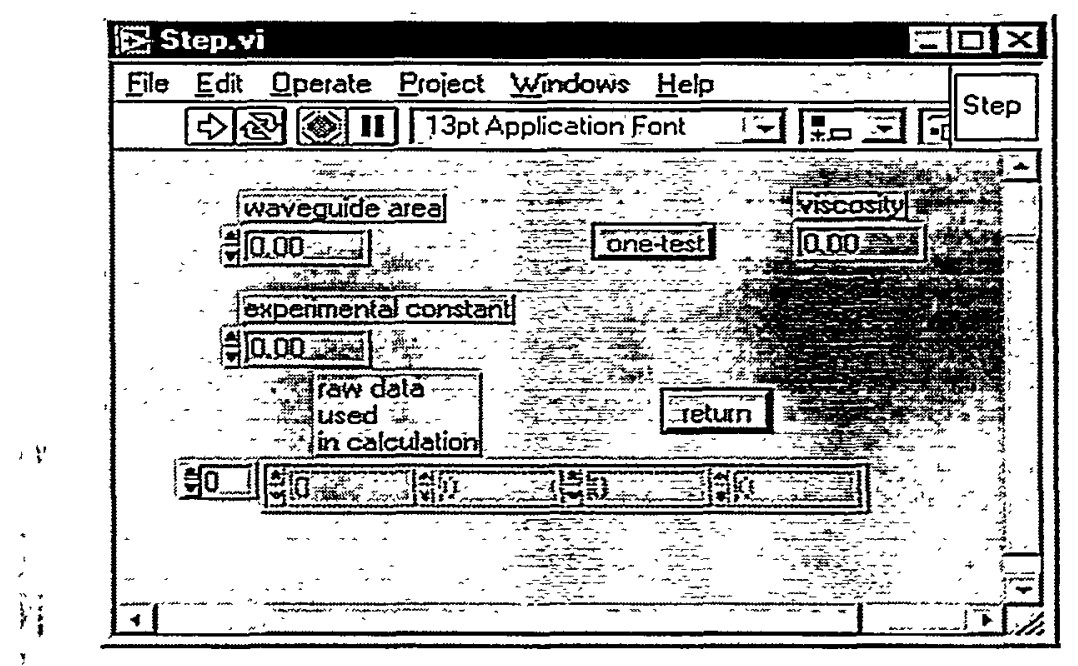

Figure 46. The Step sub-instrument panel.

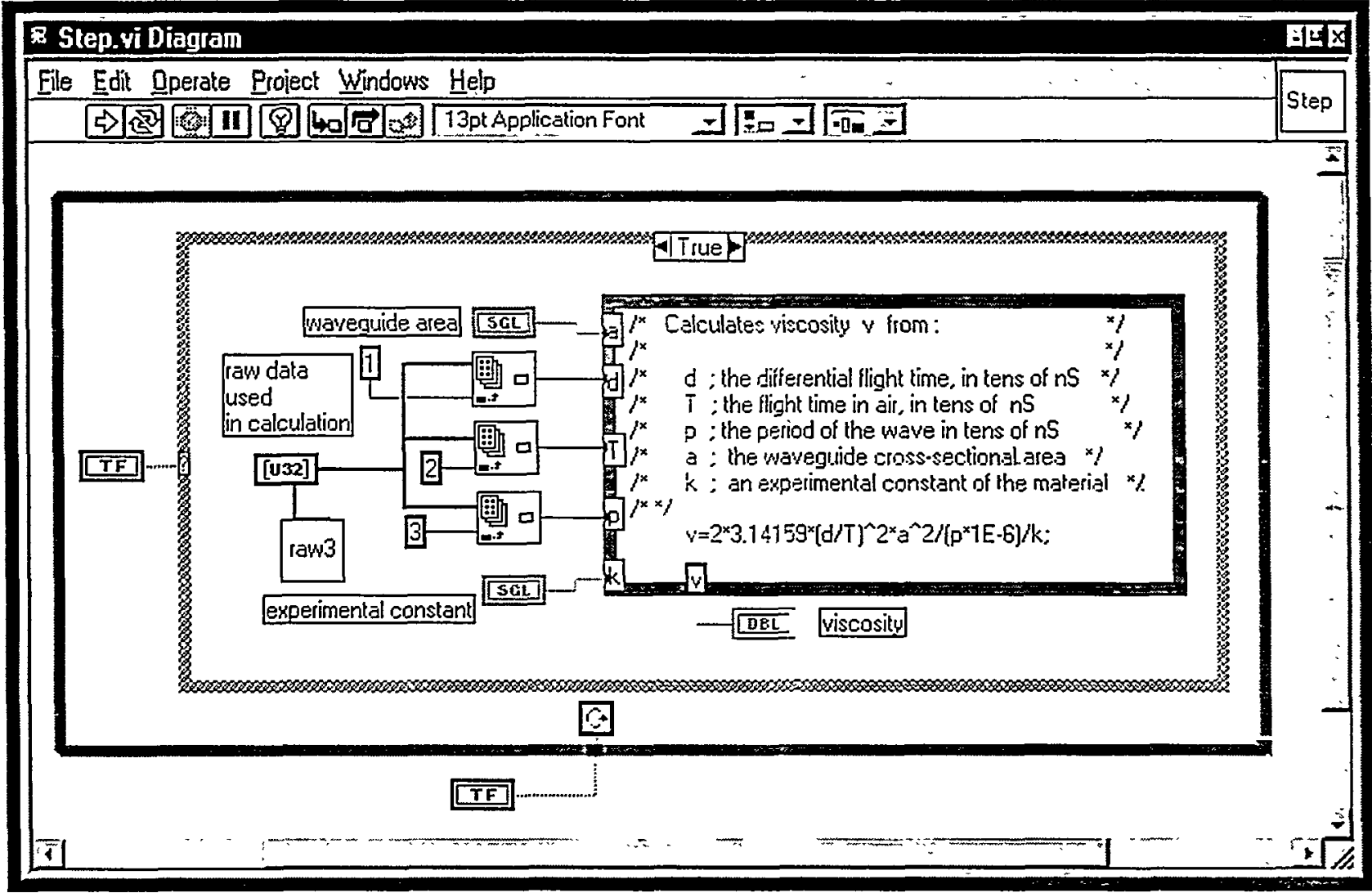

Figure 47. The Step signal flow diagram.

Selecting the "Test" option on Figure 42 causes the Test sub-instrument panel of Figure 48 to appear. The operator selects which of the three time values is to be displayed. Every time the 
"one-test" button is depressed, one time value is acquired and displayed. It then loops waiting for the next time this button is depressed, until the "return" button is depressed.

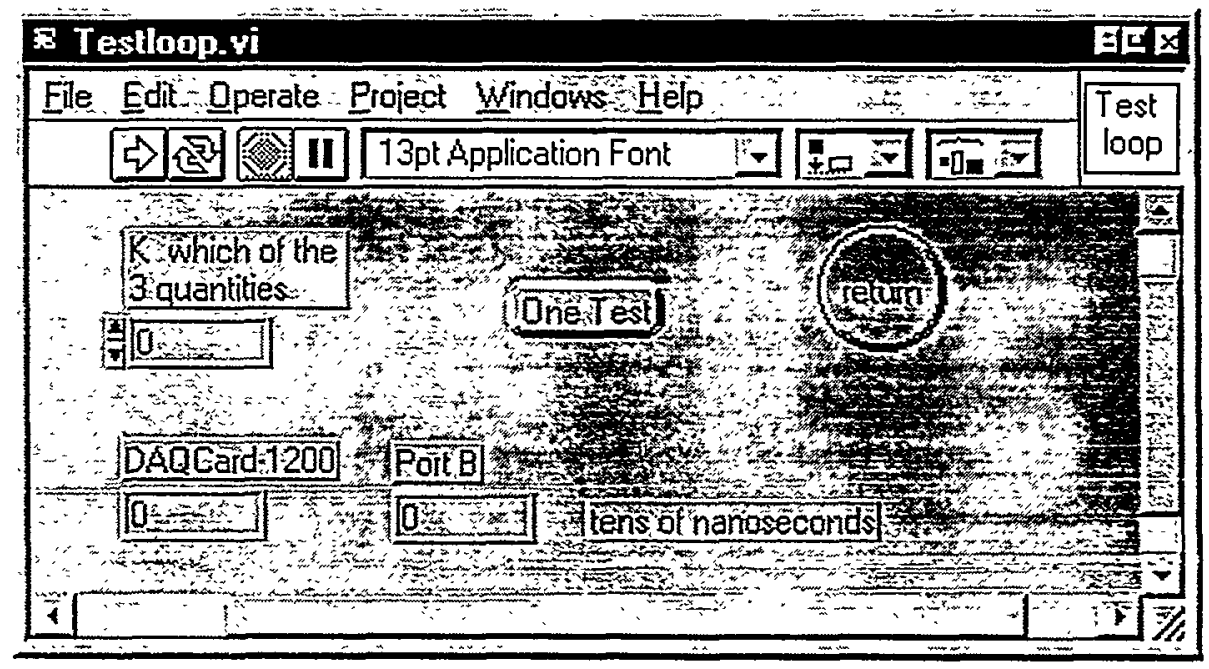

Figure 48. The Test sub-instrument panel.

\section{Status of software development}

A low-level vi still needs to be debugged. It sends one byte out to a single output port. The problem is to disengage the cumbersome overhead that LabView exacts for digital I/O for such a simple task. LabView tries to first initialize (clear) the port every time a byte is to be sent. This prevents single bit twiddling. Other than that. all upper level and digital $\mathrm{I}^{\prime} \mathrm{O}$ vis have been developed and tested, as has viscosity calculation.

Analog I/O has been written but not tested for both the acoustic and oscillating cylinder vis.

Data reduction and logging have yet to be developed for both the acoustic and oscillating cylinder vis. 


\subsection{RECOMMENDATIONS FOR FUTURE WORK}

\section{(...}

IF THE ACOUSTIC PROJECT IS CONTINUED

\section{Acoustic transducer/rod/waveguide}

Investigate making our own transducers. The transducer is just a coil. Our Panametrics coils were intended merely for proof of concept and training. They are encapsulated in a plastic cylinder that doubles its diameter. It also places a BNC connector off the side, not the end. This doubles again the effective diameter, so the resulting housing must be much larger and bulkier than necessary. In addition, their coils are not shielded. Since we wish to place two coils side-byside, shielding would be desirable.

A stable magnetic transducer/rod is needed which generates only torsional waves. This will entail a visit to Panametrics with all our rods, transducers, and pulsers, to have them make them work more reliably together. Possibly, different rods and waveguides need to be investigated. Coating the waveguide with a non-wetting material might improve the sensitivity of the waveguide and eliminate some effects like adherence over time of elements in the fluid to the surface of the waveguide. Research teams who had published results using circular waveguides have since abandoned the use of circular cross-sections.

\section{Acoustic probe assembly}

The receive transducer preamplifiers are presently mounted on a small board hung between the transmit and receiving transducers. For robustness, protection against corrosion, to simplify the cable layout, and to allow easier access for maintenance the board should be moved to a disc at the rear (top) of the assembly. See Figure 5. This disc would also include the I/O connectors and a high-voltage pulse driver (to remove the need for the Panametrics Pulser/Receiver).

A temperature sensor for measurement of temperature close to the insertion rod should be designed.

Probe housing should be designed, built, and tested. Both acoustic and environmental tests should be performed. If the probe is to be used in caustic or high-radiation environments, the design and test should reflect this with suitable additional sensors. The housing should be liquidproof and provide both acoustic isolation between the rods and from the coils to the support structure. If additional sensors are added, the support electronics will probably require preamplifiers/signal conditioners in the probe assembly or in the remote unit box.

\section{Acoustic electronics/software}

Once there are reliable and high-amplitude waveforms from both receive transducers, the few remaining timing circuits and switch settings in the control unit which require both receive signals can be tested.

The LabView initialization, system test, and data acquisition software needs to have one bug corrected. 
The data analysis and data logging software needs to be developed.

Then the LabView software needs to be developed using a GPIB interface card and bus to transfer oscilloscope waveforms to monitor and document them (not measure) into the computer report files.

The instrument needs to be field tested, and modified if problems are found.

\section{IF THE OSCILLATING CYLINDER PROJECT IS CONTINUED}

\section{Oscillating cylinder structure}

The size of the structure needs to be scaled down to reduce the mass. Leaks in the tank need to be repaired.

The nature of the noise and harmonics in the force waveform needs to be investigated. This is probably due to the friction and non-sinusoidal nature of the drive linkage.

\section{Electronics/software}

The transmission mode for motor controller pulse noise needs to be identified and corrections implemented.

LabView software needs to be developed for data control, acquisition, ensemble averaging, calculation (using Bessel functions), data logging, and waveform data transfer using the GPIB oscilloscope link.

\section{IF EITHER PROJECT IS CONTINUED, ADDITIONAL WORK IS WARRANTED}

\section{Sensors}

Measurement of the physical properties (viscosity and density) of waste slurries is critical in evaluating the transport parameters to insure turbulent flow through transport pipes. The environment for measurement and sensor exposure is extremely harsh. Reliability and ruggedness are critical in sensor design.

\section{Remote unit}

The prototype board inside the remote unit box that mounts the electronics is fragile and difficult to maintain. It should be redone as a printed circuit board along with additional circuits added. The printed circuit layout for this board has already been completed, but will have to be augmented if additional sensors are required.

\section{Custom unit}

The two printed circuit boards in the custom unit have suffered much revision as the design objectives were clarified. If they were combined, much connecting cable would not be necessary. The component count could be less, noise rejection could be improved, and potentiometers and 
switches could be mounted on it. Most of the smaller power-supply components now mounted separately could be placed there as well. The net result of these improvements would be a more robust and portable system for field tests.

\section{The viscous media solutions}

More accurate measurements require a temperature-controlled bath.

The time taken for preparing the solutions is now excessive and a better mixer is needed. An electronic mixer was used for better homogenization of the sucrose or clay, but due to the speed of mixing, air bubbles were added. 


\subsection{REFERENCES}

Bailey, P. and Gillies, D., "New Low Cost Electroviscometer," Measurement of Science Technology, Vol. 2, No. 8, pp. 735-739, 1991.

Barr, A.D., "Torsional Waves in Uniform Rods of Noncircular Section," Journal of Mechanical Engineering Science, Vol. 4, No. 2, pp. 127-135, 1962.

Ban, H.H., "Torsional Wave Sensor-A Theory," Transactions of the ASME, Vol. 53, pp. 846-848, December, 1986.

Benes, E. and Groschl, M., "Sensors Based on Piezoelectric Resonators," Sensors and Actuators, Vol. 48, No.1, pp. 56-60, 1995.

Beyer, R.T. and Letcher, S.V., Physical Ultrasonics, Academic Press, New York, 1969.

Borner, M. and Murphy, M., "Ultrasonic Measurements with Micromembranes," Sensors and Actuators, Vol. 46-47, pp. 62-65, 1995.

Boyd, G.D., "Acoustic Waveguide with a Cladded Core Geometry," Applied Physics Letters, Vol. 26, No. 2, pp. $31-34,1975$.

Costley, D., Ingham, W.. M., Simpson, J.. "Ultrasonic Viscosity Measurement of Molten Liquids," American Ceramic Societr: 99th Annual Meeting, Cincinnati, OH, May 4-7, 1997.

Cutrone, L., "Use of the Brookfield Viscometer to Predict Rhelogical Performance of Coatings," Journal of Coatings Technology, Vol. 56, 1984.

Davies, R.M.. "The Frequency of Longitudinal and Torsional Vibration of Unloaded and Loaded Bars," Philosophical Magazine, Ser. 7. Vol. 25, No. 167, pp. 364-386, 1938.

Duncan, B.L, "Density and Viscosity of Concentrated Aqueous Solutions of Potassium Hypochlorite," Journal of Chemical and Engineering Data, Vol. 39, pp. 863-864, 1994.

Gaglione, R. and Attane, P., 1993, "A New High Frequency Rheometer Based on the Torsional Wave Guide Technique," Review of Scientific Instruments, Vol. 64, No. 8, pp. 2326-2333, 1993.

Gahletner, M. and Sobzak, R., "A New Apparatus for Measuring High Viscosities," Journal of Physics, E, Scientific Instruments, Vol. 21, pp. 1074-1077, 1998.

Garza, J. and Glazmer, D., "A Fast and Easy Way to Measure Viscosity," Chemical Engineering, Vol. 102, pp. 133, 1995.

Giacomin, J. and Thomas, V., "A Rheometer to Measure the Viscoelastic Properties of Polymer Melts at Ultrasonic Frequencies," Review of Scientific Instruments, Vol. 65, No. 7, pp. 2395-2401, 1994. 
Gladkii, V. and Gerlanets, I., "Analysis of Errors of Liquid Viscosity Measurement with a Vibration Viscometer," Measurement Technology, Vol. 34, No. 6, 991, pp. 593-596, 1990.

Glover, G.M., Hall, G., "A Magnetostrictive Instrument for Measuring the Viscoelastic Properties of Liquids in the Frequency Range $20-100 \mathrm{kHz}$," Journal of Physics, Ser. 2, Vol. 1, pp. 383-387, 1968.

Golden, J.M. and Graham, G.C., "A Proposed Method of Measuring the Complex Modulus of a Thick Viscoelastic Layer," Rheologica Acta, Vol. 28, No. 5, pp. 414 416, 1989.

Guozhen, Z. and Laoli, X., "Measurements of Viscosity and Density by a Vibrational Sphere," Review of Scientific Instruments, Vol. 56, No. 8, pp. 1639-1642, 1985.

Hertz, T.G. and Dymling, S., "A Non-Invasive Ultrasonic Method for Viscosity Measurements," Ultrasonics Symposium Proceedings. Vol. 1, pp. 299-302, 1990.

Heywood, N., "Selecting a Viscometer," The Chemical Engineer, n.v., pp. 16-23, 1985.

Hitchoock, C.D. and Hammons, H.K., 1994, "The Dual-Capillary Method for Modern-Day Viscometry." American Laboratory, n.v. pp. 1-6.

Hood, J. and Mignona, B., "Determination of Elastic Moduli in Anisotropic Media from Ultrasonic Contact Measurement," Ultrasonics, Vol. 33, No.1, pp. 45-54, 1995.

Houmady, M. and Bastien, F., "Acoustic Wave Viscometer," Review of Scientific Instruments, Vol. 62, pp. 1999-2003, 1991.

Huilgol, R., "Continuum Mechanics of Viscoelastic Liquids," Hindustan Publishing Corporation, New York, Halsted Press, 1975.

Jackman, M., "In Line Viscometers Help Achieve Perfect Products," Food Technology, Vol. 45, pp. 92-96, 1991.

Josse, F., "Acoustic Wave-Liquid-Based Microsensors," Sensors and Actuators, Vol. 44, No. 3, pp. 199-208, 1994.

Kim, J.O. and Bau, H., "Instrument for Simultaneous Measurement of Density and Viscosity," Review of Scientific Instruments, Vol. 60, No. 6, pp. 1111-1115, 1989.

Kim, J.O., and Bau, H., "On Line, Real-Time Densimeter - Theory and Optimization," Journal of the Acoustical Society of America, Vol. 85, No. 1, pp. 842849, 1989a.

Kim, J.O., Wang, Y., Bau, H., "The Effect of an Adjacent Viscous Fluid on the Transmission of Torsional Stress Waves in a Submerged Waveguide," Journal of Acoustical Society of America, Vol. 89 No. 3, pp. 1414-1421, 1991.

Kim, J.O., "The Interaction Between Stress Waves Transmitted in Solid Waveguides and Adjacent Media," University of Pennsylvania, Ph.D. Thesis, 1989.

Kimura, M. and Shirane, K., "Method for Measurement of Viscosity and Density of Liquid with a Slowly Rotating Column," Review of Scientific Instruments, Vol. 59, pp. 967-970, 1988. 
Krigman, A., "Viscosity Measurement: Still Sticky but Stopping Ahead Steadily," Intech, Vol. 32, n.p., 1985.

Lansagan, R.M., "Viscosity, Density and Composition Measurements of Certain West Texas Oil Systems," Society Petroleum Engineers, Inc. pp. 157-174, 1991.

Leyh, C. et al., "New Viscosity Measurement: the Oscillating Magnetically Sphere,"Review of Scientific Instruments, Vol. 55, pp. 570-577, 1984.

Lynnworth, L., "Ultrasonic Measurements for Process Control: Theory, Techniques, Applications," Academic Press, San Diego, 1988.

Martin, Bret A., "Viscosity and Density Sensing with Ultrasonic Plate Waves Transducers," Proceedings of the 5th International Conference on Solid State Sensors and Actuators and Eurosensors III, pp. 704-708, 1989.

Moore, J.E.J., Guggenheim, N., Delfino, A., Doriot, P.A., Dorsaz, P.A., Rutishauser, W., and Meister, J. J. "Preliminary Analysis of the Effects of Blood Vessel Movement on Blood Flow Patterns in the Coronary Arteries," ASME Journal of Biomechanical Engineering, 116, pp. 302-306, 1996.

Nicolescu, G., Petrescu, N., "The manufacturing of sugar products," Technical Edition, Bucharest, pp. 7-305, 1967.

Park, N. and Thomas I., "Measurements of Rheological Fluid Properties with the Falling Needle Viscometer," Review of Scientific Instruments, Vol. 59, pp. 20512058, 1988.

Rajakovic, L. V., "Mediation of Acoustic Energy Transmission from Acoustic Wave Sensors to the Liquid Phase by Interfacial Viscosity," Analtyical Chemistry, Vol. 63, pp. 615-621, 1991.

Rosenberger, F. and Ivan, J., "Gravimetric Capillary Method for Kinematic Viscosity Measurements," Review of Scientific Instruments, Vol. 63, pp. 4196-4199, 1992.

Saad, E., "Modeling the Viscosity of Glasses Used in the Immobilization of High-Level Liquid Nuclear Waste," Nuclear Technology, Vol. 86, pp. 66-69, 1989.

Santra, L., and Bhaumick, D., "Development of a Differential Viscometer," Journal of Physics, Vol. 21, pp. 896-898, 1988.

Shackleton,.M. and Green, R., "On-Line Viscometer for Measurement in the Range 1 To 100 Pa's," Measurement Science and Technology, Vol. 4, No. 3, pp. 395-404, 1993.

Shana, A. et al., "Quartz Crystal Resonators as Sensors in Liquids Using the Acoustoelectric Effect," Analytical Chemistry, Vol. 66, No. 13, pp. 1955-1964, 1994.

Stokisch, T. and Radtke, D., "Instrument for Precise Measurement of Viscoelastic Properties of Low Viscosity Dilute Macromolecular Solutions of Frequencies from 20 to $500 \mathrm{KHz}$," Journal of Rheology, Vol. 34, No. 4, pp. 1195-1210, 1991.

Suryanarayana, C., "Propagation of Ultrasonic Waves In Liquids: A New Model" Ultrasonics, Vol. 30, No. 20, pp. 104-106, 1992. 
Thomas, V. and Giacomin, A., "Measuring the Viscoelastic Properties of an Ethylene-Tetrafluor Ethylene Copolymer at Ultrasonic Frequencies," Polymer Engineering and Science, Vol. 35, pp. 1053-1060, 1995.

Thurston, R.N., "Elastic Waves in Rods and Clad Rods," Journal of the Acoustical Society of America, Vol. 64, No. 1, pp. 1-37, 1978.

Tozaki, K. and Miyatani, T., "Instrument for Measuring Viscosity and Shear Modulus under Steady Shear Stress," Japanese Journal of Applied Physics, n.v. pp. 2892-2894, 1993.

Tzannes, N.S., "Joule and Wiedemann Effects - The Simultaneous Generation of Longitudinal and Torsional Stress Pulses in Magnetostrictive Materials," IEEE Transactions on Ultrasonics, Vol. SU-13, No.2, pp. 33-41, 1966.

Wang, J., "Piezoelectric PH Sensors: At-Cut Quartz Resonators with Amphoteric Polymer Films," Analytical Chemistry, Vol. 65, pp. 2553-2562, 1993.

Williams, R., "Theory of Magnetostrictive Delay Lines for Pulse and Continuous Ware Transmissions," IEEE Transactions on Ultrasonic Engineering, Vol. UE-7, pp. 16-38, 1959.

Winkel, V. and Oliveira, J., "Acoustic Wave Propagation in Piezoelectric Fibers of Hexagonal Crystal and Symmetry," IEEE Transactions on Ultrasonics, Ferroelectrics and Frequency. Control, Vol. 42, No. 5, pp. 949-955, 1995.

Womersley, J.R., "Method for Calculation of Velocity, Rate of Flow and Viscous Drag in Arteries when the Pressure Gradient is Known," Journal of Physiology, Vol. 127, pp. 553-563, 1955. 
APPENDIX A

\section{VISCOSITY PRINCIPLES}




\section{VISCOSITY PRINCIPLES}

\section{Definition of variables}

The measurement of the viscosity of liquids first requires the definition of variables. All fluids possess a definite resistance to change of form, and many solids show a gradual yielding to forces to change their form. This property, an internal friction, is called viscosity. The units of absolute (dynamic) viscosity are dyne-seconds per $\mathrm{cm}^{3}$ or poises. If the tangential force per unit area $\tau$, exerted by a layer of fluid upon one adjacent layer is one dyne for a tangential velocit: (shear rate) $\gamma$ of unity, the dynamic viscosity $\eta$ is one poise. A hundredth of a poise, or centipoise (cP), is commonly used because it avoids fractional values. The viscosity of water is around 1 $\mathrm{cP}$.

Isaac Newton was the first to express the basic law of viscometry. He described the flow behavior of an ideal liquid by the means of dynamic viscosity $\eta$ and shear rate $\%$ :

$$
\text { Shear stress }=(\text { viscosity }) *(\text { shear rate }) \quad \cdot \quad \tau=\eta * \gamma_{;} \quad \text { or } \quad \eta=\frac{\tau}{\gamma}
$$

Another unit of viscosity is Pascal-seconds. One milli Pascal-second is one $\mathrm{cP}$.

Another common type of viscosity is kinematic. Kinematic viscosity $v$ and dynamic viscosity $\eta$ of a fluid are linked by the density $\rho$ of the liquid:

$$
v=\frac{\eta}{\rho} \quad\left[\mathrm{mm}^{2} / \mathrm{s}\right]
$$

The unit of measurement used for kinematic viscosity is centi Stokes or Stokes:

One $\left[\mathrm{mm}^{2} / \mathrm{s}\right]$ is one $[\mathrm{cSt}]$.

\section{Magnetostriction}

The term magnetostriction is defined as the change in the dimension of a ferromagnetic material when it is placed in a magnetic field. Magnetostriction is available in the ferromagnetic materials such as nickel, iron, cobalt, Remendur 27 (48\% Co, 3\%v, Fe), and Hiperco50 (49\% Co, 2\% V. $\mathrm{Fe}$ ).

Magnetostriction effects are classified as follows:

- Widen Effect. In the Widen type magnetostrictive delay-line, the introduction of a direct current through the transmitting coil develops a circumferential field around the ferromagnetic wire that goes through the coil. The introduction of a current pulse into the transmitting coil causes a changing axial field that twists the wire. This effectively starts a shear stress pulse, which will be detected later by the receiving coil, by the virtue of the Inverse Widen Effect.

- Joule Effect (joule and Widen effects-tzannes). In 1966, Tzannes conducted a study that developed a new understanding of the Widen effect and its relationship to the basic Joule effect. His study included theoretical development and experimental verification of the phenomena of simultaneously producing two different stress pulses in magnetostrictive 
materials. The Joule effect, often called longitudinal magnetostriction, was studied under the condition of dynamic excitation.

If a changing current is introduced into the transmitting coil-consequently the ferromagnetic wire located in the coil will cause the material to change its length. This abrupt change in the length of the ferromagnetic wire generates a stress wave that propagated down the wire and into the receiving coil. This stress wave simultaneously travels toward both ends of the wire at the speed of sound within the material. The stress pulse will be extinguished when it reaches the damping pad on the sending end. When the stress pulse reaches the receiving coil, it generates a changing flux in the axial direction because of the Inverse Joule effect or Villari Effect. The changing flux links the turns of the receiving coil and generates an output voltage because of Faraday's law.

- Wertheim Effect. When a wire is placed in a longitudinal magnetic field and is twisted, there will be a transient voltage difference between the ends of the wire.

\section{Magnetostrictive delay lines-(From the theory of magnetostrictive delay lines-by Roscoe Williams)}

Magnetostrictive delay lines are passive networks that can transiently store a number of $\mathrm{dc}$ or ac pulses. This can be a simple structure of two coils and a magnetostrictive rod. The basis operation of the line is dependent upon three principles:

- The magnetostrictive effect (Joule Effect)

- The propagation of sonic energy in an elastic medium

- The Villari effect.

The following are some of the properties characteristic of delay lines:

- The maximum pulse repetition frequency is independent of the total delay.

- The insertion loss varies between 40 and $60 \mathrm{~dB}$.

- The end-to-end delay time is a function of the length of the line.

The basic assumption is that the variables concerned in magnetostriction, inverse magnetostriction, elasticity, and magnetism are linearly dependent. This requires the presence of biasing magnets at both the transmitting and receiving coils to insure that the operating points lie in the linear regions of the static characteristics of strain versus magnetic intensity. Small signal (linear) analysis will then apply, since the input magnetic field is assumed small in comparison to the saturation value of the magnetic field.

\section{Newtonian and Non-Newtonian fluids - concept definition}

Most common fluids such as water, air, and gasoline are Newtonian under normal conditions: If one considers the deformation of two different Newtonian fluids, say glycerin and water, one recognizes that they will deform at different rates under the action of the same applied shear 
stress. Glycerin exhibits a much larger resistance to deformation than water, so we say it is much more viscous. If a fluid is Newtonian, then it will follow Newton's law of viscosity:

$$
\tau=\mu \frac{d u}{d y} .
$$

Dimensionally: shear stress in the $x-y$ direction $=($ dynamic viscosity $) *$ (rate of deformation). Thus, a fluid element when subjected to shear stress experiences a rate of deformation given by $\frac{d u}{d y}$. Fluids in which shear stress is directly proportional to rate of deformation are Newtonian fluids. The term non-Newtonian is used to classify all fluids in which shear stress is not - proportional to shear rate. Most non-Newtonian fluids fall in the class of pseudoplastic (or shear thinning) fluids. Examples include polymer solutions, colloidal suspensions, and paper pulp in water. If the apparent viscosity increases with increasing deformation rate, the fluid is termed dilatant (or shear thickening). Suspensions of starch and of sand are examples of dilatant fluids.

\section{The Daniel Costel et al. Paper}

In the article "Ultrasonic viscosity measurement of molten liquid," Daniel Costel et al. describe a sensor able to take viscosity measurements in the 7 to $500 \mathrm{cP}$ range with two different calibration liquids. A versatile system has been developed in which either torsional or extensional waves can be excited and detected in thin rods made of magnetostrictive materials. Under the influence of a magnetic field, the magnetostrictive material will deform. The deformation depends on the polarization of the magnetic domains within the material and the alignment of the external magnetic field. When a current passes through a magnetostrictive rod. the domains are aligned circumferentially within the rod. A twist in the rod is produced if the rod is then subjected to an external axial magnetic field. If the external field is transient, then the twist propagates as a torsional wave down the length of the rod (Wiedemann effect). The axial magnetic field is produced by passing current through a coil that is wrapped around the wire (transducer). The detection of torsional waves is accomplished via the inverse.- Wiedemann effect, in which the torsional wave produces a current in the wire. The magnetostrictive rod can be attached by either solder or glue to another rod made of a different material, such as stainless steel. Waveguides of circular cross-section are used to determine viscosity. Waveguides of noncircular cross-section are used to determine liquid density. In two-phase fluids, such as particulate suspensions or liquid-vapor mixtures, density can be measured by using elliptical or rectangular cross-section. Both types of waveguides can be used to determine temperature and liquid level. For a waveguide with a circular cross-section immersed in a viscous fluid, it has been shown that both the attenuation and the velocity of the torsional waves depend on the ratio of the density to the viscosity. When the surface of the waveguide is in contact with a viscous fluid, shear stresses will be produced at the surface which oppose the motion in the solid rod. These stresses or viscous drag will cause the torsional wave to attenuate; the phase velocity will decrease as well. The decay in amplitude could be represented as a function of dimensionless numbers:

$$
\mathrm{A}_{2} / \mathrm{A}_{1}=\mathrm{f}\left(\frac{\lambda}{L}, \frac{a}{L}, \frac{c}{L f}, \alpha \frac{T}{L}, \beta L, \frac{\eta}{L L f \rho}\right)
$$


where $A_{2}$ and $A_{1}$ are the amplitudes of the torsional wave at two different points, $c$ is the speed of the wave, $T$ is the temperature, $a$ is the radius and $L$ is the length of the rod, $\alpha$ is the coefficient of thermal expansion for the material immersed in the fluid, $\beta$ is the attenuation in nepers or $\mathrm{dB}$ per meter, $f$ is the frequency, $\lambda$ is the wavelength, $v$ and $\rho$ are the kinematic viscosity and density of the fluid, $\mathrm{c}$ is the torsional wave speed in the rod and refers to the lowest mode of torsional wave speed. The frequency of the torsional wave pulses is under $100 \mathrm{KHz}$. It has been shown that the speed of torsional waves in the material is a function of temperature. Secondly, the rod will elongate along with the increase of the temperature, so the torsional pulse will have a longer distance to travel. The viscosity was related to the time difference between air and liquid. 


\section{APPENDIX B}

FUNCTIONAL DESCRIPTION OF THE

CURRENT AUTOMATED INSTRUMENTATION SYSTEM 


\section{FUNCTIONAL DESCRIPTION OF THE CURRENT AUTOMATED INSTRUMENTATION SYSTEM}

\section{Receiver electronics}

Signal flow is shown on by a diagram in Figure 1. Receive preamplifiers in the probe assembly boost the receive transducer's $100 \mathrm{KHz}$ signals and drive a long line with a $50 \mathrm{ohm}$ source resistance. The higher amplitudes and low impedances minimize noise pickup. The frequency response of the preamplifiers cut off below $30 \mathrm{KHz}$ to reject $60 \mathrm{~Hz}$ hum. These signals wire directly through the remote unit without interception.

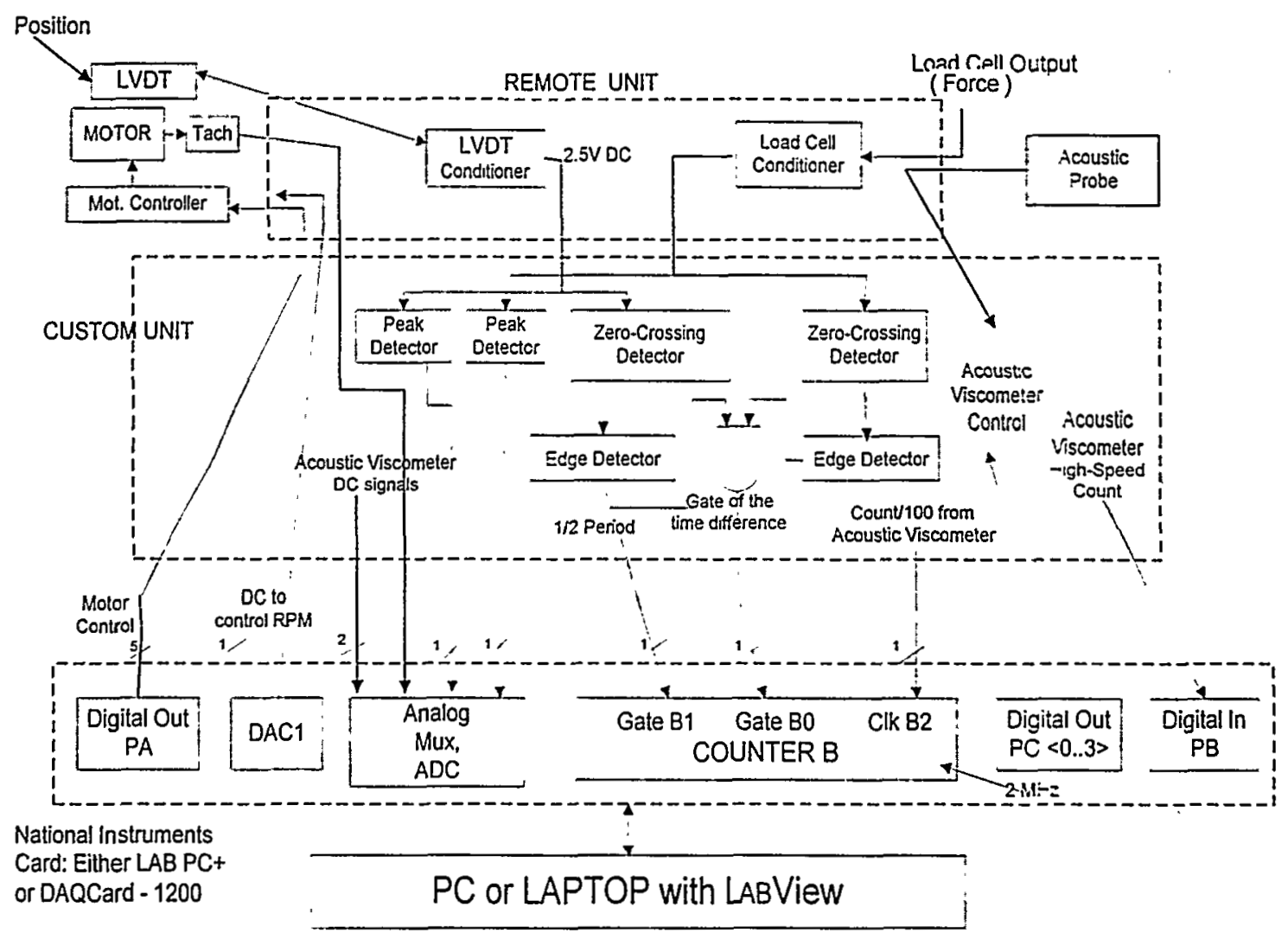

Figure 1. Signal Flow for the FIU Viscometer.

\section{Remote unit wiring for the motor controller}

Seven control terminals are provided on the motor controller ( $\mathrm{AC}$ inverter) by the designer to allow for remote control. Five terminals are for digital and two are for analog. Since there is never a need to reverse the motor direction of rotation and the RPM of the motor is controlled only by the analog signal sent to it, only two of the digital signal terminals are used. The signals these two digital terminals require originate on the instrumentation card, are sent on the long cable to high-voltage open-collector drivers in the remote unit, and then to the two input control terminals on the motor controller. The controller has at each of these two input control terminals 
an internal pull-up resistor to $+13 \mathrm{~V} \mathrm{DC}$. One driver in the remote unit has the function of pulling one of these terminals low (as if a contact closure occurred to the common pin $\mathrm{CM}$ ) to make the function associated with that terminal to occur. For example, to make the motor run in the forward direction, keep the FWD terminal low (contact closure). The motor will continue to run as long as this low condition is supplied. When the contact is opened (signal allowed to be pulled high by the internal resistor) at FWD, the $\mathrm{AC}$ power will be removed from the motor and the motor will coast to a stop. The default condition is no action during power on and off, or instrumentation card poor programming, or protection against cable noise. However. to achieve this default of "no action" an inverter needs to be inserted the custom unit. This means that a logic "one" or high must be issued by the software/instrumentation card for a pull-down (contact closure, logic "zero") to appear at the appropriate inverter and subsequent control terminal.

One of the two analog terminals is an input receiving from the instrumentation card DC (0-10 V) so that this instrumentation card can control the RPM of the motor. The second is an output analog value that the controller issues which is indicative of actual motor RPM. Unfortunately, this is a pulse whose average value is what must be obtained by calculation in LabView. Such a process is complex, and the result will be a value of less accuracy than the period measured by Gate B1. Hence, while the capability is provided to monitor period by analog voltage. this is not expected to be the method of choice.

\section{Remote unit dc power}

The receive preamplifiers require regulated $\mathrm{DC}$ of plus and minus 5 volts. Therefore five-volt regulators are located in the remote unit and driven by unregulated plus and minus 9 -volt wires in the long cable. Any noise or hum picked up on these 9-volt wires is removed by the regulators.

$A+16$ volt unregulated $\mathrm{DC}$ voltage is sent down the long cable to drive $a+10$-volt regulator in the remote unit and send it to the motor controller. This powers the motor controller's analog amplifiers. Also plus and minus 16 volts are provided to the remote unit to power the load cell signal conditioning module placed inside the remote unit. The LVDT signal conditioner comes with its own power supply, and must be supplied with $120 \mathrm{~V}$ ac $60 \mathrm{~Hz}$.

\section{Custom unit acoustic electronics}

There are three quantities whose values are used in calculation of viscosity by acoustic means:

- The quantity $\mathrm{Q}(2)$, the flight time $\mathrm{T}$ in air for an acoustic pulse train to traverse the probe and return,

- The quantity $\mathrm{Q}(1)$, the differential flight time $\Delta t$ between flight time $\mathrm{T}$ in air and the flight time in the acoustic medium, and

- The quantity $\mathrm{Q}(3)$, the period of the pulse train—approximately $100 \mathrm{KHz}$.

Each of these is measured in turn by an accurate $100 \mathrm{MHz}$ clock and decade counter string. The counter string begins with the first two (fastest) decade counters in the custom unit. The rest of the count is read by the 16-bit counter B2 in the instrumentation card. The quantity to be measured is selected remotely by the instrumentation card and computer software. The software reads the four bits from each of the two fast counters using 8-bit digital port B on the card. 


\section{Custom unit electronics for the oscillating cylinder}

The high-level conditioned analog signals of position and force are sent back to the control unit as inputs to peak and zero crossing detectors, plus an AND which generates a gate whose width is indicative of phase shift time between the two zero crossings.

\section{Digital counter function allocation for the instrumentation card}

See what is denoted Figure 1 for the connection of instrumentation card circuits to the custom and remote units.

Counter B's three 16-bit counters are used as follows:

B0 measures directly the time difference between the oscillating cylinder's zero crossings of position and force, counting one-half microsecond pulses.

B1 measures one half the period of oscillation of the cylinder in counts of one-half microsecond pulses.

B2 measures the remainder of the time of one of the three quantities needed for viscosity calculation in counts of one microsecond per clock pulse. Hardware counters in the custom unit preceding B2 measure the first two digits of count of time in units of 10 and $100 \mathrm{nS}$.

\section{Parallel digital function allocation for the instrumentation card.}

The parallel capability of the instrumentation card is based on Intel's classic 24 bit Peripheral Parallel Interface (PPI) chip, the 8255A. In this system its three digital ports are allocated as follows:

- Port $\mathrm{A}$ (i.e., $\mathrm{PA}$ ) is not now used

- $\mathrm{PB}$ is used in input mode 0 only to pick up quickly one value from one of the three 8-bit fast counters in the custom unit

- There are two separate parts of PC, whose functions depend on the mode selected for PA and PB. Since mode 0 (simple input without handshaking) is selected for PA and PB, then PC $<7.0>$ is free to be used for independent purposes. Note that these bits can be independently set (logic one, or a high) or reset (logic zero or a low).

$\mathrm{PC} 1$ and PC0 are encoded to specify the counter address of the acoustic quantity whose time is to be digitally measured:

\begin{tabular}{ccl}
\hline PC1,0 & Q & \multicolumn{1}{c}{ QUANTITY } \\
\hline & & No measurement of time is performed \\
00 & & Differential flight time $\Delta t$ \\
01 & $\mathrm{Q}(1)$ & Round-trip flight time $\mathrm{T}$ \\
10 & $\mathrm{Q}(2)$ & Wave-train period \\
11 & $\mathrm{Q}(3)$ & W
\end{tabular}


This is the address of one of the three 8-bit counters that contains the count of this time. Hence, to select the time quantity to be measured, send the appropriate byte out to port PC.

The function of $\mathrm{PC} 2$ is to control the acquisition of one time measurement value. It is described below. PC5, PC4, and PC3 are yet unspecified.

The upper two bits PC7, PC6 of PC are used to generate individually the two software inverted control signals going to the motor controller to individually control the two control terminals of the motor controller.

Consider now why we need software to invert these signals, (i.e., why inverters were required in the custom unit), so that a software inversion is necessary to compensate for the required inverters. THIS IS VERY IMPORTANT! The Oki version of this 8255 differs in two important respects from the Intel version. See pages D-9 and D-10 of the PC+ manual.

A computer normally generates a RESET signal to all its I/O circuits during power-up or when the front panel Reset push-button is depressed. This includes the National Instruments Instrumentation card. On this card's Oki 8255 such a reset causes all output latches to be cleared to zero and the mode set automatically to mode zero. This means all 24 pins of the three ports A, $\mathrm{B}$, and $\mathrm{C}$ will have on them a "low" voltage, close to zero volts. These zero values can be verified with a $D C$ voltmeter. However, we do not want any of the motor controller functions to be affected, so a zero (low) out of the 8255 must result in highs (contacts open) at the controller input digital terminals. The inverters in the custom unit perform this inversion.

On page D-10 note it says "The output registers for ports $A$ and $C$ are cleared to zero each time data is written in the command register and the mode is changed." This means zeros are placed on the cable going to the custom unit. We do not want the motor controller's input digital terminal values to go to zero when this programming operation happens, so this is another occasion when we need the inverters in the custom unit.

$\begin{array}{lllll}\text { PCi out of NI } & \begin{array}{l}\text { Interpretation of } \\ \text { the Signal out of } \\ \text { the NI card }\end{array} & \begin{array}{l}\text { Control } \\ \text { Output }\end{array} & \begin{array}{l}\text { Motr. Contr. } \\ \text { Terminal }\end{array} & \begin{array}{l}\text { Motor operation when this motor control } \\ \text { terminal is connected to (i.e., has contact } \\ \text { closure to) CM. }\end{array} \\ \text { RS7 } & \text { RST/BX* } & \text { RST/BX } & \begin{array}{l}\text { External reset signal and/or coast-to-stop } \\ \text { command }\end{array} \\ \text { PC6 } & \text { FWD* } & \text { FWD-C } & \text { FWD } & \begin{array}{l}\text { Forward operation command }\end{array}\end{array}$

* The asterisk after the letters of the name denotes an inverted value.

\section{Input allocation for Analog to}

Digital Conversion (ADC) on the instrumentation card

The eight Analog input Channels $(\mathrm{ACH}<7 . .0>$ ) are assigned as follows:

- $\mathrm{ACHj}$ APPLICATION

- $\mathrm{ACH} 7$ Motor frequency, $0-10 \mathrm{v}$ 
- ACH6 Spare-(radiation level in generation four)

- ACH5 Spare-(temperature in generation four)

- $\mathrm{ACH} 4$ Comparitor 1 threshold

- $\mathrm{ACH} 3$ Peak amplitude of force

- $\mathrm{ACH} 2$ Comparitor 2 threshold

- ACH1 Peak amplitude of position

- ACHO Reserved as a guard channel to go along with ACH1

\section{Output allocation for Digital} to Analog Conversion (DAC) on the instrumentation card

Only one (DAC1 OUT) DAC output is currently allocated, to route to the motor controller to control motor RPM in analog fashion. 
ALGORITHMS FOR INSTRUMENTATION SYSTEM SOFTWARE 


\section{ALGORITHMS FOR INSTRUMENTATION SYSTEM SOFTWARE}

\section{Definition of Variables}

L Index of the Case option, selecting one of the four processes listed in the table above.

TMP One-dimensioned temporary byte array with index J. TMP stores one set of raw binary counter data.

$\mathrm{J}$ Index number of one of three bytes acquired for one quantity. $0<\mathrm{J}<4$

$\mathrm{Q} \quad$ One-dimensioned temporary single-precision floating-point array with index $\mathrm{K}$. It stores the three decimal values needed for one calculation of viscosity.

$\mathrm{K}$ Index which defines which of the three quantities $\mathrm{Q}(\mathrm{K})$ is being referred to.

$\mathrm{Q}(1)$ Differential flight measurement. It is denoted $\mathrm{d}$ in LabView.

Q(2) Round-trip flight time. It is denoted $\mathrm{T}$ in LabView.

$\mathrm{Q(3)}$ The period of the individual cycles in the acoustic wave-train. It is denoted $p$ in LabView.

$\mathrm{v} \quad$ One calculated double-precision floating-point value of viscosity.

$\mathrm{k} \quad$ An experimental constant, based on the type of material such as aluminum used in the waveguide.

a The cross-sectional area of the waveguide.

VISC One-dimensioned double-precision floating-point array with index I and length IMAX. Stores the calculated values of viscosity v.

IMAX The total number of scans acquired before one set of statistics is calculated to give one record of logged measurement.

I The index number for a particular scan. $0<\mathrm{I}<\mathrm{IMAX}+1$

RECD One-dimensioned ASCII string array of eight fields. One record of data to be logged.

STOP Push-button that, when depressed, stops the process. Is normally off (FALSE), and reverts to TRUE when depressed.

thr1 The DC threshold voltage of comparitor 1

thr2 The DC threshold voltage of comparitor 2

dly1 The value in milliseconds that is somewhat greater than the sum of delay on and gate width. If we delay this long, the time raw data will be in the counters and counter.

dly2 The rate at which one record of final data is logged, in seconds. 
Procedure main;

Begin

Call subroutine initialize

Switch (L)

case 1: /* Generates an acoustic waveform repetitively for adjustment of threshold. */

Call subroutine adjust

case 2: * Acquires raw data and decimal displays one time measurement in microseconds. */

Call subroutine test

case 3: /* Acquires and displays in decimal one value of viscosity. *I

Call subroutine step

case 4: $I^{*}$ Automatically acquires, reduces, calculates, and logs viscosity. The full instrument. */

Call subroutine full

default: report error

Return

End of main

Subroutine adjust

Begin

Set up a front panel display of threshold voltages thr1, thr2

Call subroutine getthresholds (thr1, thr2)

Define dly 1 as one millisecond.

WHILE STOP $=$ False then trigger continuously while the waveforms are monitored and threshold is

manually adjusted by the operator. Do not acquire, save, reduce, analyze, log.

Call subroutine wave

End of while

Return

End of subroutine adjust

Subroutine test

Begin

Input an index for the desired quantity for which raw data is to be displayed. 


\section{Call subroutine wave}

Input the one packed decimal byte from the 74374 register through the 8255 Port B and store in TMP. Figures.

Display the decimal value of this byte on the front panel as the least two significant

Input the two packed-decimal bytes from counter B2 in the instrumentation card and store in TMP. four Figures.

Display the decimal value of these two bytes on the front panel as the most significant

Return

End of subroutine test

Subroutine step

Begin

Call subroutine raw3

Calculate viscosity

Output viscosity to front panel

\section{Return}

End of subroutine step

Subroutine full

Begin

Call subroutine parameters

Call subroutine getthresholds (thr1, thr2)

Get date

$\operatorname{recd}(1)=$ date

Get time

$\operatorname{recd}(2)=$ time

sum $=0=\max =\operatorname{var}$

$\min =2^{*}\left(2^{\wedge} 30-1\right)$

For $\mathrm{I}=1$, IMAX

Call raw3

Call subroutine calcvisc 
sum $=$ sum $+\operatorname{visc}(I)$

If $\operatorname{visc}(\mathrm{I})>\max$ then $\max =\operatorname{visc}(\mathrm{I})$

If $\operatorname{visc}(\mathrm{I})<\min$ then $\min =\operatorname{visc}(\mathrm{I})$

Next I

avg $=$ sum $/$ imax

$\operatorname{recd}(3)=$ ASCII (avg)

Calculate standard deviation stddev

$\operatorname{recd}(4)=$ ASCII(stddev)

$\operatorname{recd}(5)=\operatorname{ASCII}(\max )$

$\operatorname{recd}(6)=\operatorname{ASCII}(\min )$

Call subroutine logrcd

Return

End of subroutine full

Subroutine raw3

Begin

For $\mathrm{K}=1,3$-which of the three quantities

Output the value $\mathrm{K}$ to $\mathrm{PC}<1,0>$

Call subroutine rawdat(vraw)

$\mathrm{Q}(\mathrm{K})=$ vraw

Next K

Return

End of subroutine raw3

Subroutine rawdat (vraw)

Begin

Call test

Convert to one decimal 32-bit number vraw .

Return

End of Subroutine rawdat

Subroutine wave

C-4 
Begin

Call subroutine trigger

Call subroutine delay (dly)

Call subroutine trgrst

Return

End of subroutine wave

Subroutine trigger

Begin

Reset the count in DAQCard-1200 counter B2 to all ones (max count), since it counts down.

Output a one to $\mathrm{PC2}$. $(\mathrm{PC} 2)=1$. This causes the following to occur, in order:

The high-speed counter's clear* signal will be deactivated, so that a count can build up. However, the count will not yet begin.

At the remote pulser, the sync signal will rise to a one, which will cause one high-voltage transmit pulse to be sent to the transmit transducers. These transducers will generate an acoustic wavetrain.

\section{Return}

End of subroutine trigger

Subroutine dly (dely)

\section{Begin}

Delay by an amount of time in microseconds given by dely

This subroutine is called by two different routines. The first calls to delay about 600 uS between triggering and raw time data acquisition. The other is to delay about 60 seconds between successive data loggings.

In the first application, the acoustic wavetrain will propagate down the rod/waveguide, with reflections The reflections will be picked up at a later time by the receive transducers as a series of wavetrains.

In the fastboard the gate NAND will need to wait until the first of the two receive waretrains is detected. This wait needs to be slightly more than the time DELAY-ON which is manually set by the operator by manual observation. The instant the first wavetrain is detected the counter gate will "open". The gate will stay "open" until the second wavetrain begins. At this point in time the gate will "close". If time data is to be acquired, the value is the time the gate is open (i.e., the gate pulse width).

The value dely should be specified manually on the front panel at a value somewhat more than the sum of delay-on and gate width. 
Subroutine trgrst

Begin

During the time the counter gate is open the series of counters will count the $10 \mathrm{nS}$ pulses from the $100 \mathrm{MHz}$ crystal oscillator. The two low-order counter digits change the fastest and are counted by the fast counters on the Custom 1 board. The slower output from these two goes to DAQCard- 1200 counter B2.

When the gate closes all the counters will hold their combined count of $10 \mathrm{nS}$ pulses. In other words, the time in nanoseconds that the gate is open is ten times the count in the counters.

Output a logical zero to PC2. This causes the following to occur, in order:

The 4-bit counts in each of the two fast Custom 1 counters will be loaded in parallel into the $74 \mathrm{~F} 374$ register, where they will be retained until a new value is loaded in.

After the $74 \mathrm{~F} 374$ register is loaded a clear* signal will go to the fast counters, freezing their count at zero.

Counter B2 will retain its count until retriggering causes reset.

Therefore the count values are now ready to be read, if desired.

Return

End of subroutine trgrst

Subroutine calcvisc

Begin

Calculate viscosity

Store in array visc

Return

End of subroutine calcvisc

Subroutine initialize

Begin

Hardware and LabView Initialize:

During power-up LabView clears all DAQCard-1200 counters and registers automatically. The initial conditions for the 8255 are: Mode 0 for Ports A, B. Ports A, B, and C are initialized to high-impedance inputs, but supplying a zero output voltage on its port pins due to a default values sent to the output registers.

LabView configures and initializes the ADC channels and DAC channel 0.

Then specify the following configuration to the 8255 by means of a byte sent to Port $D$ (Port 3 ):

Port A (i.e., port 0 ) is ignored, but defaults to input. 
Port B (port 1) set to input

Port $\mathrm{C}$ (port 2) set to output

Output to Port $\mathrm{C}$ the following initial contents:

\begin{tabular}{|l|l|l|}
\hline Bit(s) & Value & \multicolumn{1}{c|}{ Significance } \\
\hline 0,1 & 0,0 & No measurement of time is being performed \\
\hline 2 & 0 & $\begin{array}{l}\text { Initial state of the trigger pulse is zero, fast } \\
\text { counter is cleared. (PC2) }=0\end{array}$ \\
\hline $3,4,5$ & $0,0,0$ & Unused bits, default is zero \\
\hline 6 & 0 & No action on the motor \\
\hline 7 & 0 & No reset of the motor \\
\hline
\end{tabular}

Set up a front-panel push-button STEP that steps through the succeeding sub-routines.

Return

End of subroutine initialize

Subroutine parameters

Begin

Define by input from the operator the following initial parameters as global variables:

a) IMAX, the number of scans

b) How often the logged data is obtained, in seconds

c) The path and file name it is stored in.

Return

End of subroutine parameters

Subroutine logred

Begin

Save string rec by appending to filename

Return

End of subroutine logred

Subroutine getthresholds is not yet implemented 